\title{
EXPERIMENTAL AND NUMERICAL STUDY OF DISTORTION IN FLAT, L-SHAPED, AND U-SHAPED CARBON FIBER-EPOXY COMPOSITE PARTS
}

\author{
A Thesis by \\ Pooneh Roozbehjavan \\ Bachelor of Science, Amirkabir University of Technology, 2007 \\ Submitted to the Department of Mechanical Engineering \\ and the faculty of the Graduate School of \\ Wichita State University \\ in partial fulfillment of \\ the requirements for the degree of \\ Master of Science
}

July 2012 
(C) Copyright 2012 by Pooneh Roozbehjavan

All Rights Reserved 


\section{EXPERIMENTAL AND NUMERICAL STUDY OF DISTORTION IN FLAT, L-SHAPED, AND U-SHAPED CARBON FIBER-EPOXY COMPOSITE PARTS}

The following faculty members have examined the final copy of this thesis for form and content, and recommend that it be accepted in partial fulfillment of the requirement for the degree of Master of Science, with a major in Mechanical Engineering.

Bob Minaie, Committee Chair

Walter Horn, Committee Member

T. S. Ravi, Committee Member 


\section{DEDICATION}

To my husband, Morad, who supported me each step of the way To my parents, who have never stopped their support and sacrifices to ensure my success 


\section{ACKNOWLEDGEMENTS}

I would like to show my gratitude to my advisor, Dr. Bob Minaie, who provided me with the resources and had confidence in me to perform this research. I would also like to acknowledge Dr. Walter Horn and Dr. T. S. Ravi for serving on my thesis committee.

It is my pleasure to thank all my colleagues: Behrouz Tavakol, Hoda Koushyar, Ronald Joven, Rony Das, Ashraf Ahmed, and Amdad Islam. This work was not possible without them. I also wish to thank my other friends, Mauricio Guzman, Chee Sern Lim, Khalil Vora, Mohammad Habibi, Tien Vo, and Saw Kee Hong, who made the laboratory an enjoyable environment in which to work.

I also owe my deepest gratitude to my parents who have never stopped their support and sacrifices throughout my entire life. I am indebted to my husband, Morad, who gave me strength and support whenever I needed them to go further. To my brother and my sisters, I express my grateful appreciation. I could not have better siblings than you!

Finally, financial support from the National Aeronautics and Space Administration is also acknowledged. 


\begin{abstract}
In this work, the effect of different parameters, including stacking sequence, part thickness, and tooling material, on distortion of flat panels was investigated. A Romer arm equipped with a laser scanner was used to obtain the maximum amount of distortion as well as the 3D pattern of distortion for each panel. Among the different stacking sequences, the maximum distortion was observed in the asymmetric and balanced panel, while the least distortion belonged to the symmetric and unbalanced one. Furthermore, thinner panels were more distorted than thicker panels with the same planar size and stacking sequences. This study showed that distortion of the flat panels caused by asymmetry in the stacking sequence was an order of magnitude greater than distortion of the panels due to imbalance in the stacking sequence.

L-shaped and U-shaped panels were also fabricated to investigate the effect of stacking sequence on spring-in angle and warpage of the panels. Among all the stacking sequences, the panel with an asymmetric and unbalanced stacking sequence showed the least spring-in angle, while the largest angle was observed in the symmetric and balanced panel. Although asymmetry in the stacking sequences reduced the spring-in angle, significantly more warpage was observed in the panels with asymmetric stacking sequences, as compared to the symmetric ones.

MSC Marc was used to predict the distortion of the panels, and the simulation results were compared with the experimental results for several stacking sequences of the flat and the Lshaped panels. An L-shaped panel with the stacking sequence of $[0 / 45 / 90 /-45]_{4}$ was simulated to investigate the effect of curve radius and tool geometry on the spring-in angle. The FEA results showed that curing the L-shaped panel on a concave tool led to less spring-in angle, as compared to the panel confined to a convex tool.
\end{abstract}




\section{TABLE OF CONTENTS}

Chapter

Page

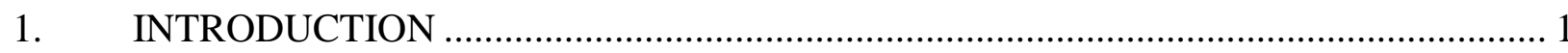

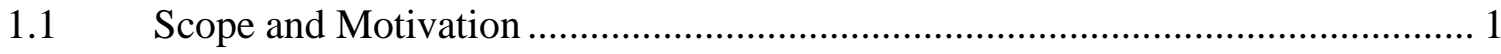

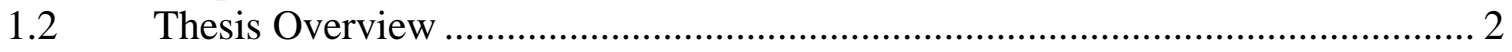

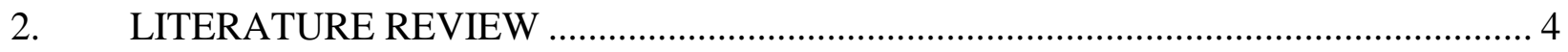

2.1 Distortion and Residual Stresses in Composite Materials .................................. 4

2.1.1 Degree of Cure ........................................................................ 4

2.1.2 Resin Cure Shrinkage ................................................................. 7

2.1.3 Material Properties ............................................................... 10

2.1.3.1 Mechanical Properties ................................................... 10

2.1.3.2 Thermal Properties....................................................... 15

2.1.4 Tool-Part Interface................................................................... 17

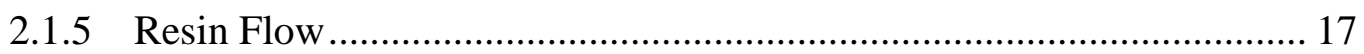

$2.2 \quad$ Numerical Models.............................................................................. 18

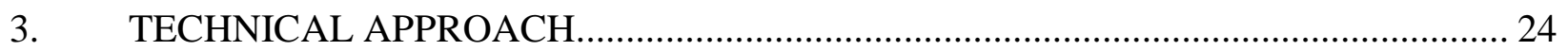

Experimental Study............................................................................. 24

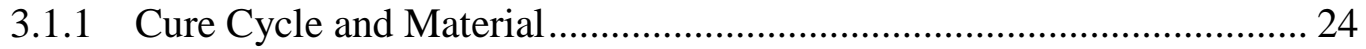

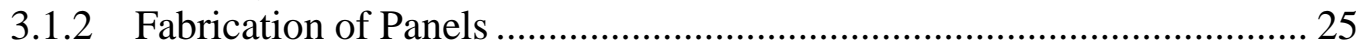

3.1.2.1 Flat Panels............................................................... 25

3.1.2.2 U-shaped and L-shaped Panels ....................................... 26

3.1.3 Measuring Method for Flat Panels .................................................... 27

3.1.3.1 3D Pattern of Distortion and Maximum Distortion............... 27

3.1.3.2 Thickness Variation Pattern................................................... 28

3.1.4 Measuring Method for U-shaped and L-shaped Panels ....................... 28

3.1.4.1 3D Pattern of Warpage and Spring-in Angle...................... 29

3.1.4.2 Thickness Variation Pattern................................................ 29

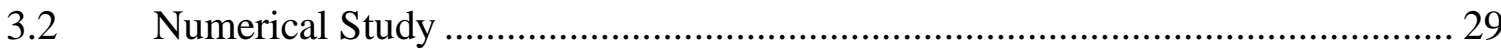

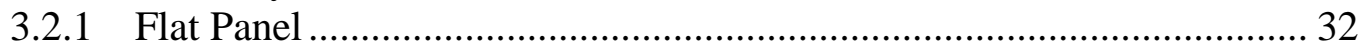

3.2.2 L-shaped Panel ....................................................................... 33

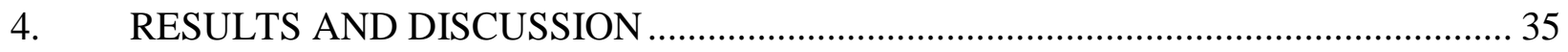

4.1 Experimental Results for Flat Panels ........................................................... 35

4.1.1 Effect of Stacking Sequence ........................................................ 35

4.1.2 Effect of Part Thickness ............................................................. 39

4.1.3 Effect of Tooling Material........................................................... 41

4.1.4 Thickness Variation Pattern .............................................................. 43 


\section{TABLE OF CONTENTS (continued)}

Chapter Page

4.2 Simulation Results for Flat Panels ........................................................ 45

4.3 Experimental Results for U-shaped and L-shaped Panels ................................ 50

4.3.1 Effect of Stacking Sequence .......................................................... 50

4.3.2 Thickness Variation Pattern .......................................................... 53

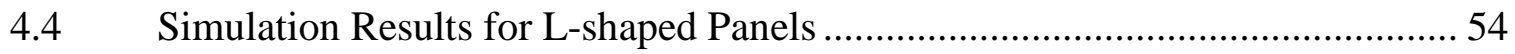

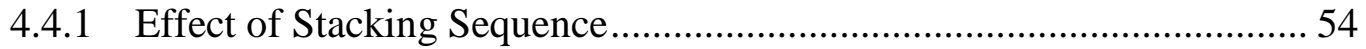

4.4.2 Effect of Curve Radius ...................................................................... 55

4.4.3 Effect of Tool Geometry ............................................................. 56

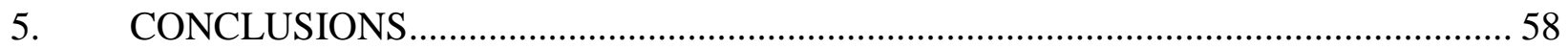

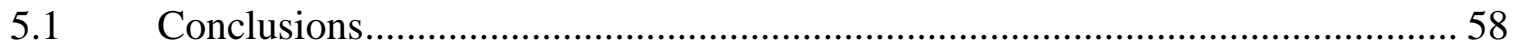

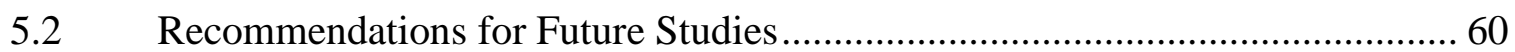

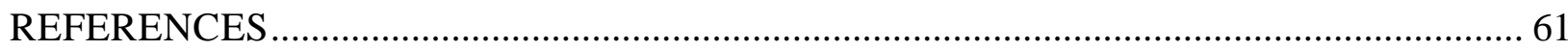




\section{LIST OF TABLES}

Table

Page

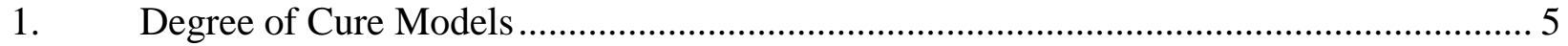

2. Parameters of Degree of Cure Models [22] ................................................................ 6

3. Resin Cure Shrinkage Models ................................................................................ 9

4. Parameters of Cure Shrinkage Models Used in Table 3 [22] .................................... 9

5. Flat Panels Fabricated for This Study ................................................................. 25

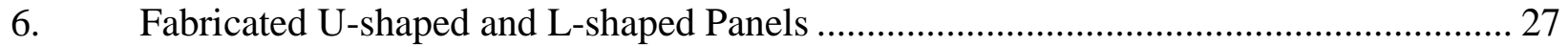

7. Parameters of the Cure Kinetics Model Used for the Simulation [61] ......................... 30

8. Directional Cure Shrinkage Coefficients Used for the Simulation [61] ....................... 31

9. Parameters of Modulus Development Used for the Simulation [61].......................... 32 


\section{LIST OF FIGURES}

Figure

Page

1. Total and partial heat of reaction as determined by DSC [11] ................................. 5

2. Cross-linking and polymerization of thermoset resin during cure resulting in chemical

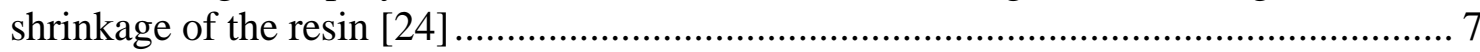

3. Chemical shrinkage strain in longitudinal and transverse directions in glass/polyester

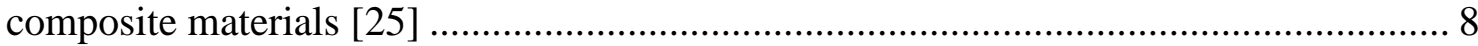

4. Development of resin dynamic modulus during cure [25] ...................................... 11

5. Development of resin elastic modulus as a function of temperature and degree of cure

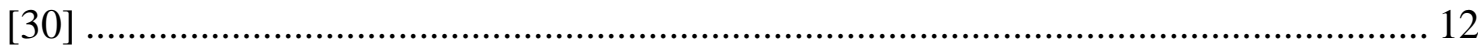

6. Resin elastic modulus estimated by rule of mixtures (linear model) and Msallem's

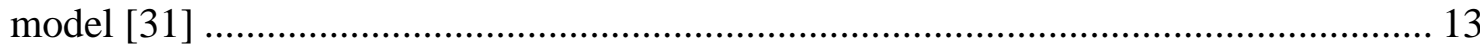

7. Development of longitudinal modulus as a function of degree of cure [16] ................ 14

8. Linear correlation between Poisson's ratio and degree of cure [16] .......................... 14

9. Development of transverse modulus as a function of degree of cure [16] ................... 15

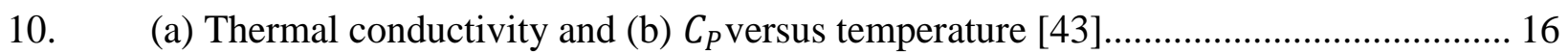

11. Thermal conductivity verses degree of cure in (a) longitudinal direction and (b)

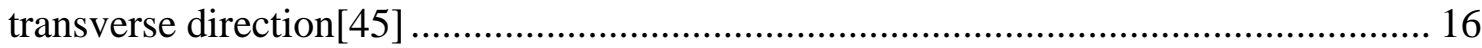

12. Distortion of a composite part due to the tool-part interface [48] ............................. 17

13. Resin flow effect on distortion of an initially flat panel [42] .................................. 18

14. Thickness variation due to non-uniform resin distribution [42]................................ 18

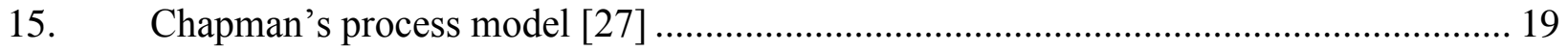

16. Process-induced stress modeling proposed by Bogetti-Gillespie [25] ....................... 20

17. Schematic of COMPRO process model developed by Johnston et al. [30] ................. 21

18. Algorithm of the model developed by Rabearison et al. [28] ................................. 22 


\section{LIST OF FIGURES (continued)}

Figure Page

19. Algorithm proposed to predict process-induced distortion[61] .............................. 23

20. Geometry of the aluminum tool used to fabricate L- and U-shaped panels ................. 25

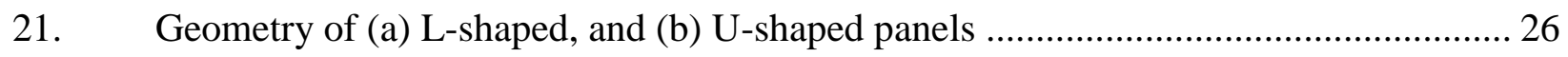

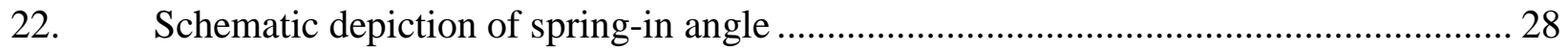

23. Schematic of set up for flat panels used in simulation [61] .................................... 33

24. 3D finite element mesh used for L-shaped panel cured on an aluminum tool .............. 34

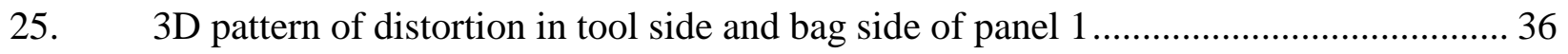

26. 3D pattern of distortion in tool side and bag side of panel 2 ................................. 36

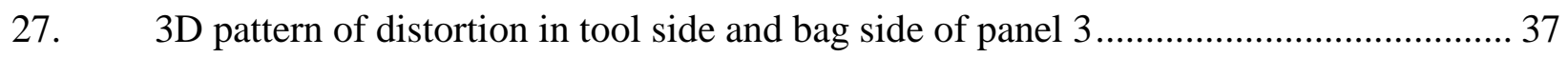

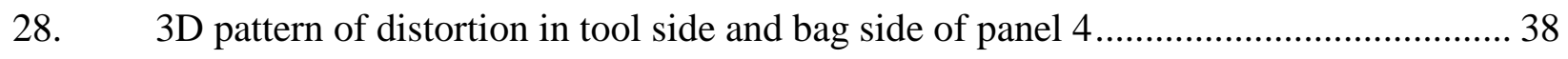

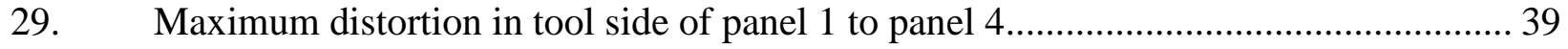

30. 3D pattern of distortion in tool side and bag side of panel 5 ...................................... 40

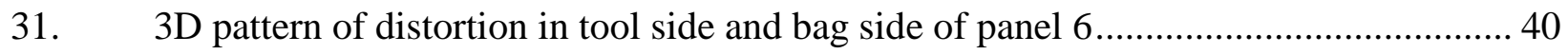

32. Effect of thickness on maximum distortion of symmetric and asymmetric panels ....... 41

33. 3D pattern of distortion in panel 7 and panel 8 cured on steel and composite tools,

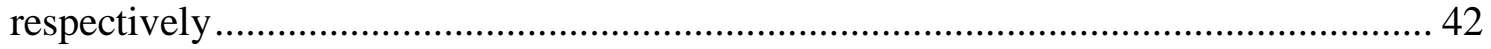

34. Effect of tool-part interface on distortion of the composite part .............................. 43

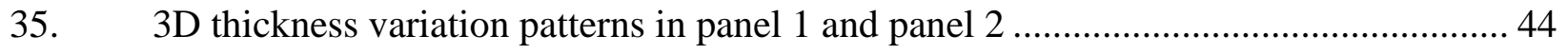

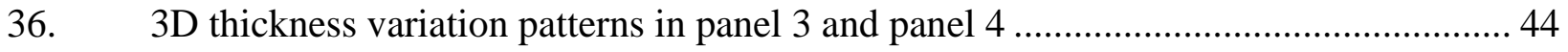

37. Comparison of tool-side distortion pattern for panel 1 ......................................... 46

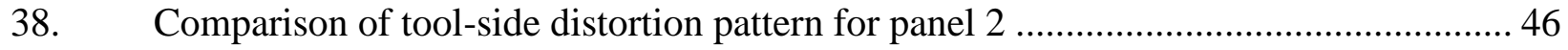




\section{LIST OF FIGURES (continued)}

Figure Page

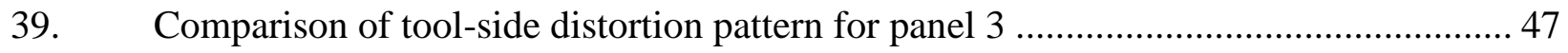

40. Comparison of tool-side distortion pattern for panel 4 ......................................... 47

41. Comparison of tool-side distortion pattern for panel 5 ........................................ 48

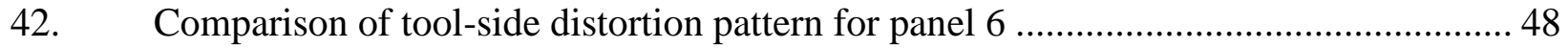

43. Comparison of simulation results with experimental results for maximum distortion of flat panels with various stacking sequences and different thicknesses...............49

44. Effect of stacking sequence on spring-in angle of L-shaped panels .........................50

45. Comparison of the spring-in angle in U-shaped and L-shaped panels ....................... 51

46. 3D warpage patterns in flanges of asymmetric and symmetric L-shaped panels.......... 52

47. $3 \mathrm{D}$ warpage patterns in flanges of asymmetric and symmetric U-shaped panels ......... 52

48. 3D warpage patterns in webs of asymmetric and symmetric U-shaped panels ............ 53

49. Thickness variation pattern in L-shaped panels with (a) balanced and symmetric stacking sequence, (b) unbalanced and symmetric stacking sequence, (c) balanced and asymmetric stacking sequence, and (d) unbalanced and asymmetric stacking sequence

50. Comparison of simulation results with the experimental results for L-shaped panels with asymmetric-balanced and asymmetric-unbalanced stacking sequences.............. 55

51. Effect of curve radius on spring-in angle of an L-shaped panel (scale factor of 3 is used

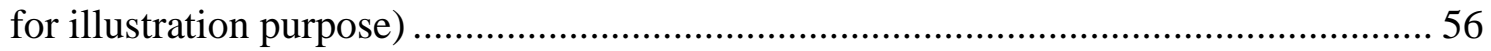

52. Effect of tool geometry on spring-in angle of an L-shaped panel (scale factor of 3 is used for illustration purpose). 


\section{LIST OF ABBREVIATION/NOMENCLATURE}

CMM

CSC

CTE

DOC

DSC

FEA

FEM

MRCC

UD
Coordinate Measurement Machine

Cure Shrinkage Coefficient

Coefficient of Thermal Expansion

Degree of Cure

Differential Scanning Calorimetry

Finite Element Analysis

Finite Element Modeling

Manufacture's Recommended Cure Cycle

Unidirectional 


\section{LIST OF SYMBOLS}

$\begin{array}{ll}\mathrm{dQ} / \mathrm{dt} & \text { Rate of heat generation } \\ t_{f} & \text { Time required achieving a complete reaction } \\ \alpha & \text { Resin degree of cure } \\ \mathrm{T} & \text { Resin temperature } \\ \mathrm{H}_{\mathrm{R}} & \text { Total resin heat of reaction } \\ \mathrm{H} & \text { Resin heat of reaction released up to time t } \\ \mathrm{A}_{\mathrm{i}} & \text { Pre-exponential factor } \\ \Delta \mathrm{E}_{\mathrm{i}} & \text { Activation energy } \\ 1 & \text { Equation superscript } \\ \mathrm{m} & \text { Equation superscript } \\ \mathrm{n} & \text { Equation superscript } \\ \mathrm{R} & \text { Gas constant } \\ \mathrm{C} & \text { Diffusion constant } \\ \alpha_{\mathrm{C} 0} & \text { Critical resin degree of cure } \\ \alpha_{\mathrm{CT}} & \text { The increase in critical resin degree of cure with temperature } \\ \mathrm{V}_{\mathrm{r}}^{\mathrm{S}} & \text { Resin volumetric cure shrinkage } \\ \mathrm{V}_{\mathrm{r}}^{\mathrm{S} \infty} & \begin{array}{l}\text { Degree of cure shrinkage } \\ \alpha_{\mathrm{S}}\end{array} \\ \alpha_{\mathrm{C} 1} & \text { and Gillespie model } \\ & \text { Dillespie model }\end{array}$




\section{LIST OF SYMBOLS (continued)}

$\begin{array}{ll}\text { A } & \text { Linear cure shrinkage coefficient } \\ \alpha_{\mathrm{C}} & \begin{array}{l}\text { Degree of cure after which the resin shrinkage begins in White and } \\ \text { Hahn model }\end{array} \\ \mathrm{B} & \text { Cure shrinkage model superscript } \\ \varepsilon_{\mathrm{r}}^{\mathrm{S}} & \text { Cure shrinkage strain } \\ \varepsilon_{\mathrm{ij}}^{\mathrm{S}} & \text { Directional cure shrinkage strain } \\ \mathrm{CSC}_{\mathrm{ij}} & \text { Directional cure shrinkage coefficient } \\ \mathrm{CP} & \text { Specific heat at constant pressure } \\ \mathrm{k} & \text { Thermal conductivity }\end{array}$




\section{CHAPTER 1}

\section{INTRODUCTION}

\subsection{Scope and Motivation}

Residual stresses induced during the curing of composite material parts could result in undesirable dimensional changes once the part is removed from the tool. Several factors could contribute to development of the residual stresses during cure. The mismatch between the coefficient of thermal expansion (CTE) of resin and fiber of the part [1], as well as chemical shrinkage of the resin during cure [2,3] are the most important sources of residual stress formation. Moreover, fiber misalignment, laminate defects such as voids, and tool-part CTE mismatch [3] could create residual stress during the manufacturing process of composite material parts.

Cured parts may exhibit different dimensional changes, depending on the original geometry of the part. Warpage and spring-in are two common dimensional changes that occur during the cure of contoured-shape parts $[1,4]$. The unfavorable dimensional deviation of the cured parts leads to assembly process issues, which, in a worst case scenario, may result in rejection of the part [5]. The current industry practice is to determine the final geometry of the cured part based on trial-and-error. An important part of the process is to modify the tooling geometry to compensate for the distortion of the cured part [3]. The current practice is timeconsuming, costly, and imprecise. Prediction of curing distortion will help to overcome the current challenges facing the manufacturing of composite materials. Finite element analysis (FEA) has been used to predict the distortion of contoured-shape composite parts [6-8]. However, the laminate stacking sequence in most of these studies has been symmetric only $[1,6$, 7]. Therefore, the effect of laminate asymmetry on the distortion of contoured-shape parts has 
not been studied extensively. As discussed in the present study, asymmetric stacking sequences reduce the spring-in angle in cured parts. In addition, while the current study demonstrates that 3D simulations are more sophisticated for an accurate estimation of distortion, many previously published studies have utilized simple 2D FEA to estimate the geometry of composite parts after curing [8]. It is also notable that only 3D models can accurately capture the warpage of flat panels.

\subsection{Thesis Overview}

This study presents an investigation into the effects of stacking sequence, thickness, and tooling material on distortion of composite parts. As stated before, previous studies have mostly investigated the balanced and usually symmetric laminates and have paid less attention to other stacking sequences. The effect of laminate balance and symmetry on the distortion of cured parts can be observed only when a variety of symmetric and asymmetric stacking sequences are studied. The results of such studies were used later on to validate simulation results.

This study also presents a new approach to capturing 3D distortion patterns in panels with square geometry, based on scanning both sides of the panels. Most previous studies have reported the $2 \mathrm{D}$ distortion of panels which were narrow on one side and sufficiently long on the other side only to eliminate the $3 \mathrm{D}$ nature of distortions $[9,10]$. However, the distortions that occur in cured panels are often $3 \mathrm{D}$ and the assumption of simple $2 \mathrm{D}$ distortions is far from the truth. In addition, the proposed 3D scanning approach makes the comparison between simulation results and experimental observations easier and more accurate. Furthermore, capturing the thickness variation throughout the panel is another advantage of the proposed 3D scanning. Using this approach, one can also obtain distortion patterns more accurately for complex geometries. Raghavan and Zeng reported the final 3D distortion pattern of the cured composite 
part by displaying discreet data points of a coordinate measurement machine CMM [3]. However, proposed method in this study provides more consistent data and, therefore, could be well utilized for comparison between experimental and simulation results which, in turn, could enhance the accuracy of simulations sufficiently to allow them to be used for industrial applications.

In this study, the effect of stacking sequence on the 3D distortion of U-shaped and Lshaped composite parts fabricated with IM7/977-2 UD was investigated. A seven-axis Romer arm equipped with a laser scanner probe was utilized to scan the deformed cured parts. The scanning data were further analyzed with PolyWorks software to obtain the warpage and the spring-in angle. The thickness variation throughout the cured parts was also measured for all the cured parts.

MSC Marc 2008 r1 was utilized to run a during-cure 3D simulation of flat and L-shaped panels and the obtained results were validated by the experimental data. In L-shaped panels, the effect of tool geometry and curve radius on the spring-in angle was also investigated. As will be shown later, the distortion of composite parts could be predicted more accurately with the 3D simulation. 


\section{CHAPTER 2}

\section{LITERATURE REVIEW}

\subsection{Distortion and Residual Stresses in Composite Materials}

Curing of composite parts is a complicated process influenced by several factors, including resin cure shrinkage, resin flow, non-uniformity of degree of cure across the part, toolpart interaction, and anisotropy of material. These factors may result in formation of residual stresses in the composite part which, in turn, could lead to dimensional deviation.

\subsubsection{Degree of Cure}

Several investigators have modeled curing processes for different composite materials over the years [11-17]. Degree of cure (DOC), $\alpha$, which is a thermal property obtained with a differential scanning calorimetry (DSC), has been used extensively to estimate the advancement of curing in thermoset composite materials. The following equations are used to calculate $\alpha$ at a specific time (t) [11]:

$$
\begin{aligned}
& \alpha=H / H_{R} \\
& H=\int_{0}^{t}(d Q / d t) d t \\
& H_{R}=\int_{0}^{t_{f}}(d Q / d t) d t
\end{aligned}
$$

where $d Q / d t$ is the heat generation rate, $t_{f}$ is the time to achieve a fully cured state, $H_{R}$ is the total heat of reaction, and $H$ is the heat of reaction released up to time $t$. The heat of reaction and the total heat of reaction are illustrated in the graph of Figure 1. 

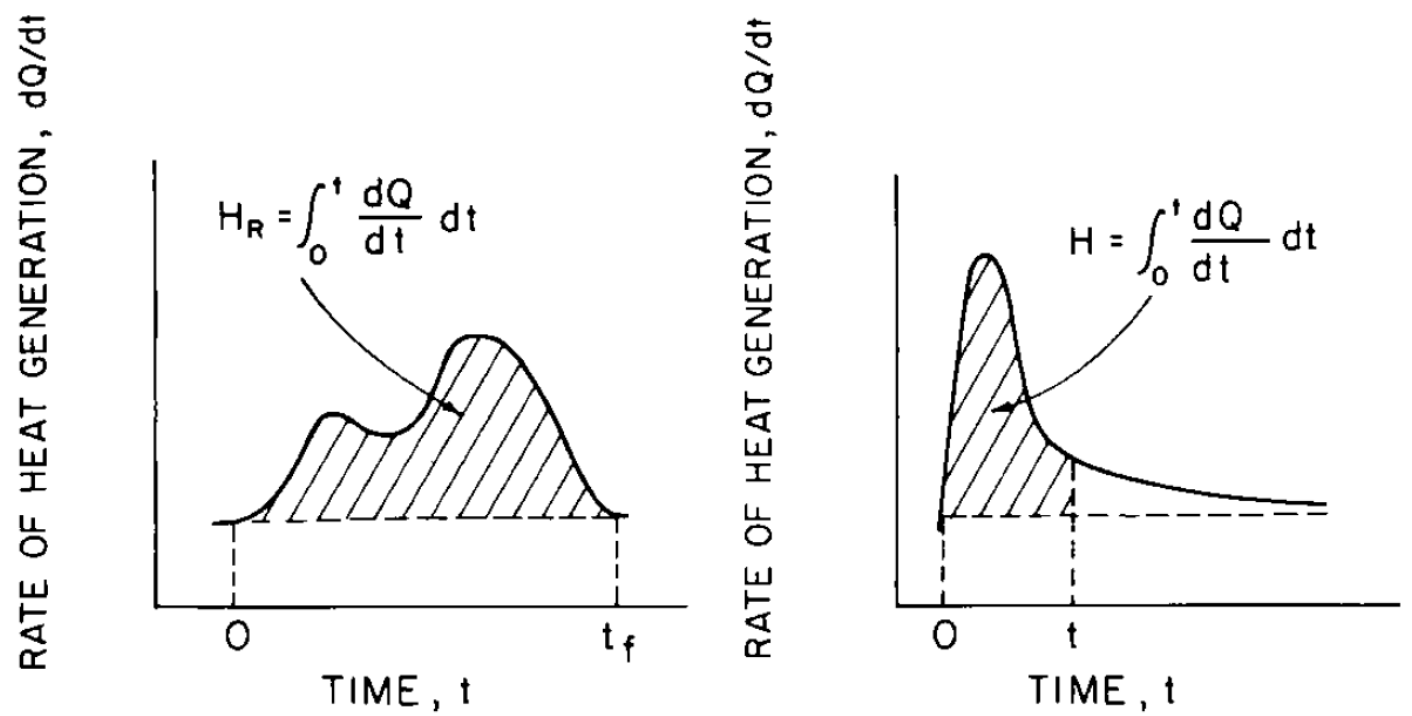

Figure 1. Total and partial heat of reaction as determined by DSC [11]

Table 1 contains several mathematical models used in previous studies to estimate the degree of cure in composite materials. The parameters of these models are listed in Table 2.

Table 1

Degree of Cure Models

Model

Equations

$\frac{d \alpha}{d t}=\left(K_{1}+K_{2} \alpha\right)(1-\alpha)(B-\alpha) \quad \alpha \ll \alpha_{c}$

Lee, Loos, and Springer (1982) [13]

$\frac{d \alpha}{d t}=K_{3}(1-\alpha) \quad \alpha>\alpha_{c}$

$K_{i}=A_{i} e^{-\Delta E_{i} /(R T)}$

Lee, Chiu, and Lin (1992) [18];

$\frac{d \alpha}{d t}=K \alpha^{m}(1-\alpha)^{n}$

White and Hahn (1992) [17]

$K=A e^{-\Delta E /(R T)}$

$\frac{d \alpha}{d t}=K(1-\alpha)^{n}$

Kenny (1992) [19]

$K=A e^{-\Delta E /(R T)}$ 
Table 1 (continued)

\begin{tabular}{ll}
\hline \multicolumn{1}{c}{ Model } & \multicolumn{1}{c}{ Equations } \\
\hline Scott (1991) [20] & $\frac{d \alpha}{d t}=\left(K_{1}+K_{2} \alpha^{m}\right)(1-\alpha)^{n}$ \\
& $K_{i}=A_{i} e^{-\Delta E_{i} /(R T)}$ \\
\hline Lee, Chiu, and Lin (1992) [18] & $\frac{d \alpha}{d t}=K_{1}(1-\alpha)^{l}+K_{2} \alpha^{m}(1-\alpha)^{n}$ \\
\hline & $K_{i}=A_{i} e^{-\Delta E_{i} /(R T)}$ \\
\hline Johnston and Hubert (1995) [21] & $\frac{d \alpha}{d t}=\frac{K \alpha^{m}(1-\alpha)^{n}}{1+e^{C\left\{\alpha-\left(\alpha_{C 0}+\alpha_{C T} T\right)\right\}}}$ \\
\hline
\end{tabular}

Table 2

Parameters of Degree of Cure Models [22]

\begin{tabular}{|l|l|l|}
\multicolumn{1}{|c|}{ Variable } & \multicolumn{1}{c|}{ Description } & \multicolumn{1}{c|}{ Units } \\
\hline$\alpha$ & Resin degree of cure. & $\mathrm{K}$ or R \\
\hline $\mathrm{T}$ & Resin temperature & $\mathrm{J} / \mathrm{kg}$ or BTU $/ \mathrm{lb}_{\mathrm{m}}$ \\
\hline $\mathrm{H}_{\mathrm{R}}$ & Total resin heat of reaction $(\alpha=0$ to 1$)$ & $/ \mathrm{s}$ \\
\hline $\mathrm{A}_{\mathrm{i}}$ & Pre-exponential factor. & $\mathrm{J} / \mathrm{mol}$ or BTU $/ \mathrm{mol}$ \\
\hline$\Delta \mathrm{E}_{\mathrm{i}}$ & Activation energy. & - \\
\hline $\mathrm{l}$ & Equation superscript. & - \\
\hline $\mathrm{m}$ & Equation superscript. & - \\
\hline $\mathrm{n}$ & Equation superscript. & $\mathrm{J} /(\mathrm{mol} \mathrm{K})$ or BTU/(mol R) \\
\hline $\mathrm{R}$ & Gas constant & - \\
\hline $\mathrm{C}$ & Diffusion Constant & - \\
\hline$\alpha_{\mathrm{C} 0}$ & Critical Resin Degree of Cure & - \\
\hline$\alpha_{\mathrm{CT}}$ & $\begin{array}{l}\text { The Increase in Critical Resin Degree of Cure with } \\
\text { Temperature }\end{array}$ & - \\
\hline
\end{tabular}


It is possible to estimate development of thermal and mechanical properties during-cure in composite parts, once the degree of cure is accurately modeled. Modeling of the degree of cure is done by using the best curve fit to the experimental data obtained from DSC. The degree of cure through the thickness of the composite laminates may vary. This variation may lead to nonuniformity of material properties through the thickness which, in turn, could result in dimensional instability of the part.

\subsubsection{Resin Cure Shrinkage}

Chemical shrinkage of thermoset resin occurs during curing of the composite part due to cross-linking and polymerization of the resin molecules. As illustrated in Figure 2, thermoset resin shrinks during the cure since the thermal energy of the monomers decreases, and the Van der Waal bonds between the monomers change to the covalent bonds in a polymer chain, resulting in less space occupation [23, 24].

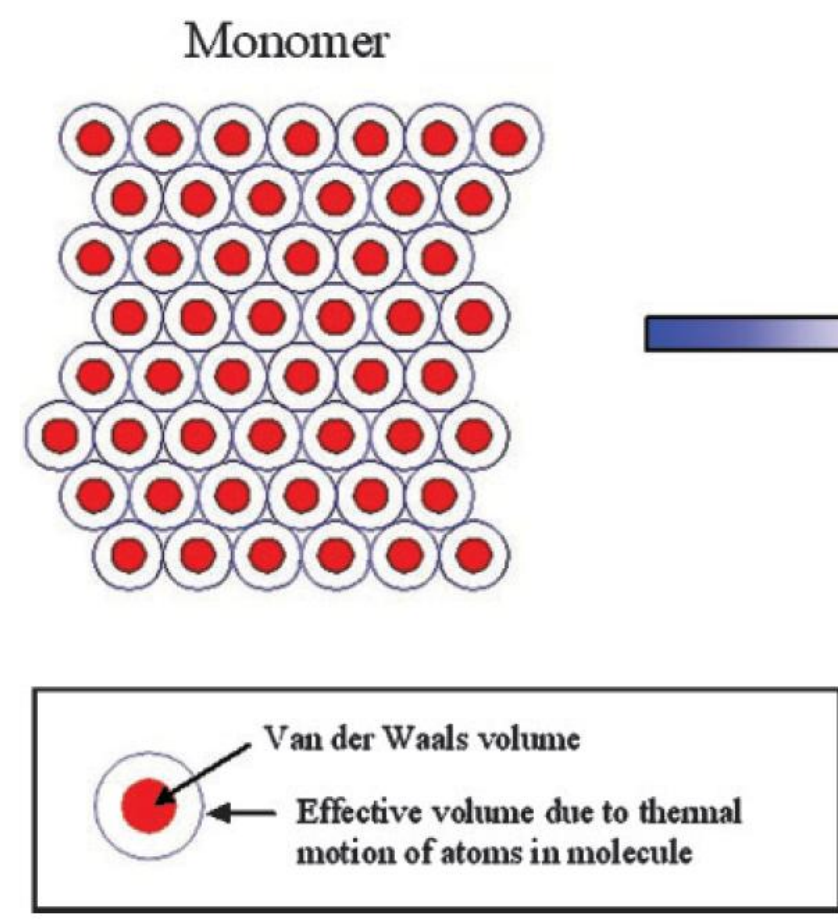

Figure 2. Cross-linking and polymerization of thermoset resin during cure resulting in chemical shrinkage of the resin [24] 
The cure shrinkage strain in a composite part is more pronounced in resin dominated directions (through the thickness direction and transverse direction), since cure shrinkage is a resin defined phenomenon. Bogetti and Gillespie reported the chemical strain in transverse and longitudinal directions for glass/polyester composite materials (Figure 3). As shown in the figure, chemical shrinkage in transverse direction, which is resin dominated direction, is higher than chemical shrinkage in longitudinal direction, which is fiber dominated direction. The residual stresses, caused by directional dependence of the chemical shrinkage, result in distortion of the part.

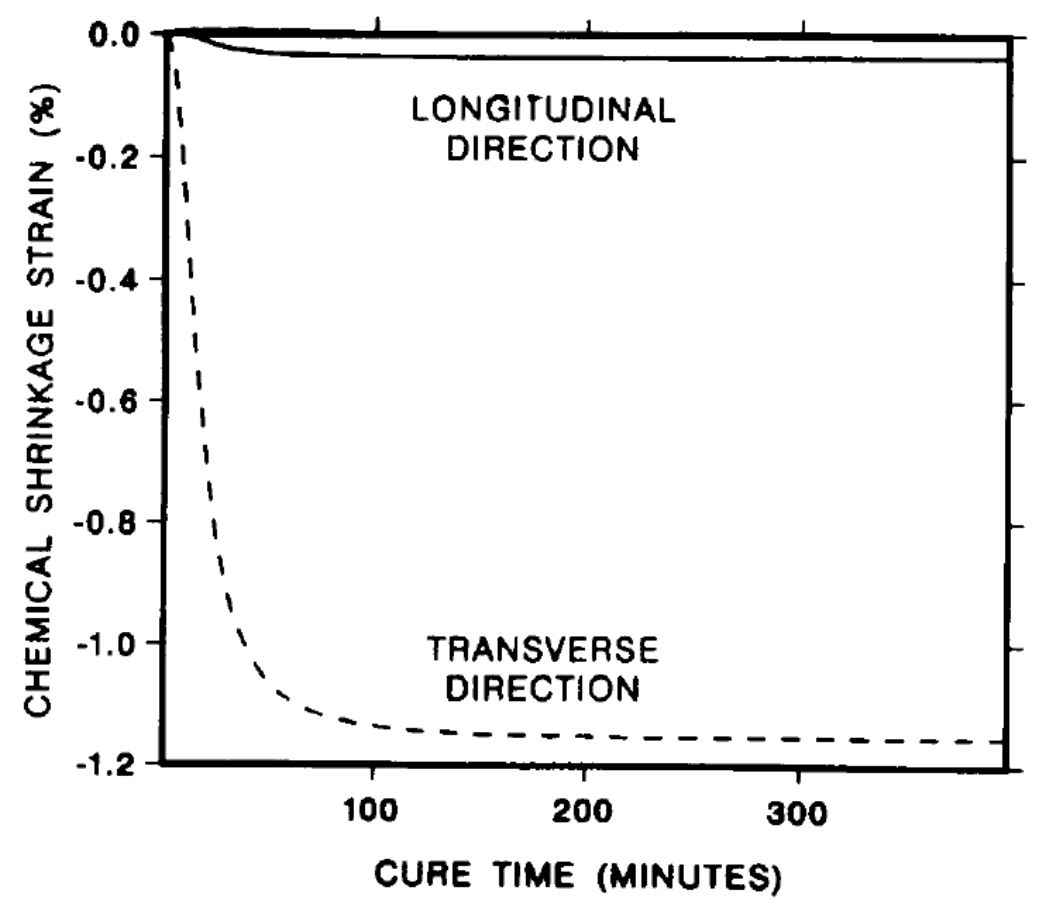

Figure 3. Chemical shrinkage strain in longitudinal and transverse directions in glass/polyester composite materials [25]

The resin volumetric cure shrinkage $\left(V_{r}^{S}\right)$ is the volumetric change of the resin happening during the curing. The following models have been developed (Table 3) to determine the resin volumetric cure shrinkage $\left(V_{r}^{S}\right)$. In Bogetti-Gillespie model three stages of the curing were 
considered as explained in section 2.1.3.1, whereas White and Hahn proposed an exponential relation for their two-stage model. The parameters used in the models are described in Table 4.

Table 3

Resin Cure Shrinkage Models

Model

Equations

\begin{tabular}{llr}
\hline & $V_{r}^{S}=0$ & $\alpha<\alpha_{C 1}$ \\
& $V_{r}^{S}=A \times \alpha_{S}+\left(V_{r}^{S \infty}-A\right) \times \alpha_{S}^{2}$ & $\alpha_{C 1} \ll \alpha<\alpha_{C 2}$ \\
Bogetti and Gillespie (1992) [25] & $V_{r}^{S}=V_{r}^{S \infty}$ & $\alpha \gg \alpha_{C 2}$ \\
& $\alpha_{S}=\frac{\alpha-\alpha_{C 1}}{\alpha_{C 2}-\alpha_{C 1}}$ & \\
\hline & $V_{r}^{S}=V_{r}^{S \infty} \times 10^{B\left(\alpha-\alpha_{C}\right)}$ & $\alpha \ll \alpha_{C}$ \\
White and Hahn (1992)[16] & $V_{r}^{S}=V_{r}^{S \infty}$ & $\alpha>\alpha_{C}$ \\
\hline
\end{tabular}

Table 4

Parameters of Cure Shrinkage Models Used in Table 3 [22]

\begin{tabular}{|l|l|}
\multicolumn{1}{|c|}{ Variable } & \multicolumn{1}{c|}{ Description } \\
\hline$V_{r}^{S}$ & Resin volumetric cure shrinkage \\
\hline$V_{r}^{S \infty}$ & Total volumetric resin shrinkage from 0 to 1 \\
\hline$\alpha_{s}$ & The degree of cure shrinkage \\
\hline$\alpha_{C 1}$ & Degree of cure after which the resin shrinkage begins (Bogetti and Gillespie). \\
\hline$\alpha_{C 2}$ & Degree of cure after which the resin shrinkage stops (Bogetti and Gillespie). \\
\hline$A$ & Linear cure shrinkage coefficient \\
\hline$\alpha_{C}$ & Degree of cure after which the resin shrinkage begins(White and Hahn). \\
\hline$B$ & Cure shrinkage model superscript \\
\hline
\end{tabular}


The cure shrinkage strain, $\varepsilon_{r}^{S}$, is the strain in a composite part due to the shrinkage of the resin. It is calculated using the following equation [24] invoking volumetric cure shrinkage using the developed models:

$$
\varepsilon_{r}^{S}=\left(1+V_{r}^{S}\right)^{1 / 3}-1
$$

Since shrinkage strain in a composite part is anisotropic, the directional cure shrinkage coefficient (CSC) should be defined. Following equation [22] is used to obtain the components of the strain in three different directions.

$$
\varepsilon_{\mathrm{ij}}^{S}=\operatorname{CS}\left(\mathrm{C}_{\mathrm{ij}} \cdot \varepsilon_{r}^{S}\right) \quad \mathrm{i}, \mathrm{j}=1,2,3
$$

\subsubsection{Material Properties}

\subsubsection{Mechanical Properties}

Studying changes of mechanical properties in composite materials in order to better understand the residual stresses and resulting distortion in composite parts is important $[4,16$, 17, 25-34]. Knowledge of the mechanical properties variation in a composite part makes it possible to estimate the residual stresses developed during the curing of the part.

To investigate cure shrinkage, Bogetti and Gillespie [25] divided the curing of composite materials into three different regions. Region I corresponds to the completely uncured state of resin. In this region, resin is assumed to behave as a viscous fluid with no stiffness. Region II starts at the resin gelation point, which is the point when the resin molecules form an infinite network, and ends once the resin is fully cured. The curing of the resin, the development of the resin modulus, and chemical shrinkage, all take place in this region. In Region III, the resin is assumed to be completely cured. Based on the works of Dillman et al. [35] and McGee [36], Bogetti and Gillespie proposed a model which correlates resin modulus development with the 
degree of cure, $\alpha$, in Region II, while a constant value for resin muduli were defined for regions I and III.

Unlike Bogetti and Gillespie [25], who suggested models for estimating mechanical properties of composite materials as a function of degree of cure, Johnston et al. [30] considered the effect of both temperature and degree of cure in the development of mechanical properties during-cure (Figure 5). However, both groups used the properties of the constituent materials of the composite to estimate the mechanical properties of composite materials.

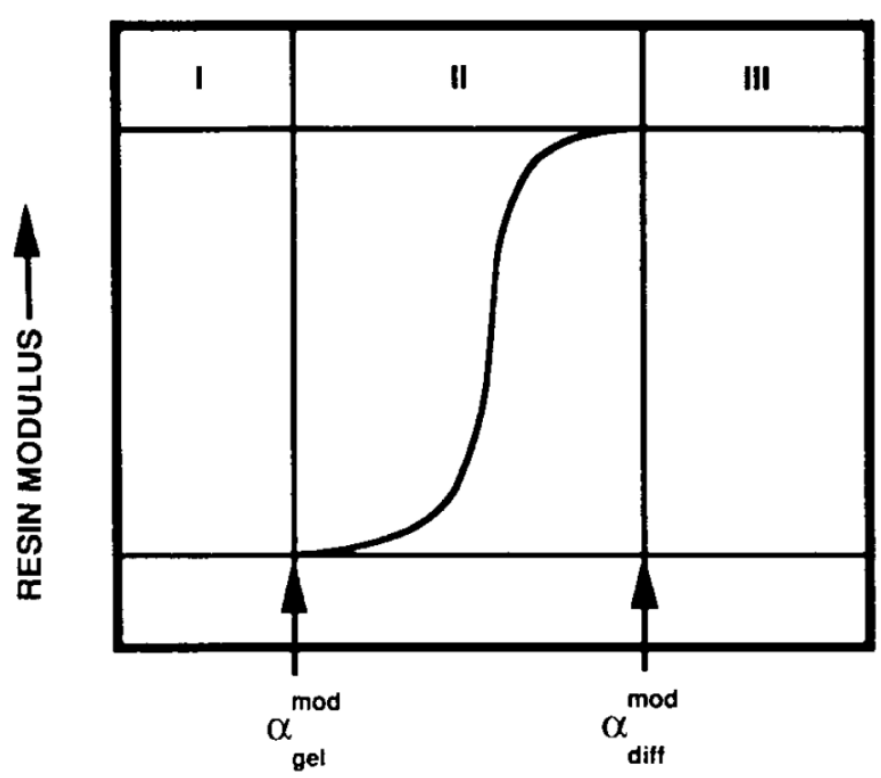

Figure 4. Development of resin dynamic modulus during cure [25] 


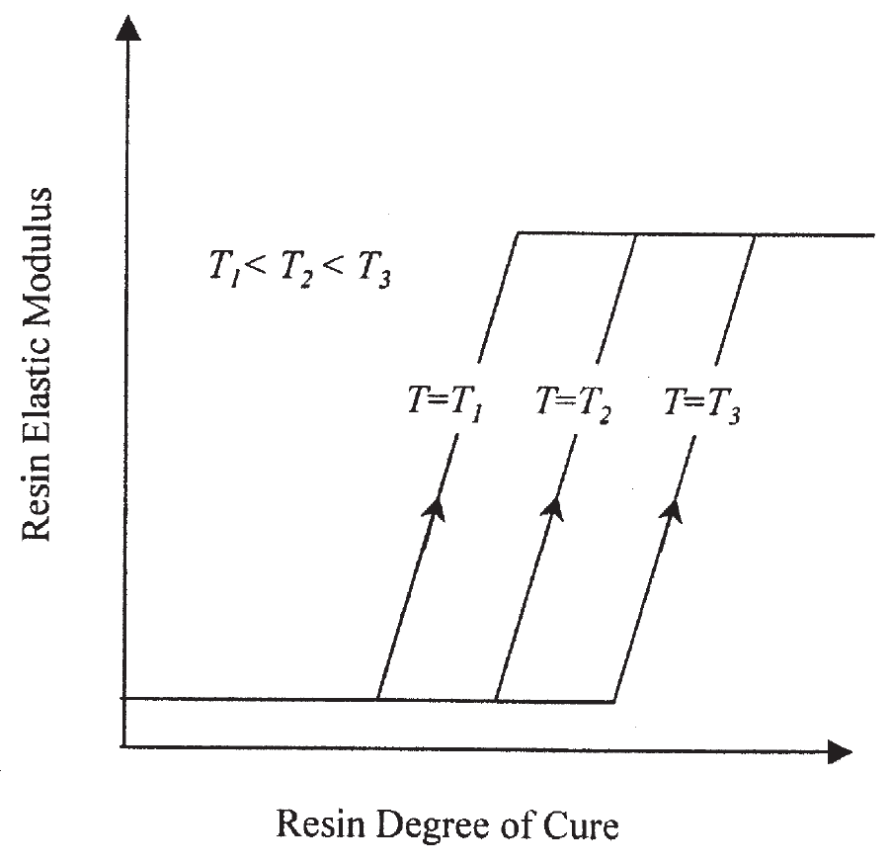

Figure 5. Development of resin elastic modulus as a function of temperature and degree of cure [30]

Figure 5 shows that resin elastic modulus is changing as a function of both degree of cure and temperature. It means that different cure temperatures result in different trends of resin modulus improvement during cure.

Msallem et al. [31] also proposed a model for estimating the variation of elastic modulus of the resin as a function of degree of cure and temperature. Figure 6 depicts the difference between the proposed model and the modulus predicted by the rule of mixture. In the linear model, resin elastic modulus changes proportional to the degree of cure, while their proposed model predicts a slower evolution during cure and a continuous increase during the cool-down. Similar to the aforementioned models of Bogetti-Gillespie and Johnston, Msallem's model used the resin and fiber properties to estimate the lamina properties. 


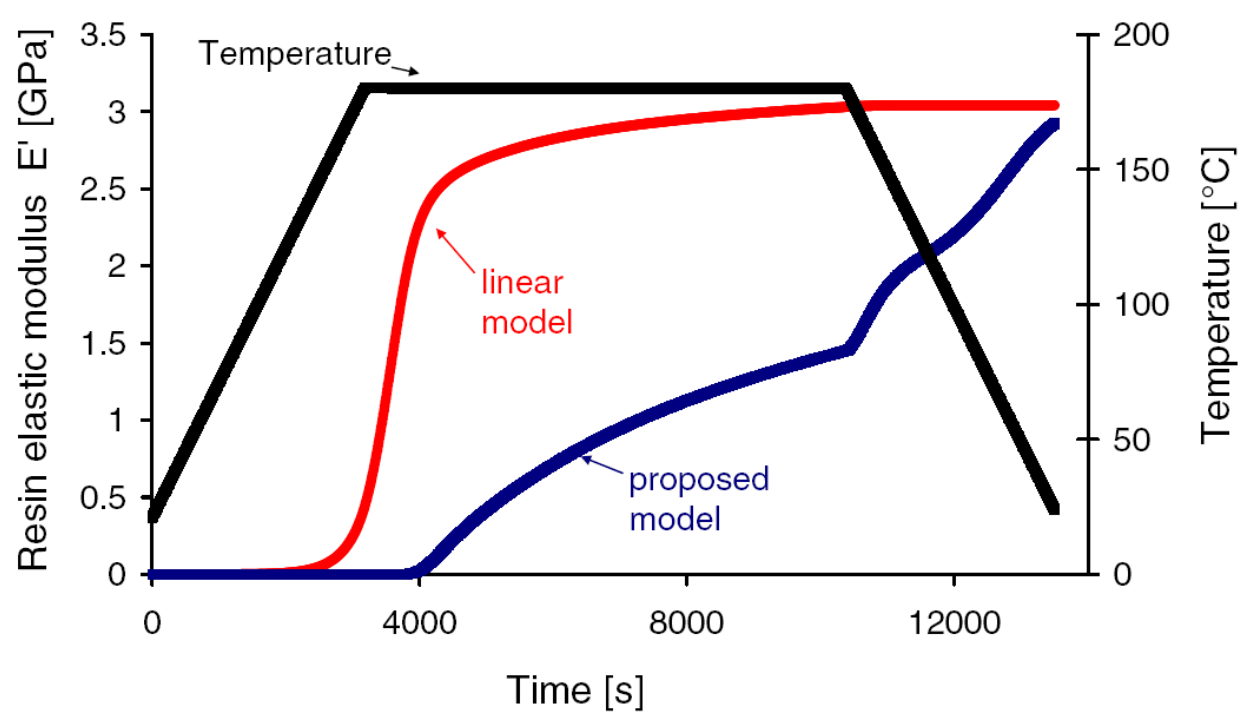

Figure 6. Resin elastic modulus estimated by rule of mixtures (linear model) and Msallem's model [31]

White and Hahn [16] also investigated the development of mechanical properties in composite materials during the cure cycle by testing composite specimens cured partially up to different stages of curing. The stage of cure was measured by differential scanning calorimetry (DSC). They suggested linear models to predict the correlation between the longitudinal elastic modulus of the laminate and the degree of cure as well as Poisson's ratio of the laminate and the degree of cure. As shown in Figure 7, elastic modulus of the laminate in longitudinal direction varies linearly as a function of degree of cure. Furthermore, Poisson's ratio of the laminate decreases linearly as the laminate gets cured (Figure 8). Figure 9 depicts the quadratic relationship between the transverse elastic modulus of the laminate and the degree of cure developed by White and Hahn as a result of their investigation. Since properties of the laminate in transverse direction are dominant with the resin properties, the transverse modulus increases rapidly once the resin gets cured. It should be noted that the specimens with the degree of cure of less than 0.82 were too vulnerable to be tested in their study. 


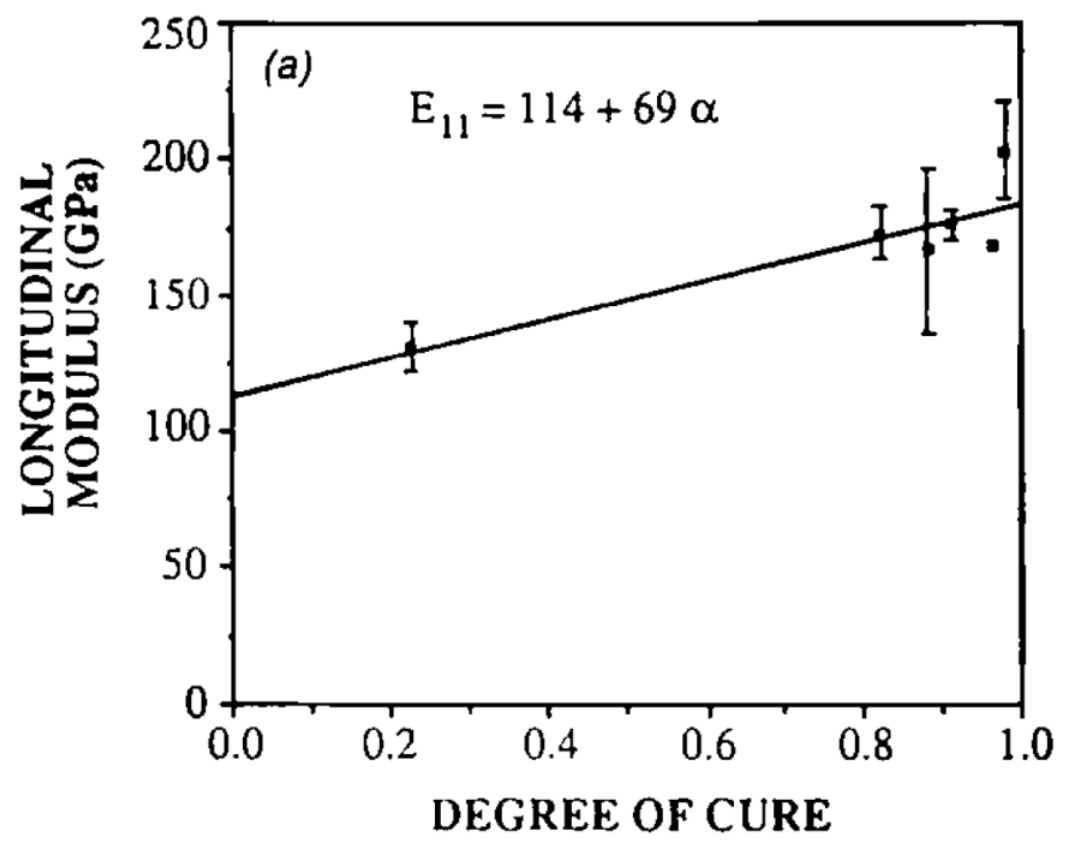

Figure 7. Development of longitudinal modulus as a function of degree of cure [16]

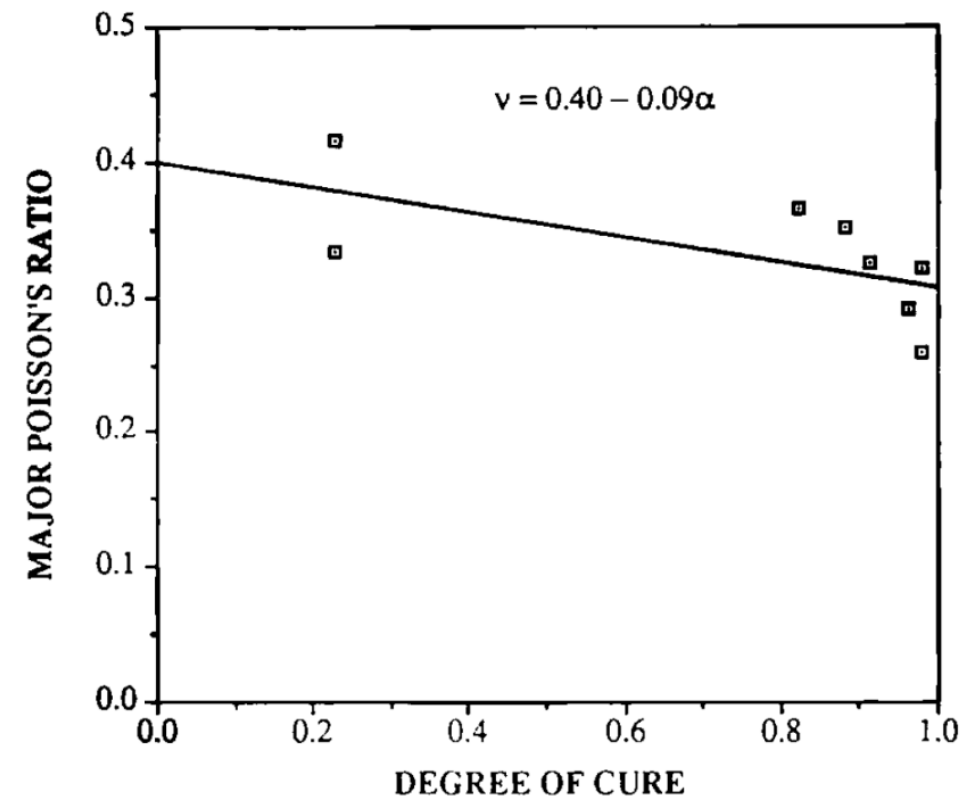

Figure 8. Linear correlation between Poisson's ratio and degree of cure [16] 


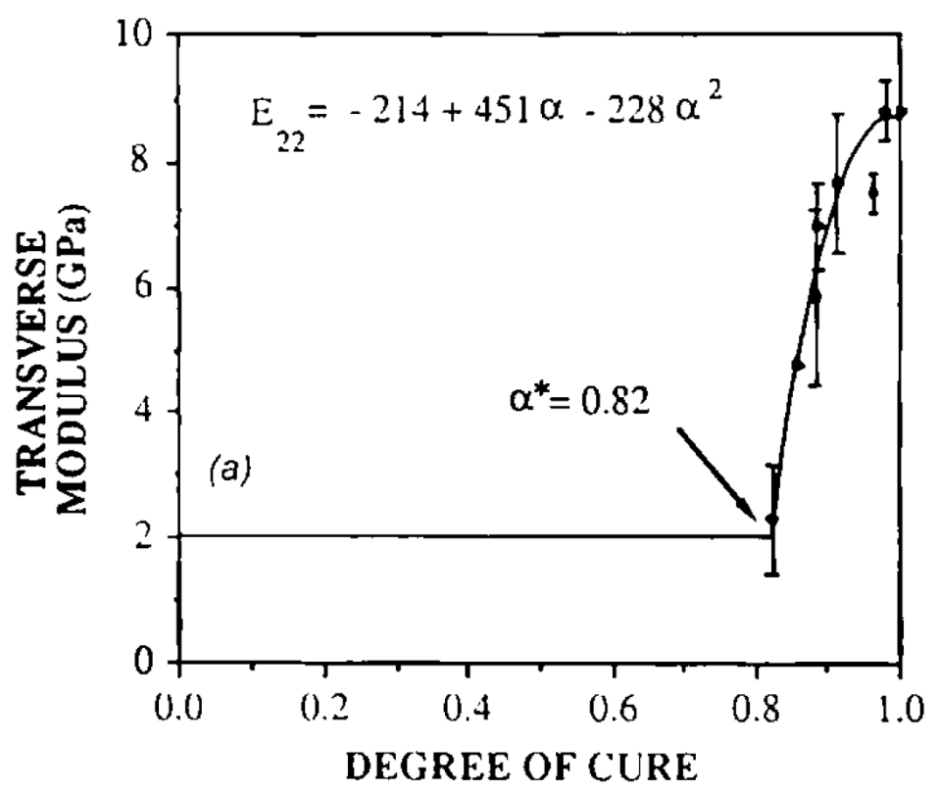

Figure 9. Development of transverse modulus as a function of degree of cure [16]

\subsubsection{Thermal Properties}

Thermal conductivity $(\mathrm{k})$ and specific heat at constant pressure $\left(\mathrm{C}_{P}\right)$ are two important thermal properties of composite materials which can influence the distortion of composite parts. As such, several studies reported in the literature have tried to establish the correlation between these properties and the curing temperature and the degree of cure [37-45].

Henderson et al. [43] measured the thermal conductivity of $\mathrm{H} 41 \mathrm{~N}$ which is a phenolic resin with glass and talc filler. They also measured the specific heat of the glass fiber/ polymer composite material using a differential scanning calorimetry. They reported a third-order representation, as shown in Figure 10(a), between thermal conductivity and cure temperature. They also obtained a linear relationship for specific heat as a function of the curing temperature, as shown in Figure 10(b).

Chern et al. [38] also measured the $\mathrm{C}_{P}$ of partially cured specimens and reported that the specific heat was not dependent on the degree of cure as much as cure temperature. They reported similar findings for thermal conductivity. 


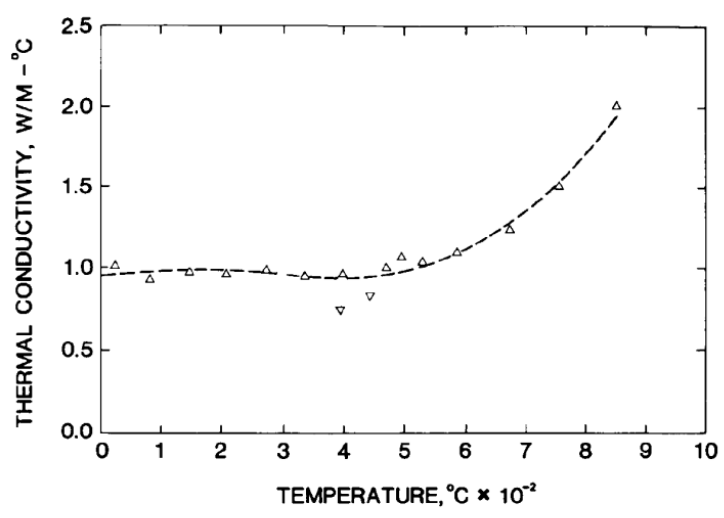

(a)

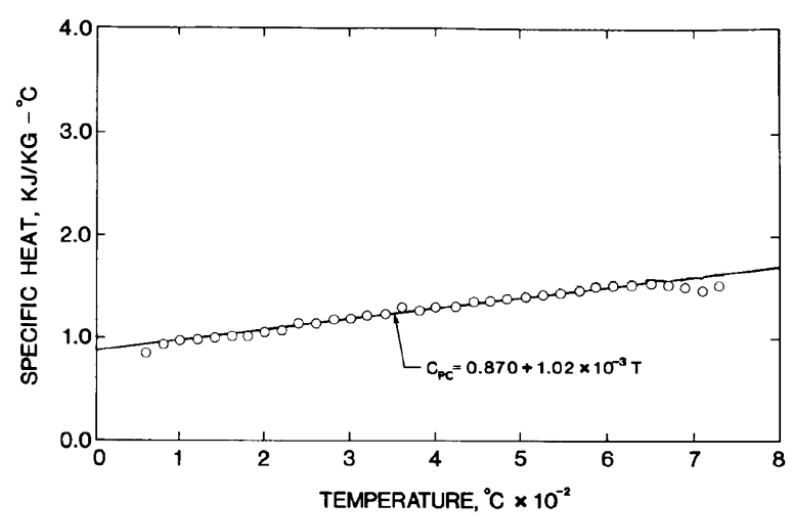

(b)

Figure 10. (a) Thermal conductivity and (b) $\mathrm{C}_{P}$ versus temperature [43]

Johnston [42] and Innocenti et al. [45] described thermal conductivity of composite materials as a vector quantity which is directionally dependent. Figure 11 shows the analytical results and FEM results for thermal conductivity in longitudinal and transverse directions of a composite sandwich panel. As it is illustrated in the figure, thermal conductivity in fiber direction decreases as a function of degree of cure, $\alpha$, and thermal conductivity in transverse direction increases as the part gets cured. Directional dependence of the thermal conductivity results in residual stress formation with may cause dimensional deviation of the composite part.
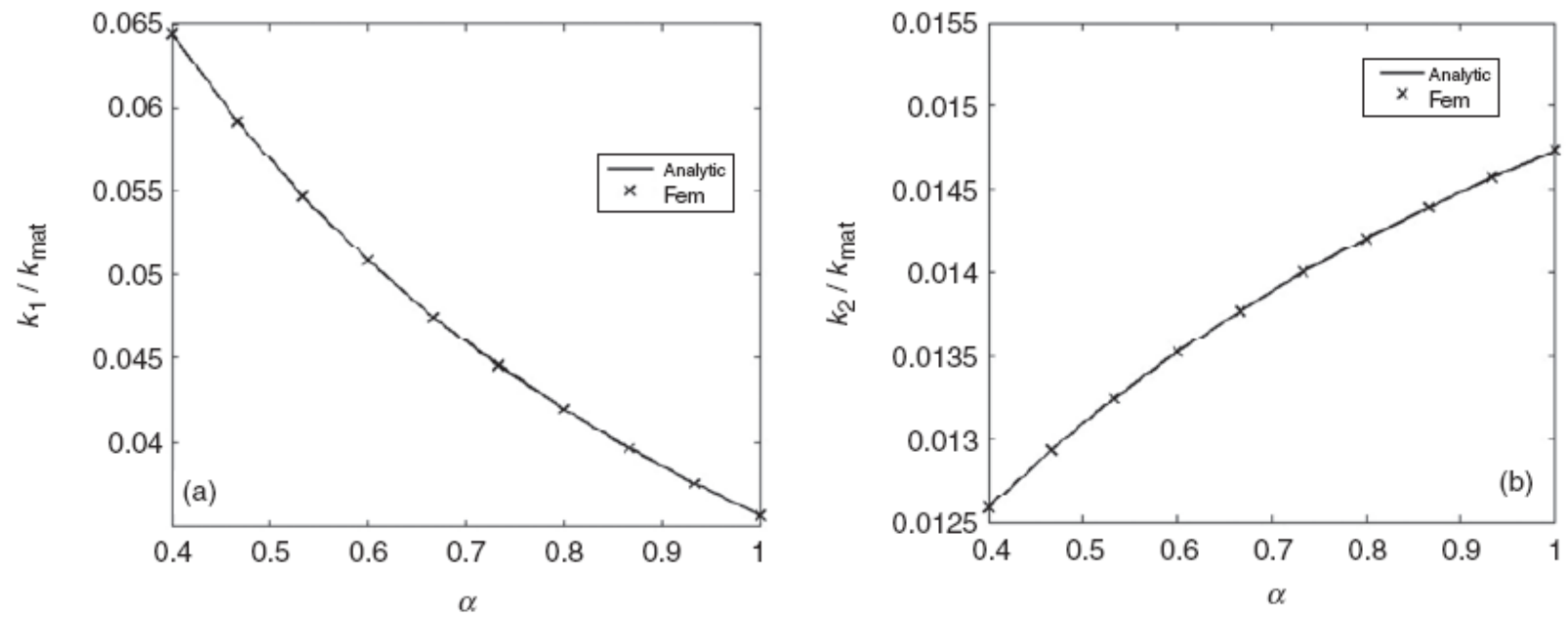

Figure 11. Thermal conductivity verses degree of cure in (a) longitudinal direction and (b) transverse direction[45] 


\subsubsection{Tool-Part Interface}

Mismatch of the coefficient of thermal expansion (CTE) between a composite part and a tool is considered to be one of the most important sources of distortion in the cured parts [46].

As shown in Figure 12a, when a part is cured on a tool with a higher CTE, the thermal expansion of the tool results in expansion of the part due to development of interfacial shear stresses (friction) between the tool and the part. Nevertheless, since the laminate is soft in shear during early stages of the cure, the layers adjacent to the tool expand more than those distant from the surface of the tool (Figure 12b). Non-uniform expansion of the plies induces residual stresses locked in the part as it cures. As a result of the residual stress development, the part distorts once removed from the tool (Figure 12c) [47-50].

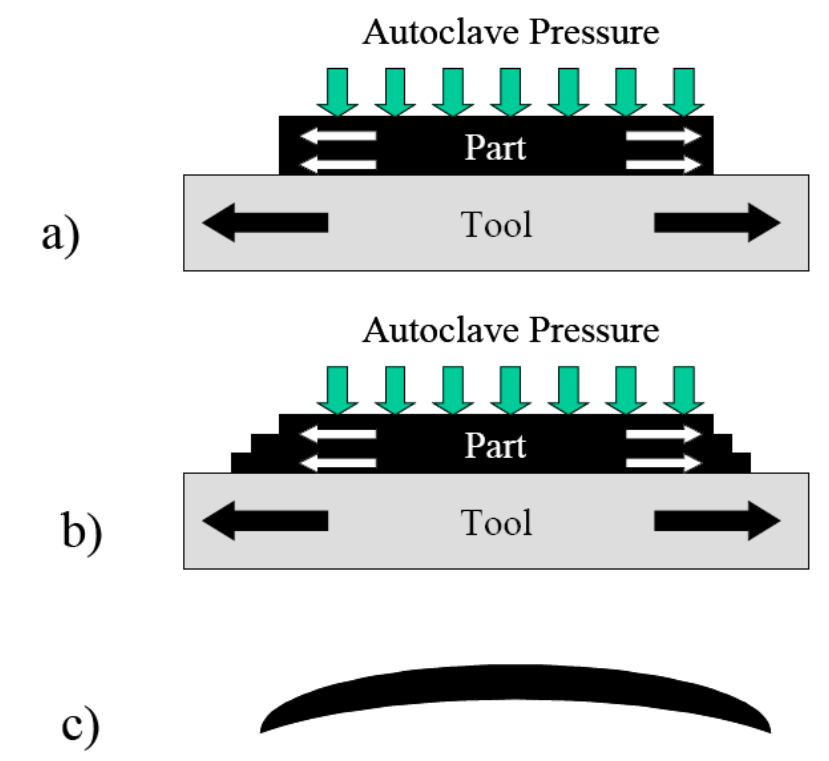

Figure 12. Distortion of a composite part due to the tool-part interface [48]

\subsubsection{Resin Flow}

Resin flow during the curing of composite parts helps to push out any excess resin in the part and to strengthen the bonds between the plies $[51,52]$. In addition, resin carries out voids and volatiles as it flows [42]. On the other hand, this phenomenon is considered to be one of the 
sources which help development of residual stresses during the curing. Uneven resin distribution in the part may cause resin cure shrinkage and thermal strain that are not uniform across the part. Consequently, the residual stresses are developed and lead to the distortion of the part [29, 42]. Figure 13 shows the uneven resin distribution in a composite part. More resin bleeding has occurred in the plies close to the bleeder, while the plies near the tool have contained larger amount of the resin. Since plies with more resin have higher CTE, residual stresses are formed in the part and result in distortion of the part once it is cured.

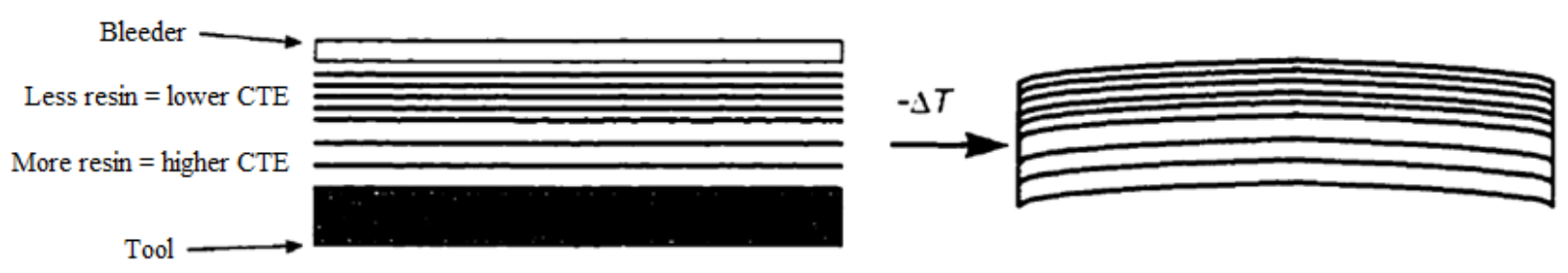

Figure 13. Resin flow effect on distortion of an initially flat panel [42]

As Figure 14 shows, the pressure gradient in the curved sections and on the edges of a part may also induce non-uniform resin flow which may result in thickness variation in the part [21].

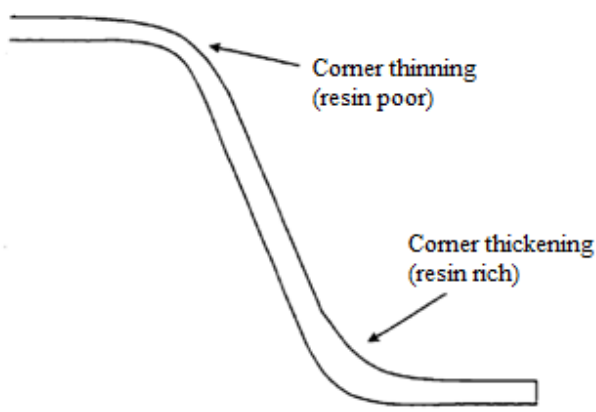

Figure 14. Thickness variation due to non-uniform resin distribution [42]

\subsection{Numerical Models}

As a result of different phenomena explained in section 2.1, residual stresses are formed during the cure of a composite part, resulting in dimensional changes of the part which, in turn, 
induces complexity in assembly of the parts. To avoid this issue, prediction of the dimensional changes has been of interest to many investigators who tried to address the issue by developing simple equations $[53,54]$ as well as analytical and numerical models $[6,12,25,26,30,32,55-$ 60]. The model that incorporates more phenomena can provide more accurate predictions. Some of the common models are explained as follows:

Chapman et al. [27] considered three components, including stress analysis, mechanical properties, and thermal history to predict residual stresses during cooling of a composite part. The thermal history section included crystallization kinetics and heat transfer, while a micromechanics was utilized to estimate the properties of semicrystalline composite in the mechanical properties section. Finally, the stress analysis was performed by considering incremental lamination theory. Figure 15 shows the components of Chapman's model.

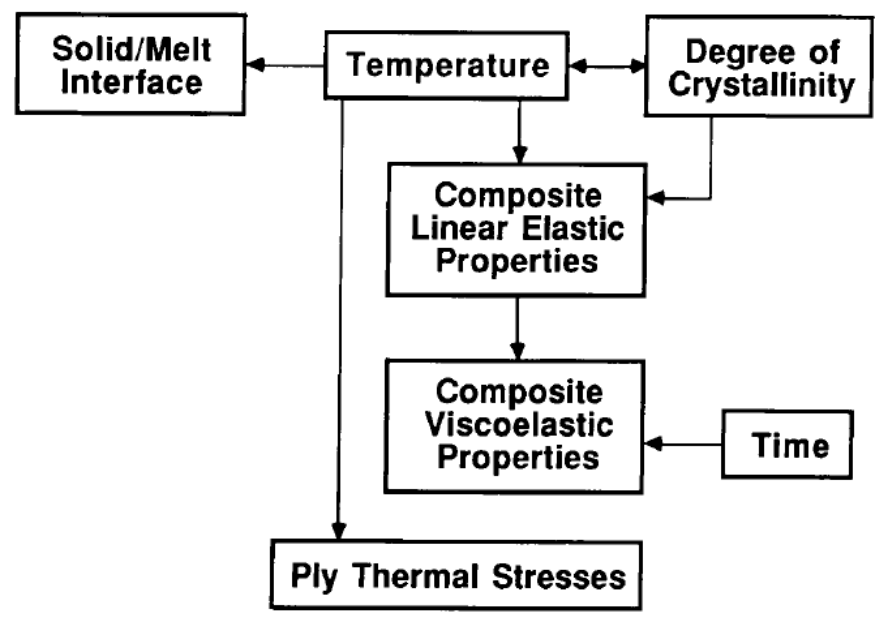

Figure 15. Chapman's process model [27]

Figure 16 illustrates the process model proposed by Bogetti and Gillespie [25]. Kinetic parameters, thermal properties, and resin cure shrinkage were fed into their model as the required inputs. Using a micromechanics model, mechanical properties were obtained from properties of constituent materials. The laminated plate theory was used to analyze process-induced stress. 


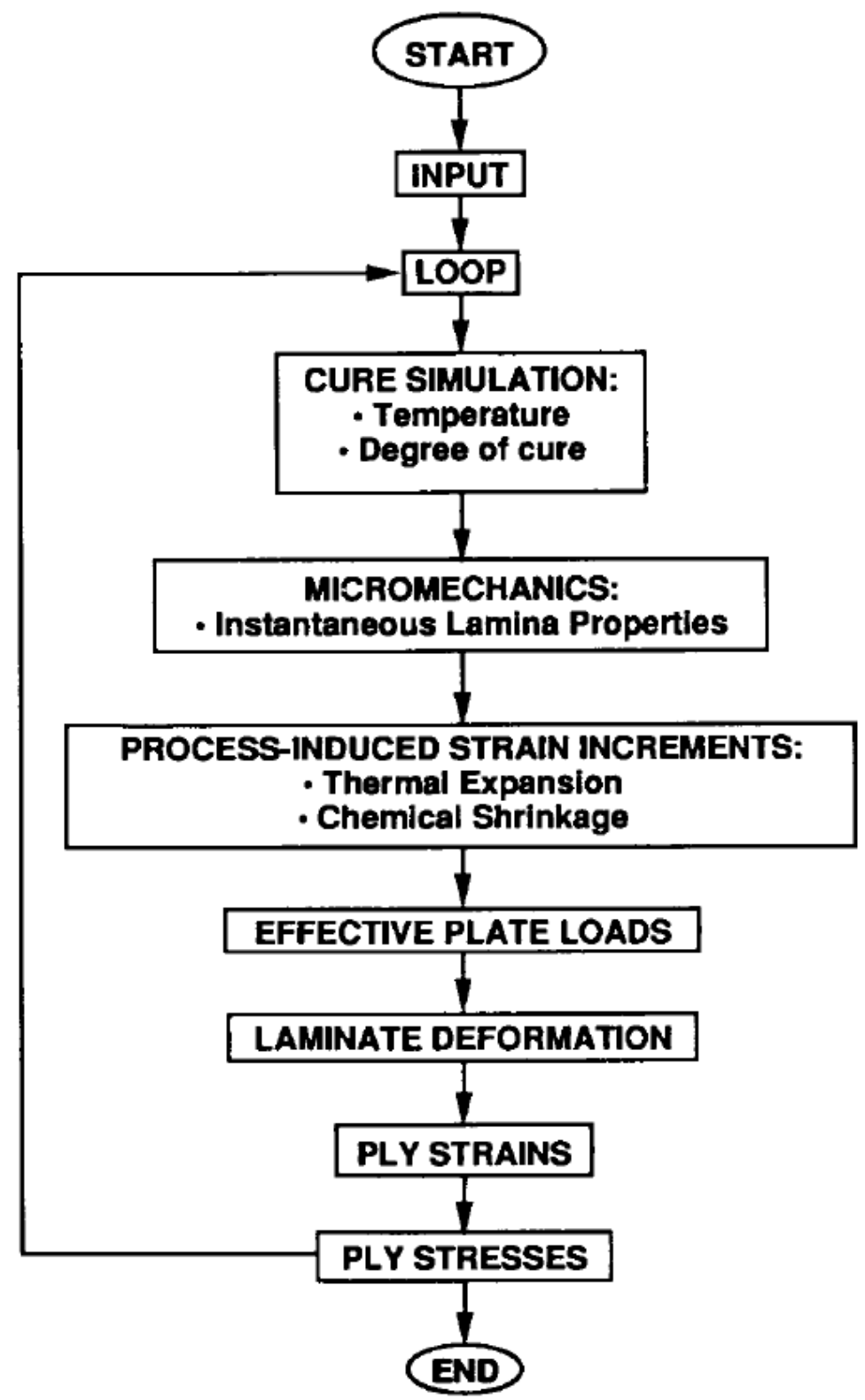

Figure 16. Process-induced stress modeling proposed by Bogetti-Gillespie [25]

As mentioned earlier, applying the micromechanics model to estimate mechanical properties of the lamina resulted in excluding fiber-matrix interactions in the Bogetti-Gillespie model. In addition, resin flow phenomenon and tool-part interface were not taken into account in their model. 
Johnston et al. [30] offered a modular approach to divide the problem into a group of submodels or modules as shown in Figure 17. As such, each module was performed to provide a set of data. For instance, the thermochemical module estimated the temperature, and the degree of cure and prediction of resin flow was made possible by the flow-compaction module.

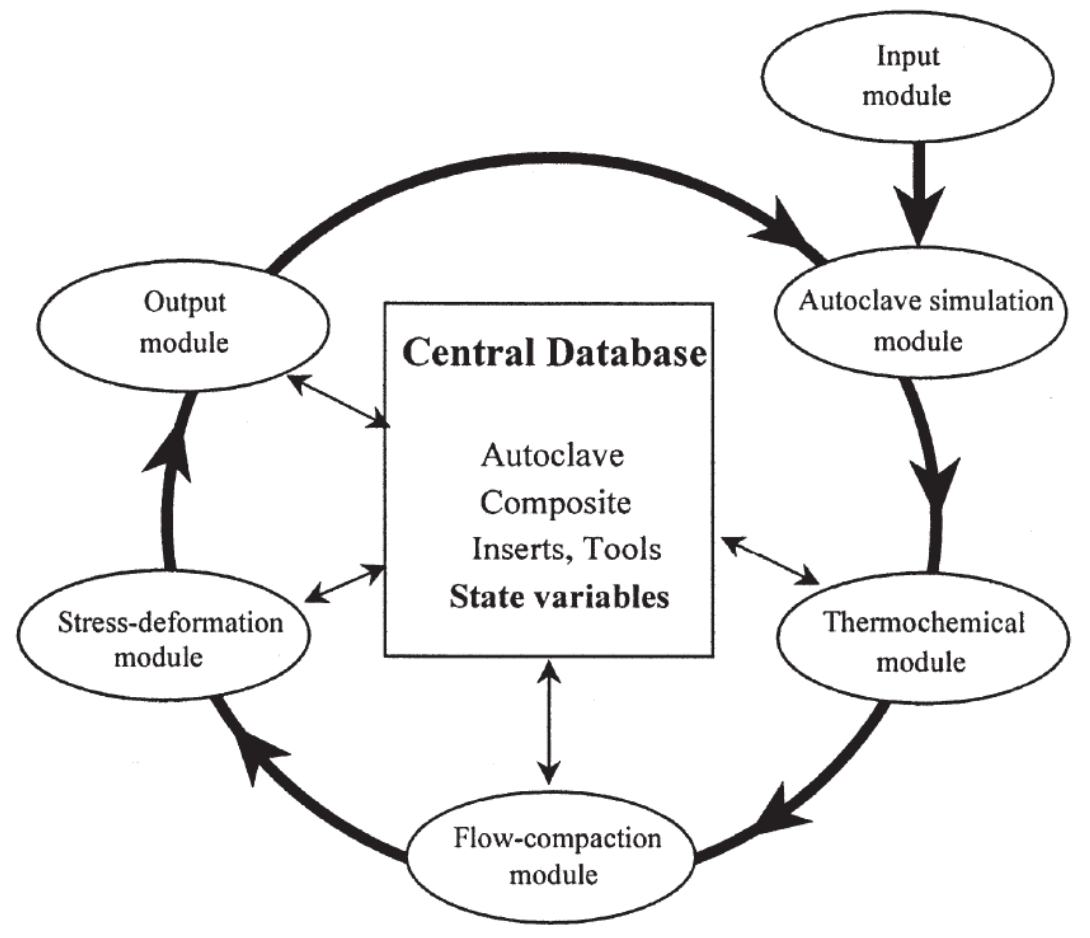

Figure 17. Schematic of COMPRO process model developed by Johnston et al. [30]

Although Johnston et al. [30] considered resin flow and tool-part interface in their model, similar to the Bogetti-Gillespie model, lamina properties were calculated from the properties of matrix and fiber and the effect of the fiber-matrix interface was not accounted for. In addition, they developed a 2D plane strain model which could decrease the accuracy of the prediction in real cases.

Considering a fully coupled thermal-stress analysis, Rabearison et al. [28] used Abaqus software to develop a numerical method. Three categories were taken into account, including 
transient thermal analysis, mechanical balance, and the law of the degree of cure, using three different subroutines as depicted in Figure 18.

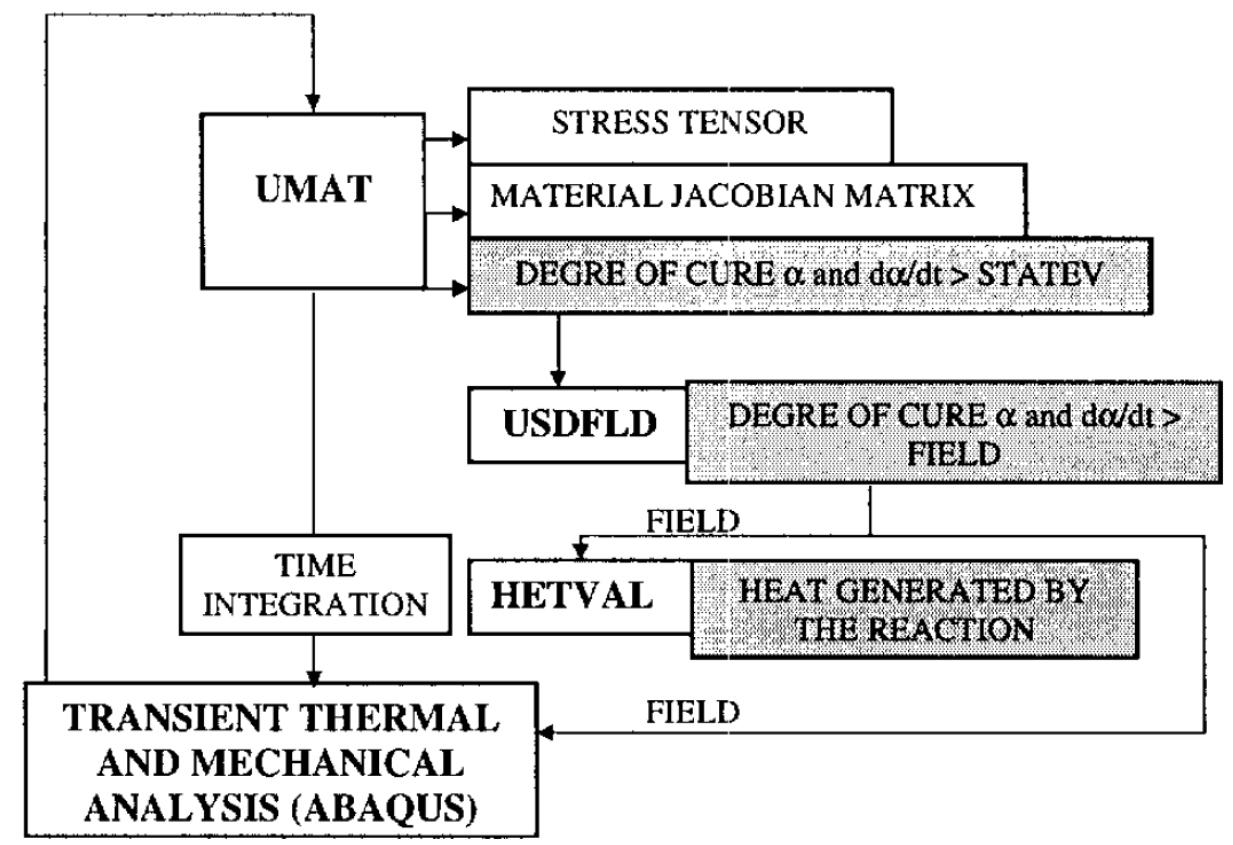

Figure 18. Algorithm of the model developed by Rabearison et al. [28]

A methodology was introduced in the literature [61] to estimate dimensional distortion of a carbon fiber-epoxy composite part upon being removed from the tool. Different phenomena were taken into consideration in this estimation, including cure shrinkage, cure kinetics, tool-part interaction, thermal strains, and improvement of the mechanical properties during cure. A module was developed for each phenomenon, and a 3D coupled thermo-mechanical analysis was performed to estimate the residual stresses and consequent distortion of the part. Figure 19 illustrates the algorithm followed in this study. Measuring the ply properties directly from the specimens resulted in accounting for the effect of fiber-matrix interface which was a topic of interest in the study. In addition, consideration of the tool-part interface and application of the resin-flow module in the analysis led to the more accurate results. 


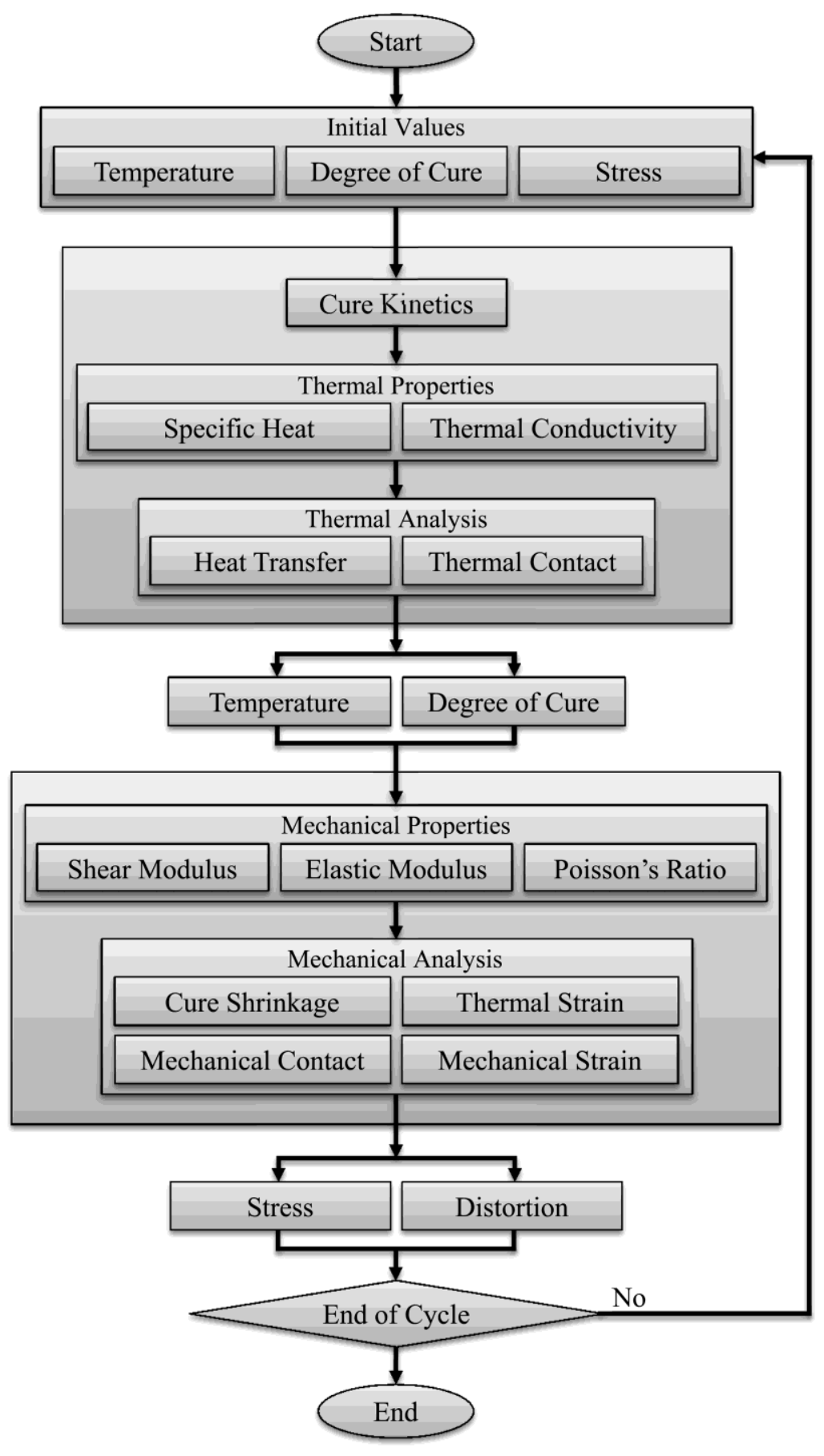

Figure 19. Algorithm proposed to predict process-induced distortion[61] 


\section{CHAPTER 3}

\section{TECHNICAL APPROACH}

\subsection{Experimental Study}

\subsubsection{Cure Cycle and Material}

In this study, IM7/977-2 UD was used to fabricate panels. This commercial unidirectional prepreg consists of IM7 carbon fibers impregnated with CYCOM 977-2, a curing toughened epoxy resin manufactured by Cytec Engineered Materials [62].

Flat panels for the study of thickness and stacking sequence were cured on an aluminum tool with a size of 1800 by $700 \mathrm{~mm}$ and a thickness of $12 \mathrm{~mm}$. Composite and steel tools, both with a size of 600 by $600 \mathrm{~mm}$ and a thickness of $12 \mathrm{~mm}$ were used to study the effect of tooling material on the distortion.

To fabricate the U-shaped and the L-shaped panels, an aluminum tool was used with the geometry depicted in Figure 20.

Using the vacuum bagging method, all the thin panels were cured using the manufacture's recommended cure cycle (MRCC). These panels were heated from room temperature up to $177^{\circ} \mathrm{C}$ with a heat-up rate of $2.78^{\circ} \mathrm{C} / \mathrm{min}$, were kept 3 hours at this cure temperature $\left(177^{\circ} \mathrm{C}\right)$, and finally, were cooled down to room temperature at a rate of $2.78^{\circ} \mathrm{C} / \mathrm{min}$. The maximum cure pressure of $586 \mathrm{kPa}$ was applied during the cure cycle. 


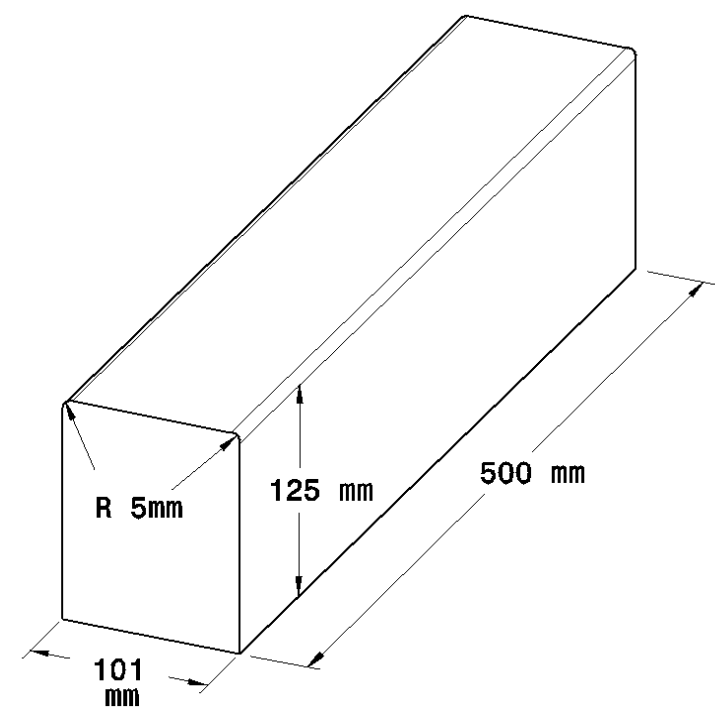

Figure 20. Geometry of the aluminum tool used to fabricate L- and U-shaped panels

\subsubsection{Fabrication of Panels}

\subsubsection{Flat Panels}

To observe the effect of panel thickness, stacking sequence, and tooling material on the distortion of flat laminates, the flat panels shown in Table 5 were fabricated.

Table 5

Flat Panels Fabricated for This Study

\begin{tabular}{cccccc}
\hline $\begin{array}{c}\text { Panel } \\
\text { No. }\end{array}$ & $\begin{array}{c}\text { Panel Size } \\
\left(\mathbf{m m}^{\mathbf{2}}\right)\end{array}$ & $\begin{array}{c}\text { No. of } \\
\text { Plies }\end{array}$ & $\begin{array}{c}\text { Panel Stacking } \\
\text { Sequence }\end{array}$ & Panel Type & $\begin{array}{c}\text { Tooling } \\
\text { Material }\end{array}$ \\
\hline 1 & $430 \times 430$ & 16 & {$[0 / 45 / 90 /-45]_{4}$} & Asymmetric, Balanced & Aluminum \\
\hline 2 & $430 \times 430$ & 16 & {$[0 / 45 / 90 /-45]_{2 S}$} & Symmetric, Balanced & Aluminum \\
\hline 3 & $430 \times 430$ & 16 & {$[0 / 45 / 90 / 45]_{2 S}$} & Symmetric, Unbalanced & Aluminum \\
\hline 4 & $430 \times 430$ & 16 & {$[0 / 45 / 90 / 45]_{4}$} & Asymmetric, Unbalanced & Aluminum \\
\hline 5 & $430 \times 430$ & 8 & {$[0 / 45 / 90 /-45]_{S}$} & Symmetric, Balanced & Aluminum \\
\hline 6 & $430 \times 430$ & 8 & {$[0 / 45 / 90 /-45]_{2}$} & Asymmetric, Balanced & Aluminum \\
\hline
\end{tabular}


Table 5 (continued)

\begin{tabular}{cccccc}
\hline $\begin{array}{c}\text { Panel } \\
\text { No. }\end{array}$ & $\begin{array}{c}\text { Panel Size } \\
\left(\mathbf{m m}^{\mathbf{2}}\right)\end{array}$ & $\begin{array}{c}\text { No. of } \\
\text { Plies }\end{array}$ & $\begin{array}{c}\text { Panel Stacking } \\
\text { Sequence }\end{array}$ & Panel Type & $\begin{array}{c}\text { Tooling } \\
\text { Material }\end{array}$ \\
\hline 7 & $430 \times 430$ & 16 & {$[0 / 45 / 90 /-45]_{4}$} & Asymmetric, Balanced & Steel \\
\hline 8 & $430 \times 430$ & 16 & {$[0 / 45 / 90 /-45]_{4}$} & Asymmetric, Balanced & Composite \\
\hline
\end{tabular}

\subsubsection{U-shaped and L-shaped Panels}

Figure 21 depicts the geometries of the panels fabricated on a convex aluminum tool. Several stacking sequences were considered in the fabrication of the U-shaped and the L-shaped panels (see Table 5) to study the effect of stacking sequence on the final geometry of the panel.
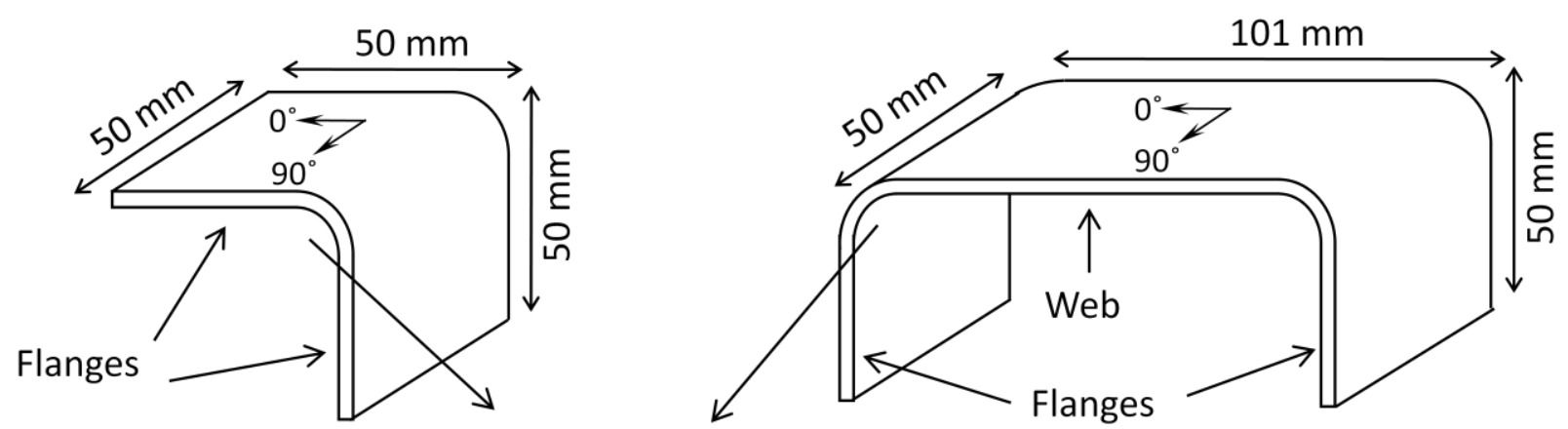

Corner radius $=5 \mathrm{~mm}$

(a)

(b)

Figure 21. Geometry of (a) L-shaped, and (b) U-shaped panels

Having the same plies count, a thickness of $2 \mathrm{~mm}$ was obtained for all the panels shown in Table 6. 
Table 6

Fabricated U-shaped and L-shaped Panels

\begin{tabular}{cccccc}
\hline $\begin{array}{c}\text { Panel } \\
\text { No. }\end{array}$ & $\begin{array}{c}\text { Panel } \\
\text { Geometry }\end{array}$ & $\begin{array}{c}\text { No. of } \\
\text { Plies }\end{array}$ & $\begin{array}{c}\text { Panel Stacking } \\
\text { Sequence }\end{array}$ & Panel Type & $\begin{array}{c}\text { Tooling } \\
\text { Material }\end{array}$ \\
\hline 1 & L-shape & 16 & {$[0 / 45 / 90 /-45]_{4}$} & Asymmetric, Balanced & Aluminum \\
\hline 2 & L-shape & 16 & {$[0 / 45 / 90 /-45]_{2 S}$} & Symmetric, Balanced & Aluminum \\
\hline 3 & L-shape & 16 & {$[0 / 45 / 90 / 45]_{4}$} & Asymmetric, Unbalanced & Aluminum \\
\hline 4 & L-shape & 16 & {$[0 / 45 / 90 / 45]_{2 S}$} & Symmetric, Unbalanced & Aluminum \\
\hline 5 & U-shape & 16 & {$[0 / 45 / 90 /-45]_{4}$} & Asymmetric, Balanced & Aluminum \\
\hline 6 & U-shape & 16 & {$[0 / 45 / 90 /-45]_{2 S}$} & Symmetric, Balanced & Aluminum \\
\hline
\end{tabular}

\subsubsection{Measuring Method for Flat Panels}

A seven-axis Romer arm equipped with a laser scanner probe was utilized to obtain three types of parameters for each panel: 3D pattern of distortion, maximum amount of distortion, and pattern of thickness variation. During scanning, the panels were held vertically to minimize the weight effect on the measured distortion.

\subsubsection{3D Pattern of Distortion and Maximum Distortion}

To obtain the maximum distortion, a surface was created using the scanned data and three corners of the surface were fixed on a flat reference surface. The maximum distortion was defined as the maximum distance between the positioned surface and the reference surface. In addition, the 3D pattern of distortion was established for each side of the panel by comparing 
each point of the positioned surface with an equivalent point on the reference surface obtained using PolyWorks.

\subsubsection{Thickness Variation Pattern}

The panels had significant thickness variation especially due to resin flow, even though a caul plate was used during curing of all the panels. To obtain the thickness variation pattern, both sides of the panel were scanned in one coordinate system and the data obtained from the bag side were compared to the tool side data.

\subsubsection{Measuring Method for U-shaped and L-shaped Panels}

Distortion of the U-shaped and the L-shaped panels was categorized into two parts of warpage and spring-in angle. As illustrated in Figure 22, spring-in angle was defined as the angle formed between the deformed shape and the original shape of the panel. Also warpage was observed in the flanges of the L-shaped panels and the webs and the flanges of the U-shaped panels as a deviation in flatness from their original shape.

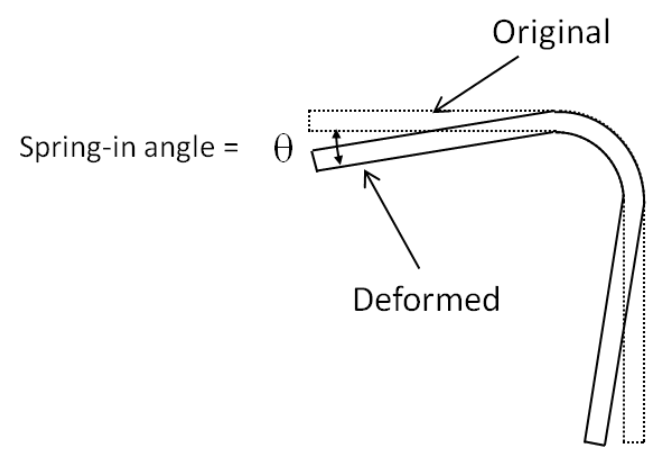

Figure 22. Schematic depiction of spring-in angle

A seven-axis Romer arm equipped with a laser scanner probe was used to scan the tool side and the bag side of the panels. 


\subsubsection{3D Pattern of Warpage and Spring-in Angle}

The spring-in angle was obtained for the tool-side of the panels with different stacking sequences by analyzing the data in PolyWorks.

The 3D warpage pattern was obtained for the flat sections of the panels ( flanges in the Lshaped parts, and webs and flanges in the U-shaped parts). Similar to the flat panels described in section 3.1.3.1, a surface was created from the scanned data obtained from the flat sections of the panel and was subsequently compared to a flat reference surface to obtain the warpage pattern.

\subsubsection{Thickness Variation Pattern}

To obtain the thickness variation pattern, both sides of the panels were scanned in a fixed coordinate system. The data from the bag side was compared to the data from the tool side for each panel; as such, the thickness variation pattern was obtained for the panels with different stacking sequences.

\subsection{Numerical Study}

MSC Marc 2008r1 was utilized to run a 3D simulation to estimate the distortion of carbon fiber-epoxy composite parts. L-shaped and Flat geometries were considered with the same dimensions as those applied to the fabricated panels. Simulation results were compared with the experimental data subsequently and a good agreement was observed. As explained before, the methodology was introduced in the previous study for flat panels [61]. Several Fortran codes were incorporated into the model as user subroutines to account for different phenomena, including cure shrinkage, cure kinetics, thermal strains, tool-part interaction, and the development of mechanical properties during cure. 
Using the algorithm illustrated in Figure 19, several models were incorporated into the simulation to estimate processing parameters and development of the material properties during cure.

To estimate the degree of cure, the Springer-Loos model (eq. 6) was used:

$$
\frac{d \alpha}{d t}=\left(A_{1} \exp \left(-\frac{\Delta E_{1}}{R T}\right)+\mathrm{A}_{2} \exp \left(-\frac{\Delta E_{2}}{R T}\right) \alpha\right)(1-\alpha)(B-\alpha)
$$

where $\Delta E$ is the activation energy, $\mathrm{T}$ is the absolute temperature, $\mathrm{R}$ is the universal gas constant, and $A_{i}$ and $B$ are the constants determined from experiment. Table 7 shows the parameters of the cure kinetics model used for the simulation.

Table 7

Parameters of the Cure Kinetics Model Used for the Simulation [61]

\begin{tabular}{ccc}
\hline Parameter & Value & Unit \\
\hline$A_{1}$ & $2.46 \mathrm{E}+02$ & $1 / \mathrm{sec}$ \\
\hline$A_{2}$ & $-4.18 \mathrm{E}-05$ & $1 / \mathrm{sec}$ \\
\hline$E_{1}$ & $8.26 \mathrm{E}+04$ & $\mathrm{~J} / \mathrm{mol}$ \\
\hline$E_{2}$ & $2.65 \mathrm{E}+04$ & $\mathrm{~J} / \mathrm{mol}$ \\
\hline$B$ & $6.26 \mathrm{E}+03$ & -- \\
\hline
\end{tabular}

A modified version of the Bogetti-Gillespie model was utilized to account for the effect of cure shrinkage on distortion of the composite part. While Bogetti and Gillespie proposed their model for resin [25], in this study their model was used for simulating a composite laminate as discussed in reference [61]. The following equation was used to obtain cure shrinkage for each principal direction: 


$$
\varepsilon_{i}^{S}=C_{i}\left(\sqrt[3]{1+V_{r}^{s}}-1\right)
$$

where $\varepsilon_{i}^{S}$ is the cure shrinkage in i direction, $V_{r}^{s}$ is the volumetric cure shrinkage, and $C_{i}$ is the linear coefficient of cure shrinkage determined by experiment. Table 8 shows the cure shrinkage parameters used in this study.

Table 8

Directional Cure Shrinkage Coefficients Used for the Simulation [61]

\begin{tabular}{ccc}
\hline Parameter & Associated Property & Value \\
\hline $\mathrm{C} 1$ & Longitudinal cure shrinkage & 0.42 \\
\hline $\mathrm{C} 2$ & Transverse cure shrinkage & 2.11 \\
\hline $\mathrm{C} 3$ & Through-thickness cure shrinkage & 4.82 \\
\hline$V_{r}^{s}$ & Total volumetric cure shrinkage & 0.01 \\
\hline
\end{tabular}

A separate module was utilized to estimate development of the mechanical properties during cure. A linear model was used to predict shear and elastic moduli in three principal directions as a function of degree of cure similar to the Bogetti-Gillespie model applied to estimate the mechanical properties of the resin. Table 9 shows the normalized elastic moduli. Before $\alpha_{\text {gelation, }}, \mathrm{E} 0$, and after $\alpha_{\text {diffusion, }}, \mathrm{E} \infty$, were used in the model for two different directions.

Additional modules were used to estimate other parameters, such as specific heat capacity and coefficient of thermal expansion. The methodology used in this study is explained and discussed in detail in reference [61]. 


\section{Table 9}

Parameters of Modulus Development Used for the Simulation [61]

\begin{tabular}{ccc}
\hline $\begin{array}{c}\text { Model } \\
\text { Parameter }\end{array}$ & $\begin{array}{c}\text { Set 1 (Fiber- } \\
\text { Dominant) }\end{array}$ & $\begin{array}{c}\text { Set 2 (Resin- } \\
\text { Dominant) }\end{array}$ \\
\hline E0 & 0.165 & 0.025 \\
\hline E $\infty$ & 1 & 1 \\
\hline$\alpha$ gel & 0.33 & 0.50 \\
\hline$\alpha$ diff & 0.84 & 0.95 \\
\hline
\end{tabular}

\subsubsection{Flat Panel}

Using the aforementioned methodology, a 3D simulation was conducted for flat panels to estimate the maximum value of distortion as well as the 3D distortion pattern for each panel. Figure 23 depicts schematic of the set up used for the panels. Each composite panel was confined by the caul plate on the top and the tool at the bottom. The simulation was conducted assuming autoclave conditions. For example, a temperature cycle was applied on free surfaces of the tool and the caul plate, and pressure cycle was exerted on the caul plate to affect the panel indirectly. An eight-node composite brick element was selected consisting of different layers, each of which could have individually defined thickness, material properties, and orientation. Simulation was conducted for panels with different thicknesses and stacking sequences. Subsequently, the simulation results were compared with the experimental results. 


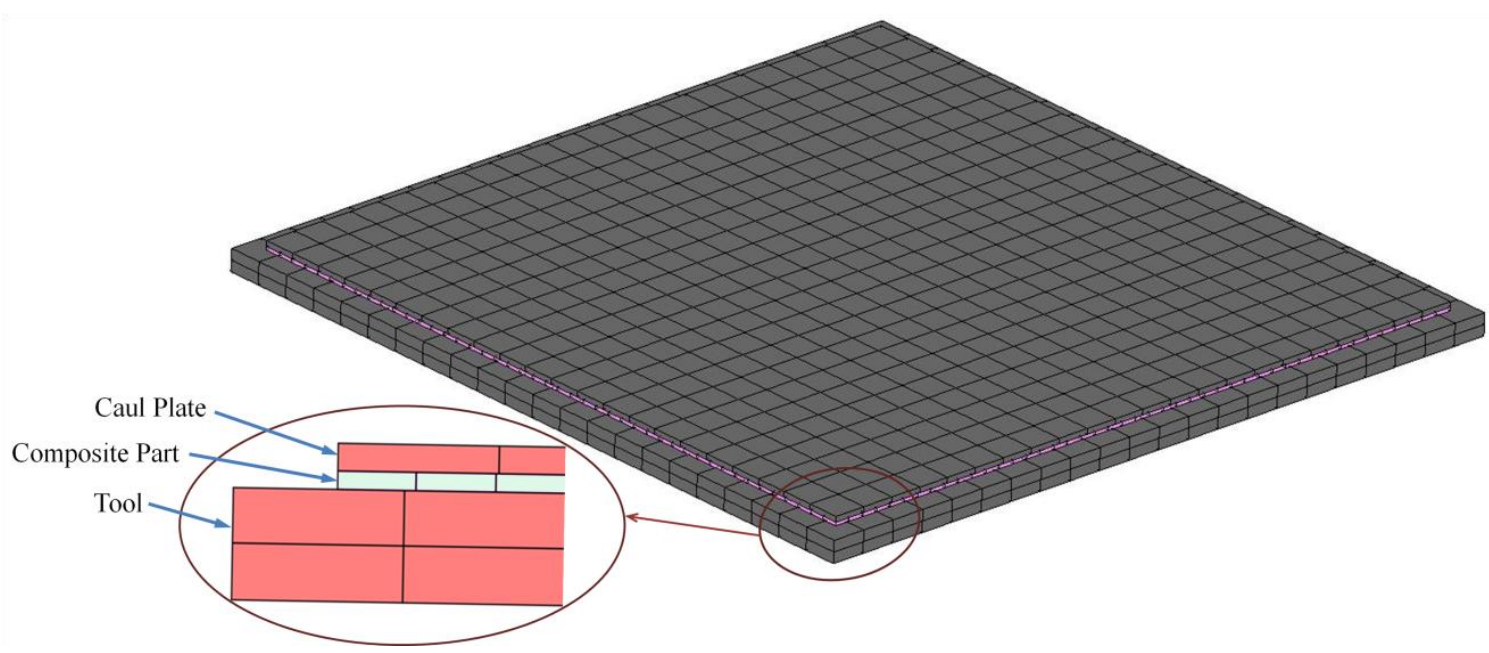

Figure 23. Schematic of set up for flat panels used in simulation [61]

\subsubsection{L-shaped Panel}

The same methodology was used to develop a 3D model to estimate warpage and springin angle for L-shaped panels. Figure 24 illustrates the finite element mesh used for the panel and the tool. A temperature cycle was applied on free surfaces of the tool and top of the panels, whereas autoclave pressure was applied only on top of the part. The asymmetric stacking sequences were considered intentionally to show capability of the simulation in an estimation of more complicated cases. To study the effect of curve radius on the spring-in angle of L-shaped panels, two panels with curve radii of $23 \mathrm{~mm}$ and $5 \mathrm{~mm}$ were simulated. In addition, to investigate the effect of tool geometry on spring-in angle, the curing of an L-shaped panel with a curve radius of $5 \mathrm{~mm}$ was simulated on tools with two different geometries (concave and convex). 


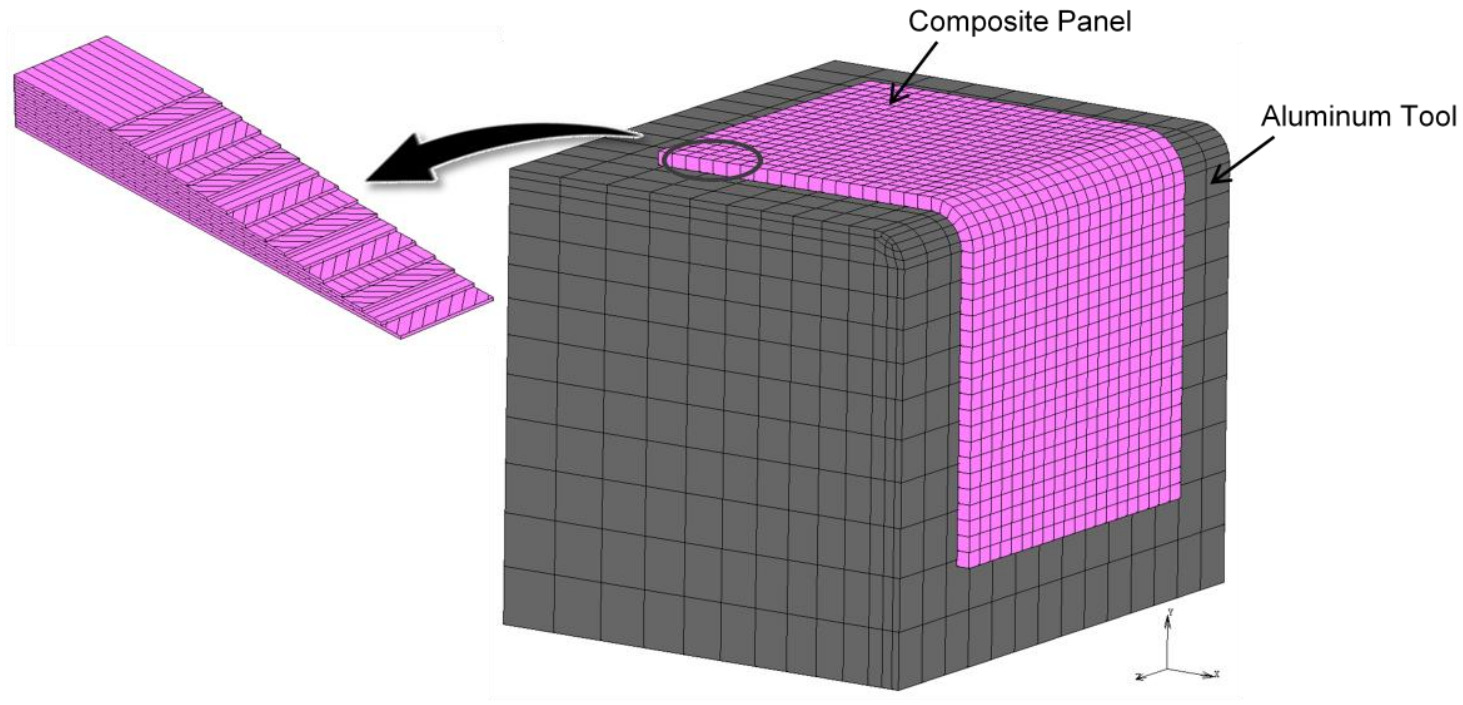

Figure 24. 3D finite element mesh used for L-shaped panel cured on an aluminum tool 


\section{CHAPTER 4}

\section{RESULTS AND DISCUSSION}

\subsection{Experimental Results for Flat Panels}

The effect of different stacking sequences, part thickness, and tooling material was investigated on distortion of the fabricated composite panels.

\subsubsection{Effect of Stacking Sequence}

To attain the effect of stacking sequence on distortion of the flat panels, 3D distortion patterns of panel 1 to panel 4 (with different stacking sequences) were obtained. Distortion patterns of the tool side and the bag side of the panels are depicted in Figure 25 to Figure 28. The amounts of maximum distortion in the panels were also compared as shown in Figure 29. Although panel 1 was fabricated using an asymmetric stacking sequence, it showed comparable patterns of distortion in tool side and bag side (Figure 25). However, distortion of the bag-side was slightly more than distortion of the tool-side.

In contrast with panel 1 which showed considerable distortion, curing of panel 2 resulted in insignificant distortion since panel 2 was symmetric and balanced. On the other hand, the maximum distortion was located differently on the bag side and the tool side of the panel. In other words, the pattern of distortion in the bag side of panel 2 was not the same as the one in the tool side of the panel (Figure 26). 


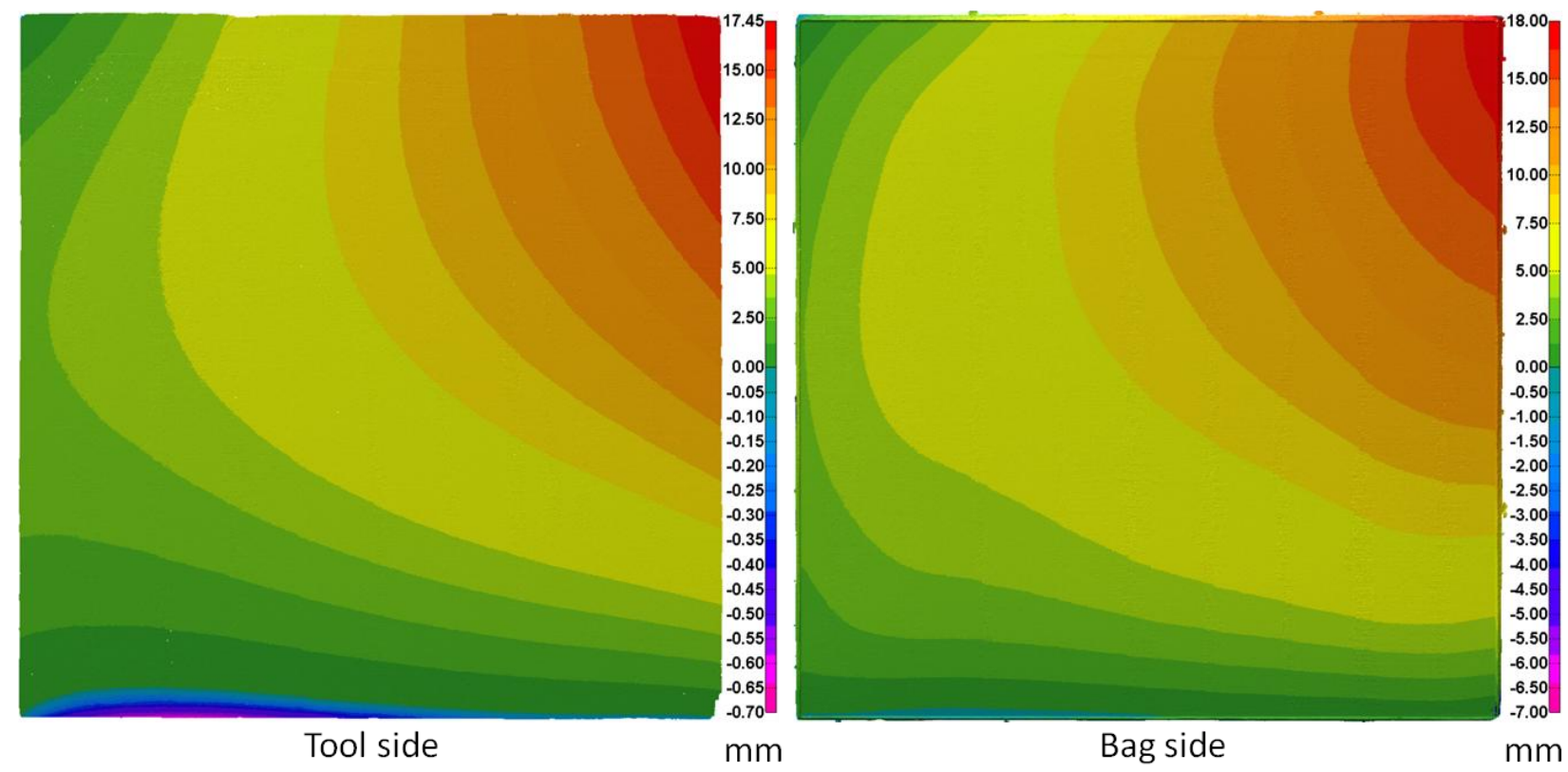

Figure 25. 3D pattern of distortion in tool side and bag side of panel 1

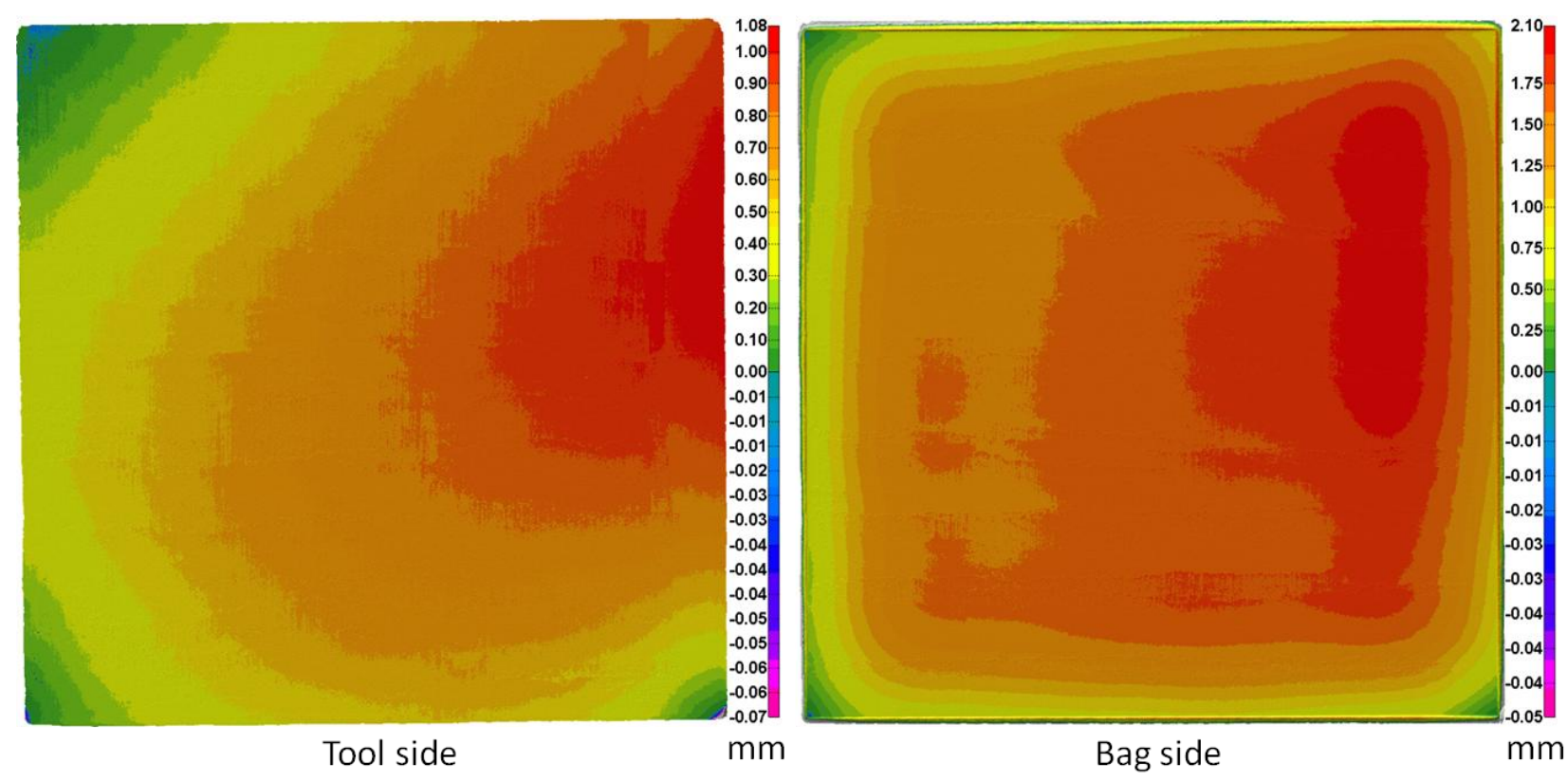

Figure 26. 3D pattern of distortion in tool side and bag side of panel 2 

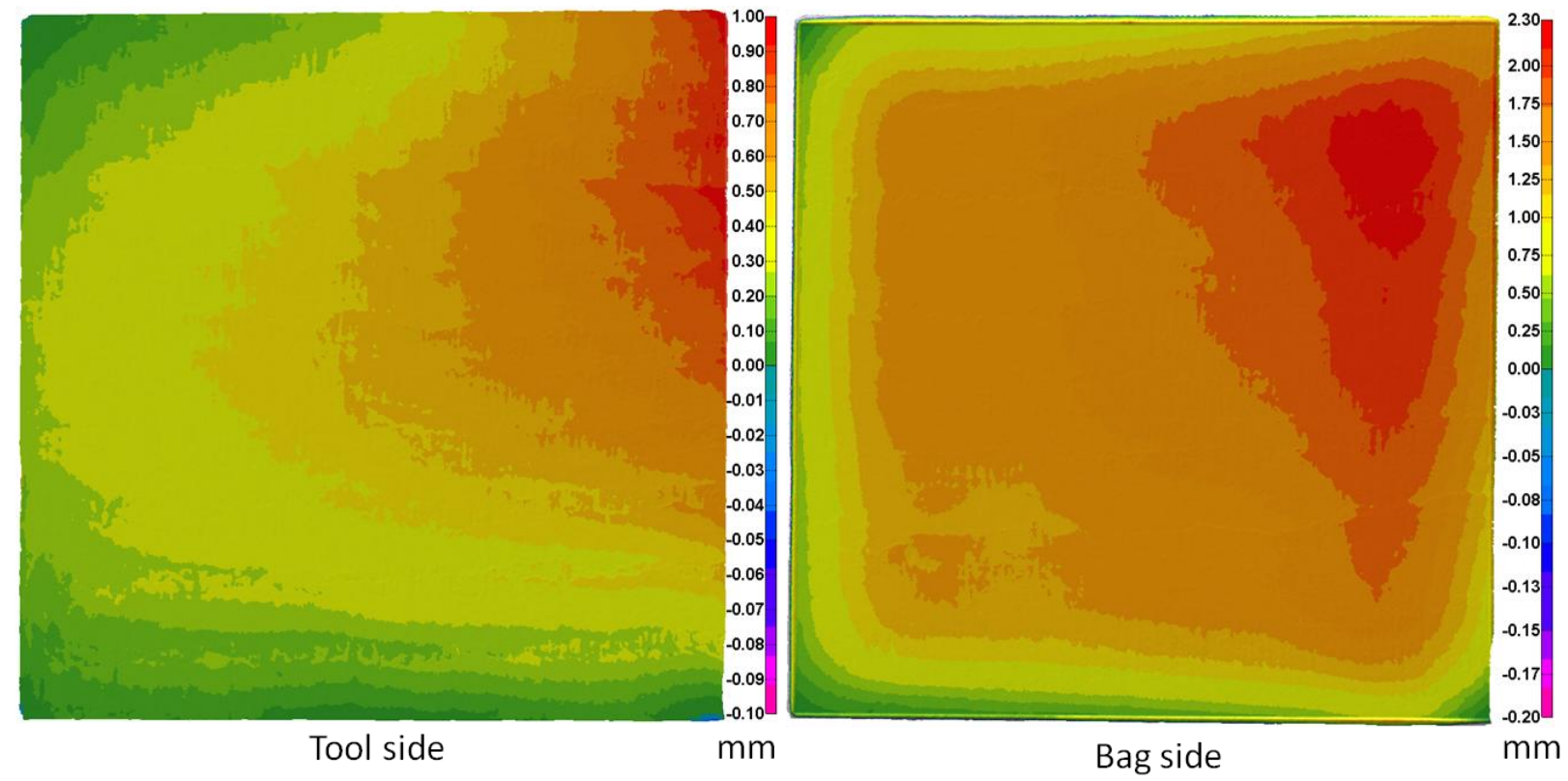

Figure 27. 3D pattern of distortion in tool side and bag side of panel 3

If obtained patterns of distortion in the tool side and the bag side of panel 3 (Figure 27) were compared to the patterns of distortion in panel 2, a specific pattern of distortion would be revealed for the symmetric stacking sequence, which was different from the asymmetric one. As shown in Figure 27, the location of maximum distortion in panel 3 was not exactly the same in both sides.

Like panel 1, patterns of distortion were the same in both sides of panel 4 which was asymmetric and unbalanced (see Figure 28). Having an asymmetric stacking sequence resulted in a considerable amount of distortion compared to the symmetric panels. Conversely, imbalance in the stacking sequence did not cause significant distortion. On the other hand, comparing panel 1 with panel 4 shows that imbalance in the asymmetric panels could even decrease the distortion. 

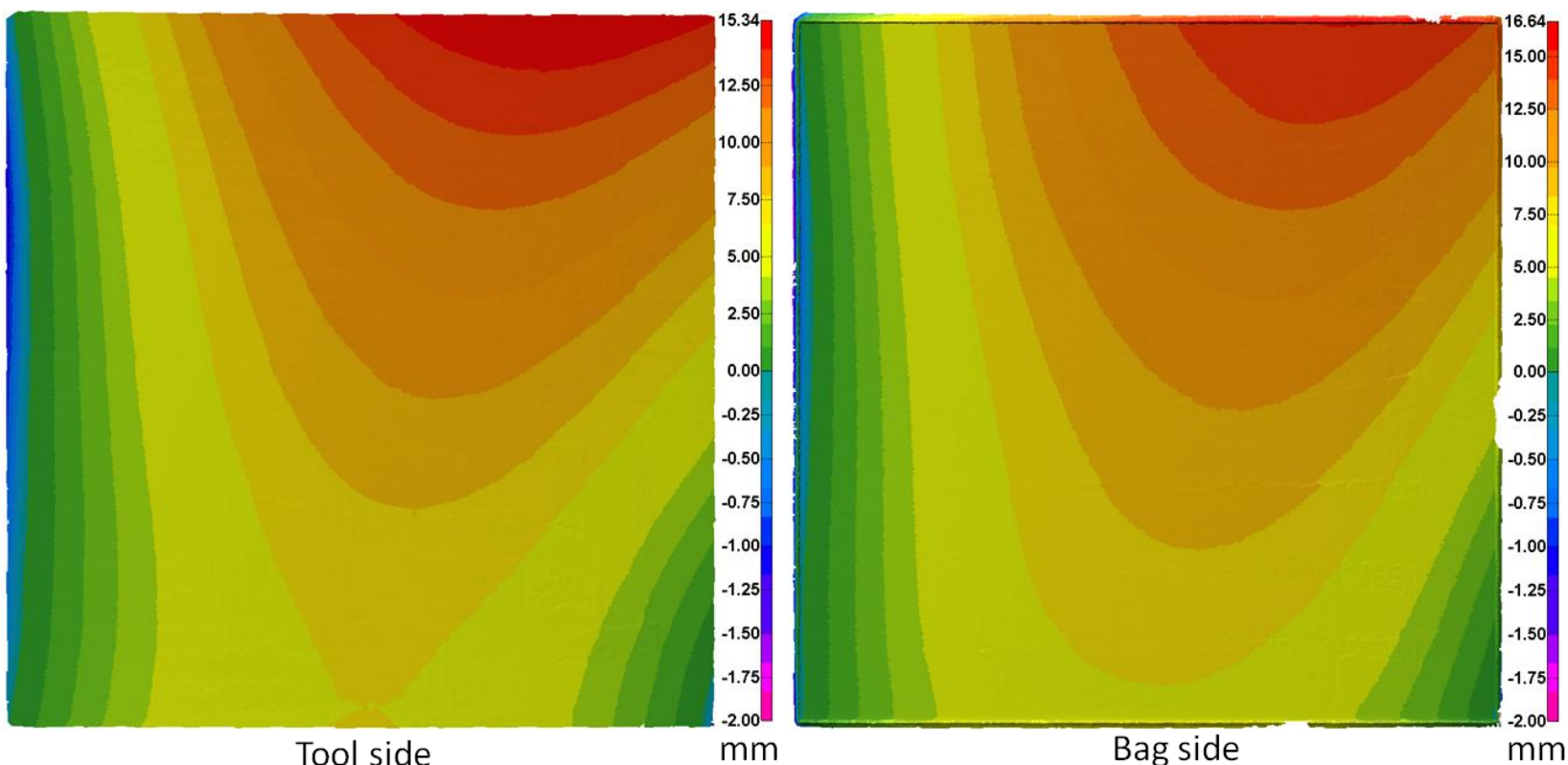

Figure 28. 3D pattern of distortion in tool side and bag side of panel 4

Experimental results for different stacking sequences of asymmetric and balanced, symmetric and balanced, asymmetric and unbalanced, and symmetric and unbalanced showed that the maximum amount of distortion was powerfully influenced by the asymmetric stacking sequence, not the unbalanced stacking sequence. In other word, asymmetry played a big role in the distortion of the composite parts compared with imbalance. Figure 29 depicts the comparison of maximum distortion in panels 1 to 4 . It was noted that diversity in the maximum amount of distortion in panel 2 and panel 3 could be considered as measurement error. Therefore, it could be assumed that the maximum distortion of the symmetric panels, once the panel was thick, was not dependent on the balance or imbalance in its stacking sequence. On the other hand, once the panel was asymmetric, imbalance in stacking sequence could decrease the maximum distortion and compensate the effect of asymmetry. 


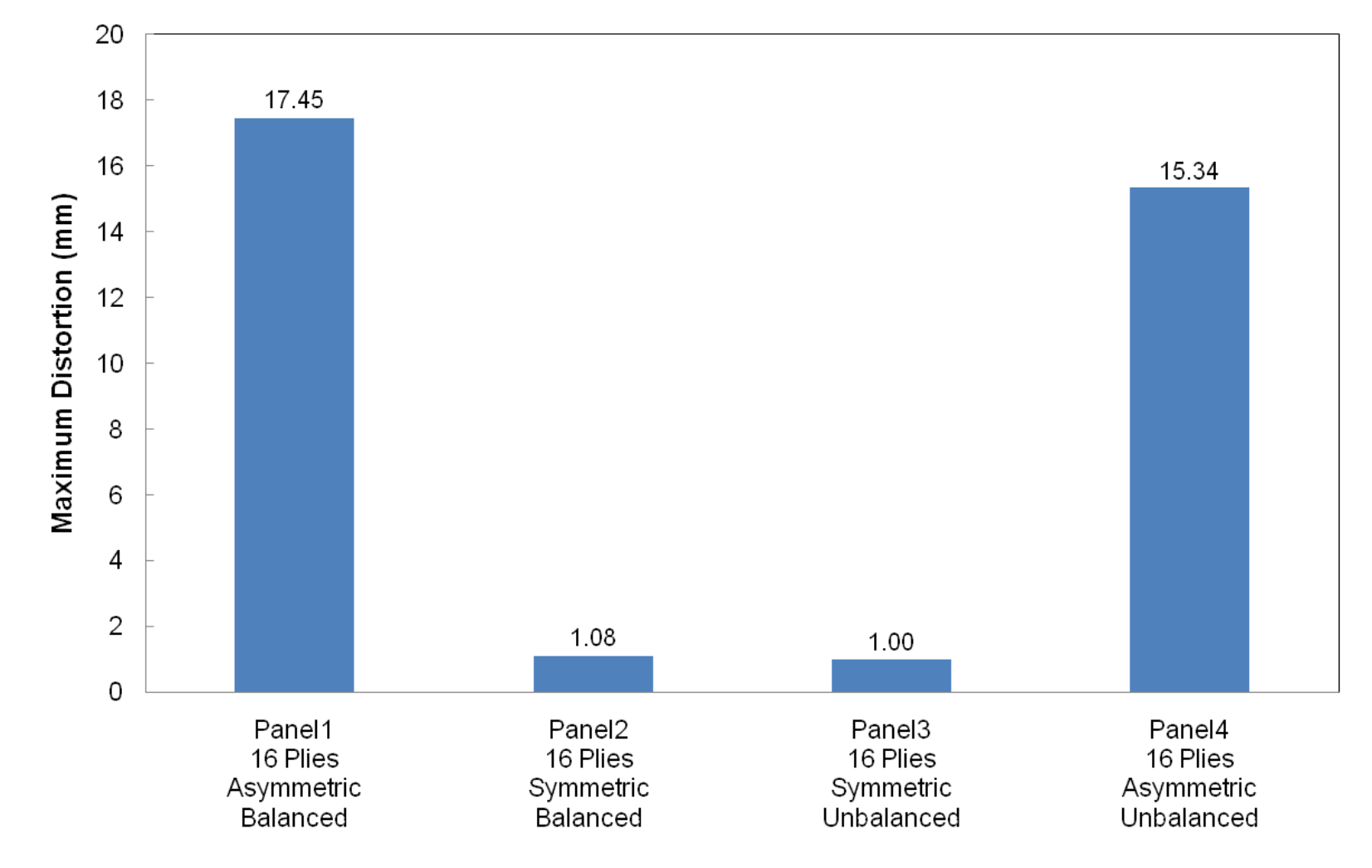

Figure 29. Maximum distortion in tool side of panel 1 to panel 4

\subsubsection{Effect of Part Thickness}

The 3D distortion patterns of panel 5 and panel 6 are shown in Figure 30 and Figure 31 , respectively. To identify how part thickness affected distortion in the flat panels, the distortion of panel 2 (Figure 26) was compared with the distortion of panel 5 (Figure 30) while both panels were cured using the stacking sequences of symmetric and balanced $\left([0 / 45 / 90 /-45]_{\mathrm{nS}}\right)$ resulted in different thicknesses. Comparison of the distortion in panel 1 (Figure 25) and panel 6 (Figure 31) was also performed to find the effect of thickness on distortion of the panels with asymmetric and balanced stacking sequences. 

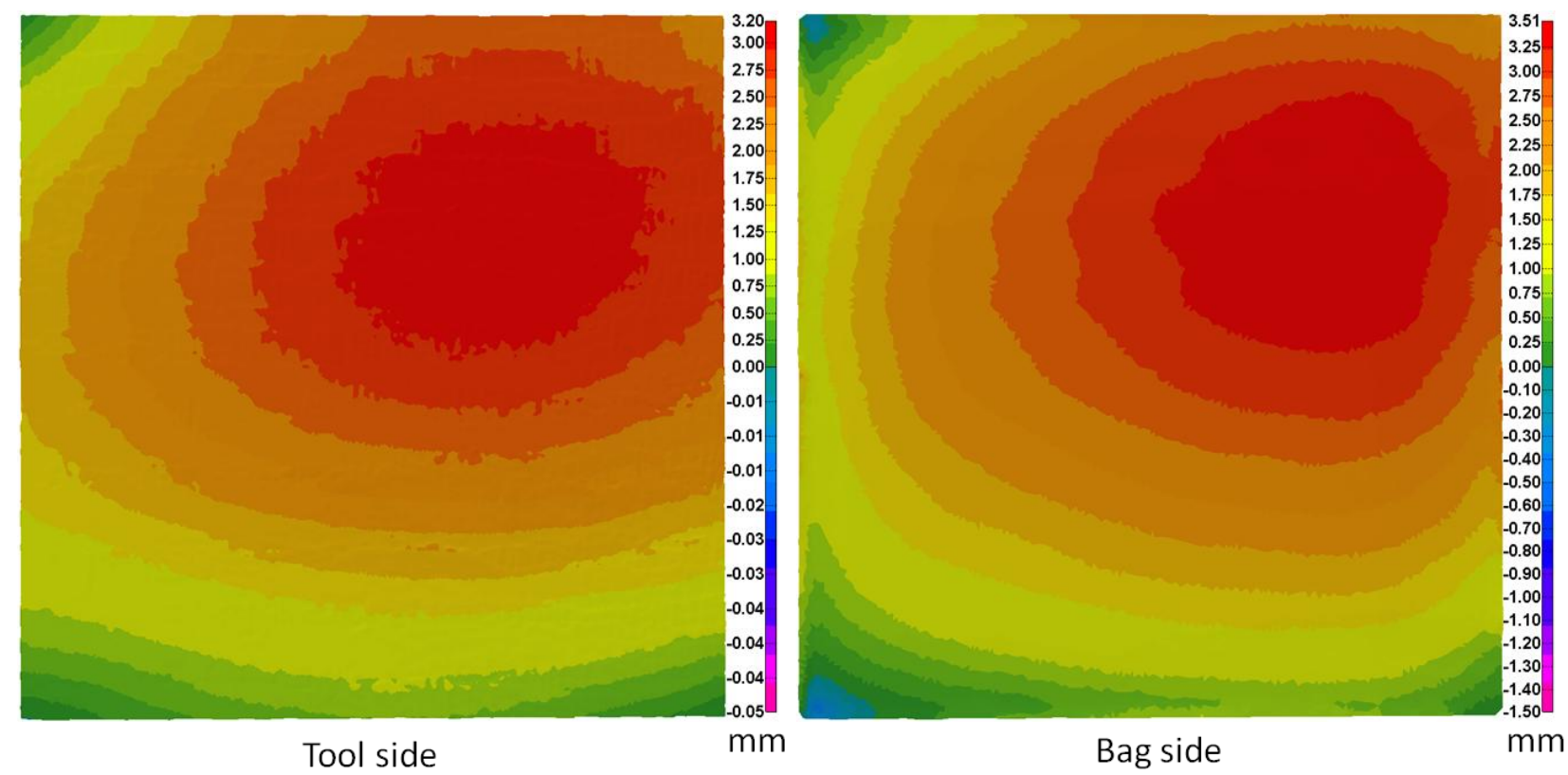

Figure 30. 3D pattern of distortion in tool side and bag side of panel 5

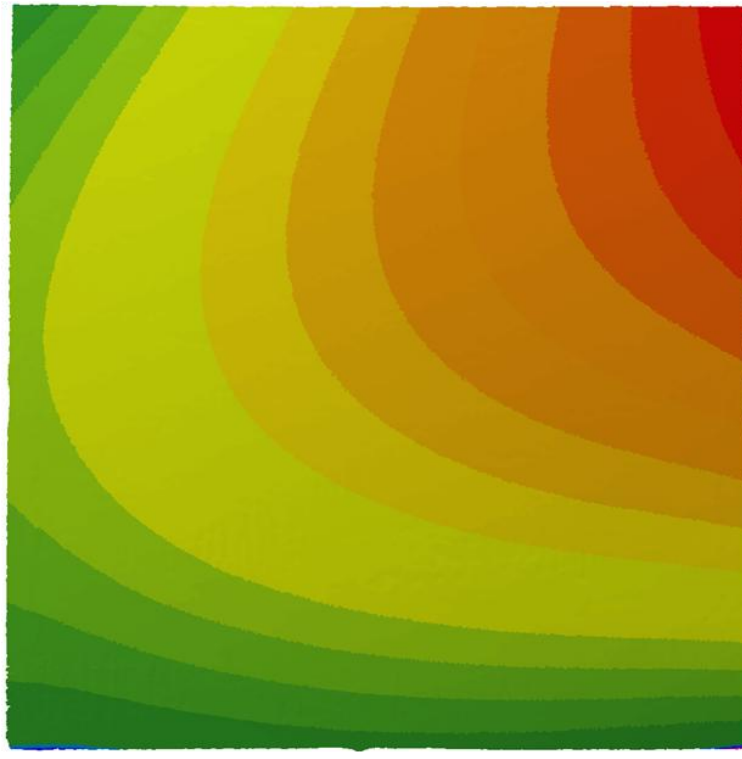

Tool side

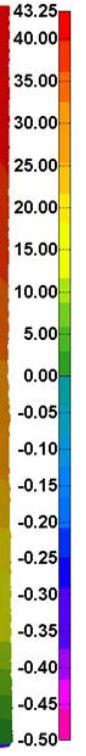

$\mathrm{mm}$

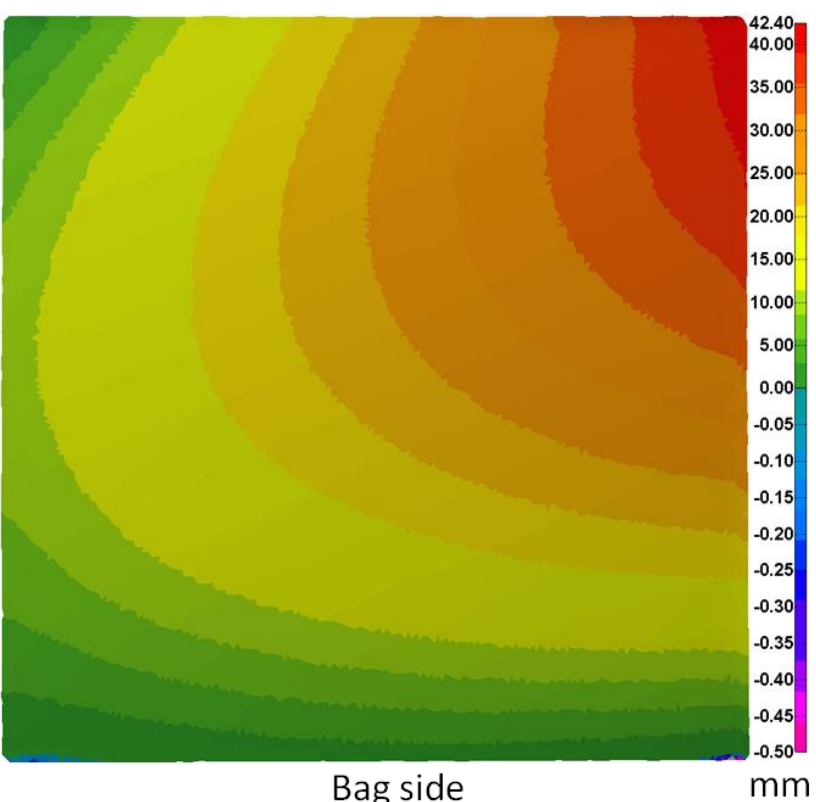

Bag side

Figure 31. 3D pattern of distortion in tool side and bag side of panel 6

Figure 32 shows the effect of thickness on the maximum distortion of composite panels. In general, as mentioned in the previous section, asymmetric panels resulted in more distortion 
than symmetric panels. Furthermore, it was evident that the thinner panels showed more distortion than the thicker panels while an identical stacking sequence was applied due to reduced stiffness of the thinner panels. The results showed satisfactory agreement with previous studies $[9,10]$.

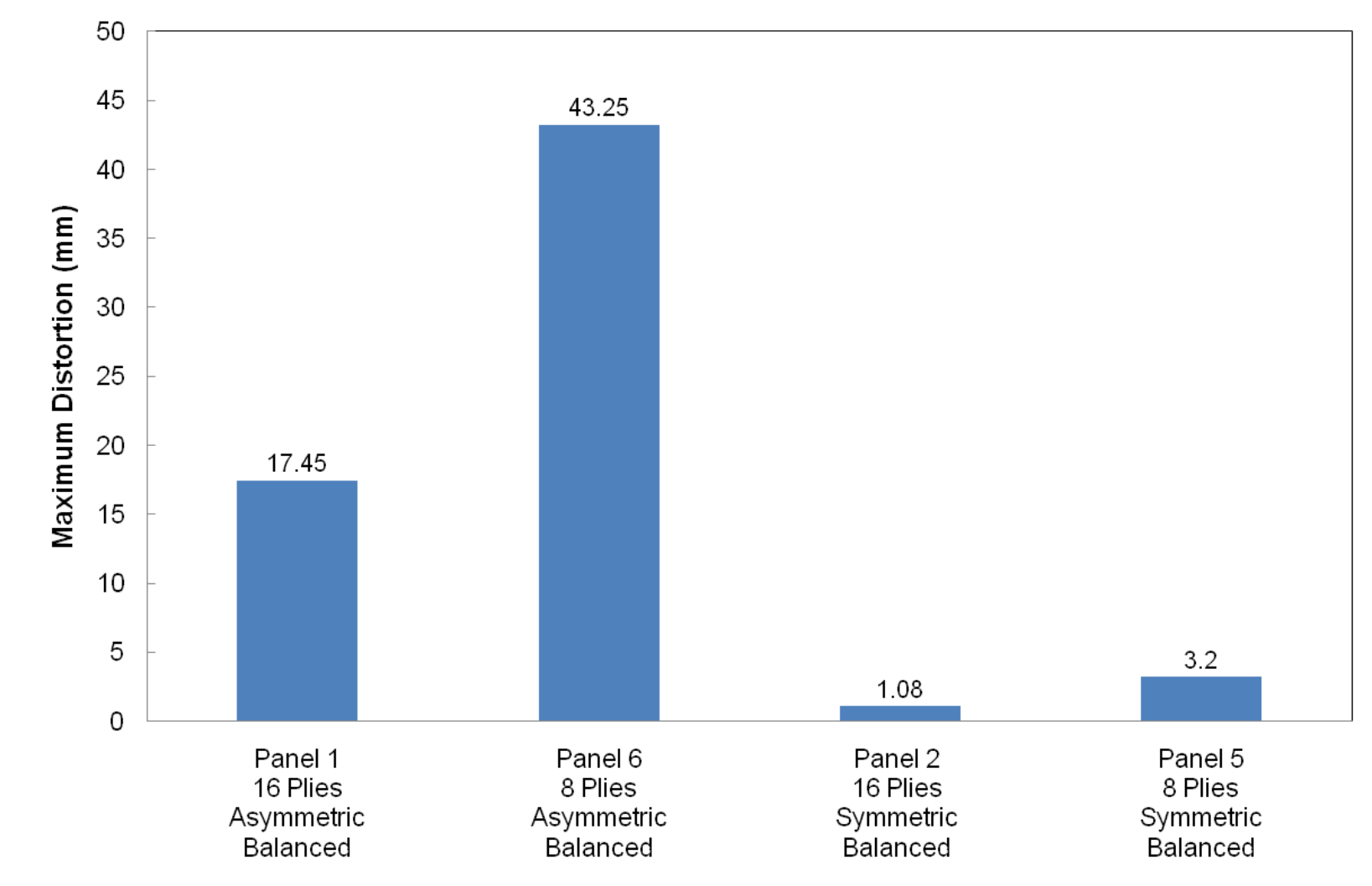

Figure 32. Effect of thickness on maximum distortion of symmetric and asymmetric panels

\subsubsection{Effect of Tooling Material}

To investigate the effect of tool material on distortion of a composite part, three panels were fabricated using three different tools of aluminum, steel, and composite while the other conditions were kept the same. The stacking sequence of $[0 / 45 / 90 /-45]_{4}$ was taken into account to obtain the largest amount of distortion. The 3D pattern of distortion for the tool-side of the panels cured on steel and composite tools are depicted in Figure 33 and compared with the distortion of tool-side in panel 1 (Figure 25). 
Utilizing different tools, the material resulted in a dissimilar coefficient of thermal expansion mismatch between the tools and the panels. Consequently, different amounts of distortion were observed in the panels. As shown in Figure 34, panel 1 cured on the aluminum tool had the greatest amount of maximum distortion between three panels and panel 8 cured on the composite tool had the less amount of maximum distortion. However, maximum distortion in panel 8 decreased by $7 \%$ compared to panel 1 . Similar distortion patterns were observed for three aforementioned panels since they were fabricated with the same stacking sequences. It is worth mentioning that the release film was used between the panel and the tool, and also between the panel and the caul plate during curing of all the panels to ease removing the panel from the tool and caul plate. Considering flat geometry for the panels, and, accordingly, the tools, tool-part interface had a minimal contribution in developing residual stresses since no locking affected the deformation. The results showed that using release film in the composite panels with flat geometry resulted in maximum $7 \%$ difference in distortion of the panels cured on the tools with materials of aluminum, steel, and composite.

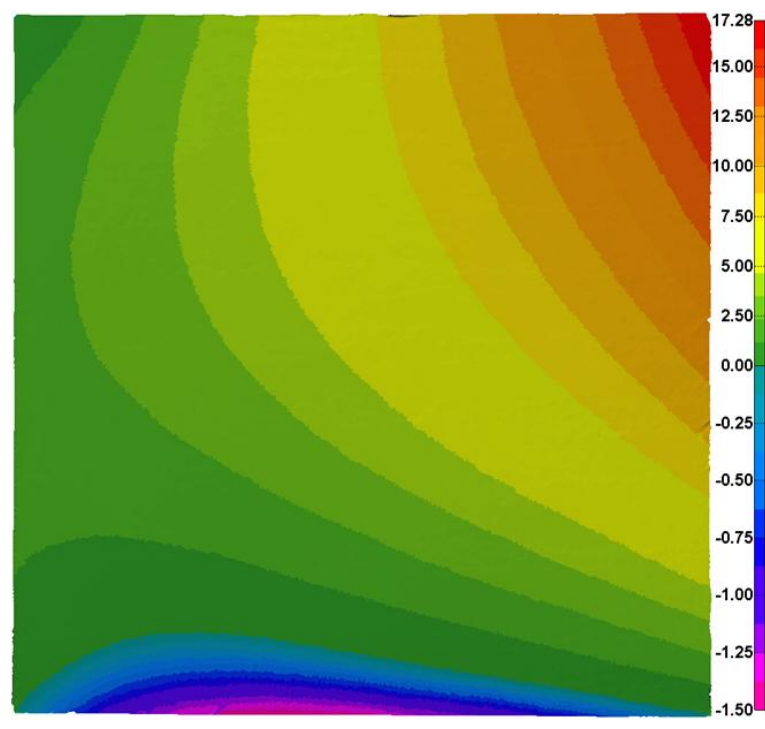

Tooling material: Steel

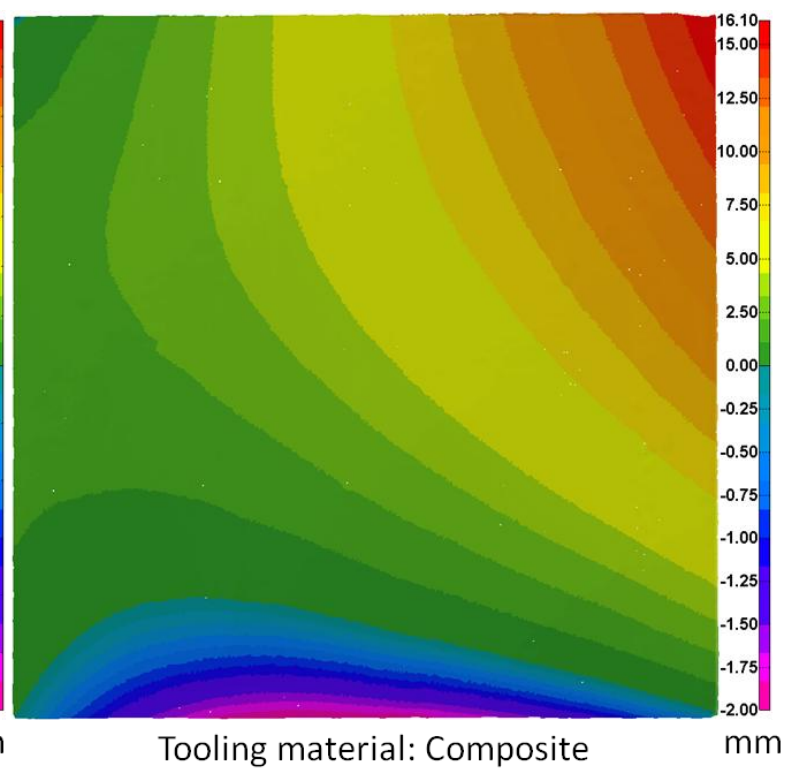

Figure 33. 3D pattern of distortion in panel 7 and panel 8 cured on steel and composite tools, respectively 


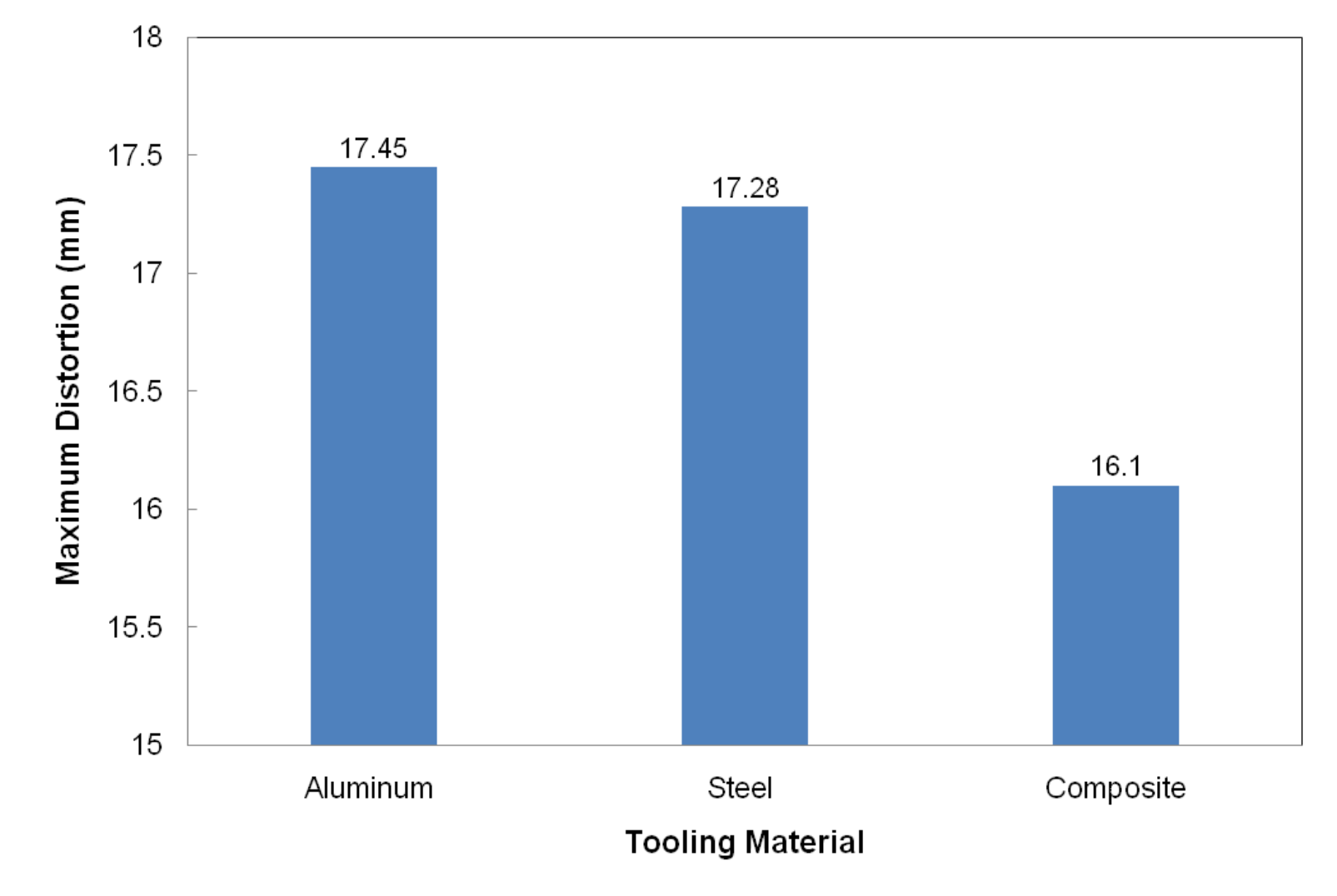

Figure 34. Effect of tool-part interface on distortion of the composite part

\subsubsection{Thickness Variation Pattern}

Figure 35 and Figure 36 show the pattern of thickness variation observed in the panels with different stacking sequences using the explained procedure in section 3.1.3.2. 


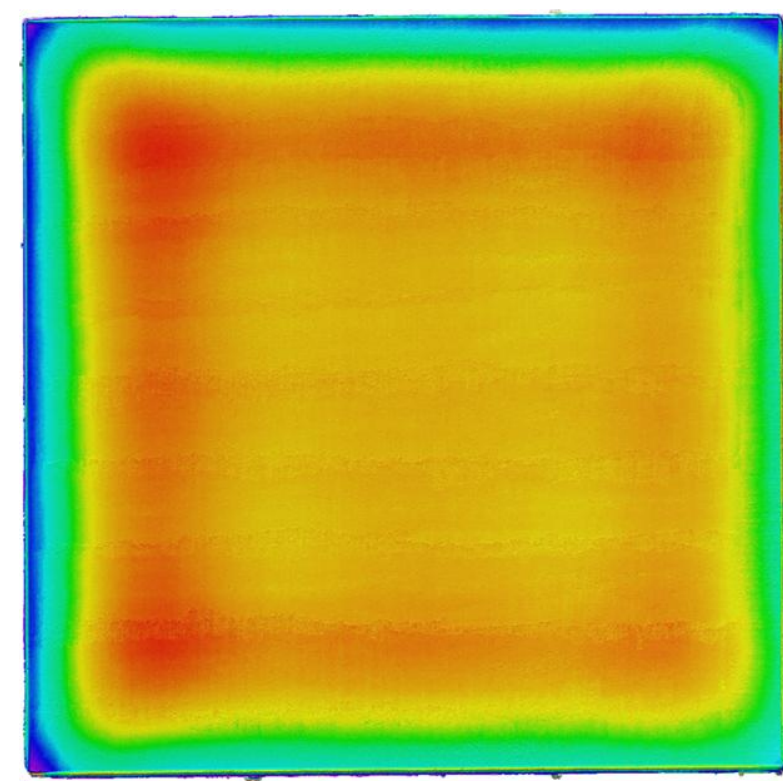

Panel 1: Asymmetric and balanced

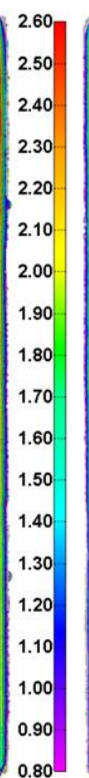

$\mathrm{mm}$

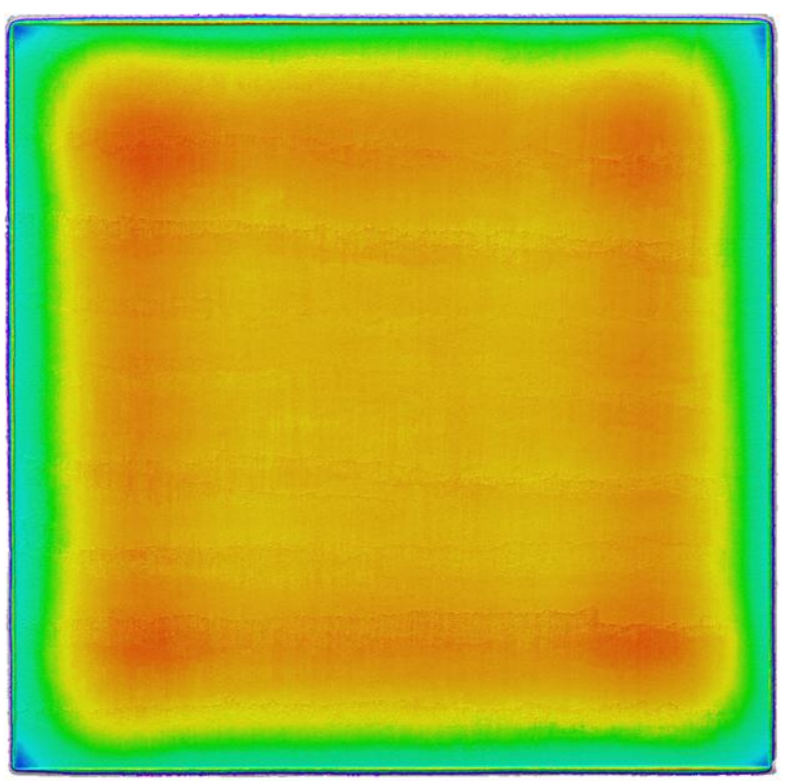

Panel 2: Symmetric and balanced

Figure 35. 3D thickness variation patterns in panel 1 and panel 2

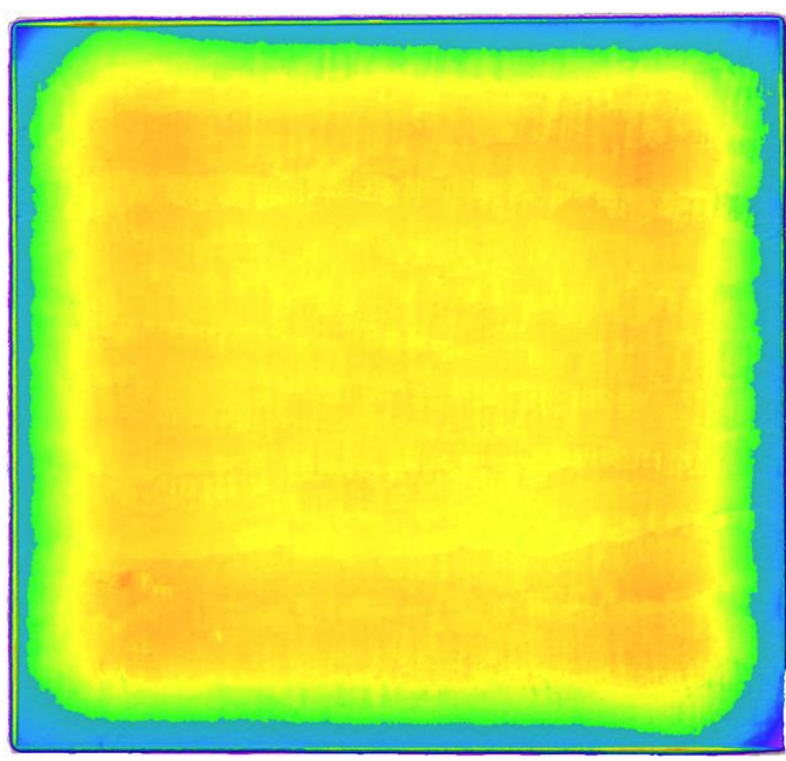

Panel 3: Symmetric and unbalanced

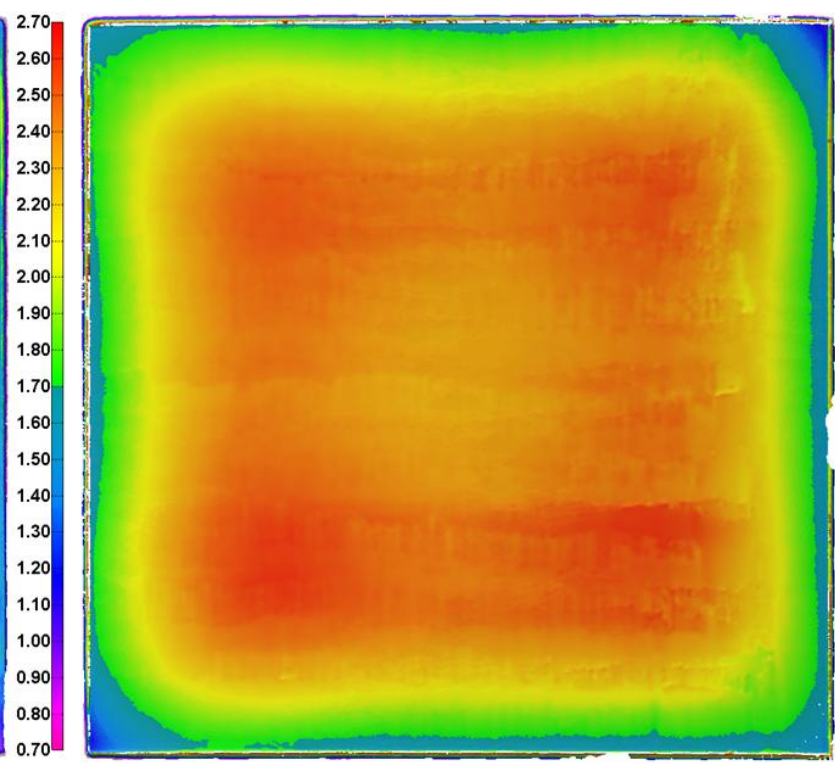

Panel 4: Asymmetric and unbalanced

Figure 36. 3D thickness variation patterns in panel 3 and panel 4

Similar thickness variation patterns were obtained for several panels with different stacking sequences, whereas they showed different amounts of distortion (Figure 29). It should be noted that the same caul plates were used in curing of the panels. As a result, thickness and surface 
roughness of the caul plates were kept invariable in all cases. The regions near the edges showed a smaller thickness mostly because pressure gradient and consequently resin bleeding were greater in those regions compared to the center; nevertheless, the thickest parts were found next to such areas with the least thickness not at the center of the panels.

\subsection{Simulation Results for Flat Panels}

Simulation of distortion was conducted for panels with different stacking sequences and several thicknesses. Comparing data from simulation with a virtual flat surface resulted in 3D pattern of distortion for each panel. The simulation results were compared with the experimental results obtained previously following the procedure explained in section 3.1.3.1. Figure 37 to Figure 42 illustrate the comparison of simulation results with experimental results presented in section 4.1. Simulation results showed satisfactory agreement with experimental results not only for the maximum amount of distortion but also, in most cases, for the $3 \mathrm{D}$ distortion pattern.

The predicted amount of maximum distortion for panel 5, depicted in Figure 41, was almost the same as experiment. However, in spite of estimating the same places for maximum and minimum distortion of the panel, the model could not accurately predict the 3D distortion pattern. 


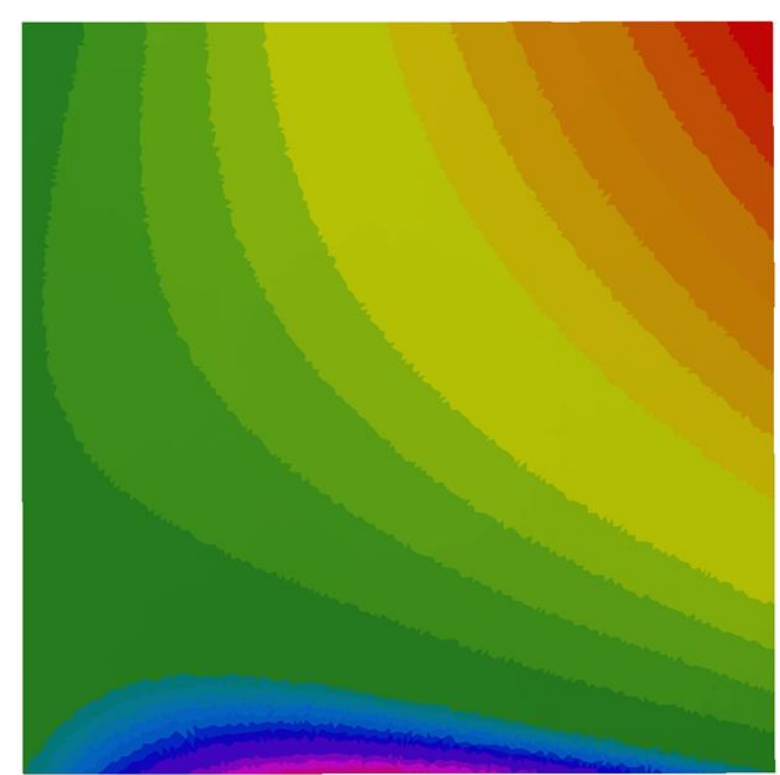

Simulation result

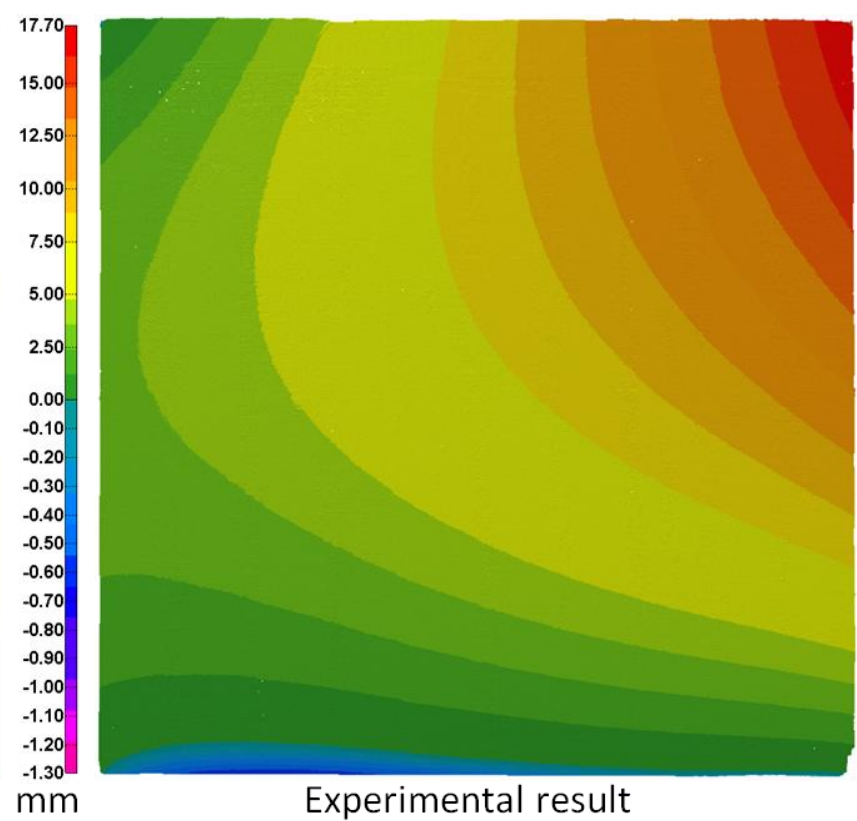

Figure 37. Comparison of tool-side distortion pattern for panel 1

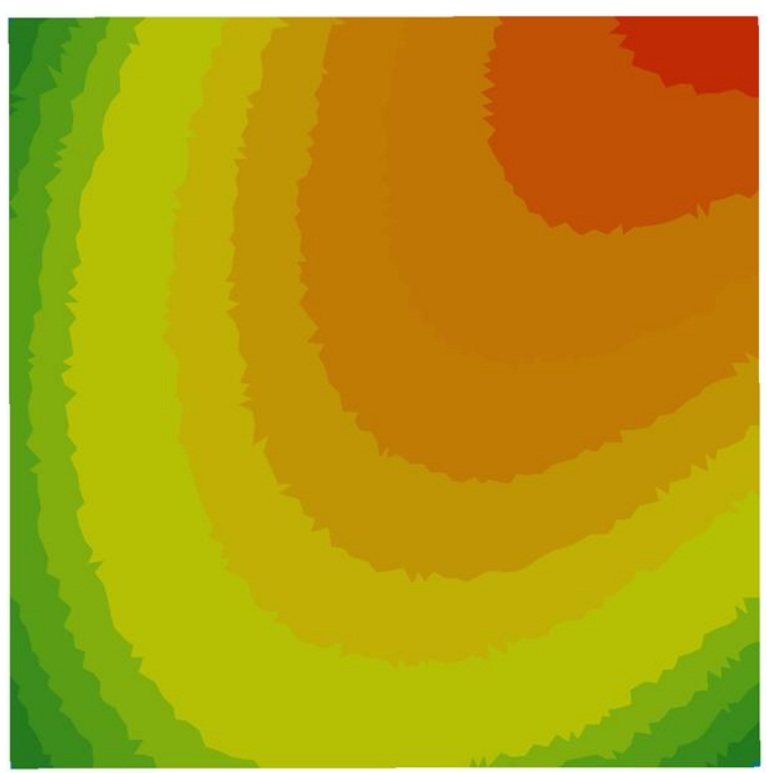

Simulation result

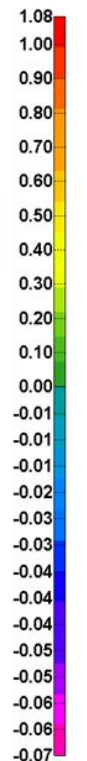

$\mathrm{mm}$

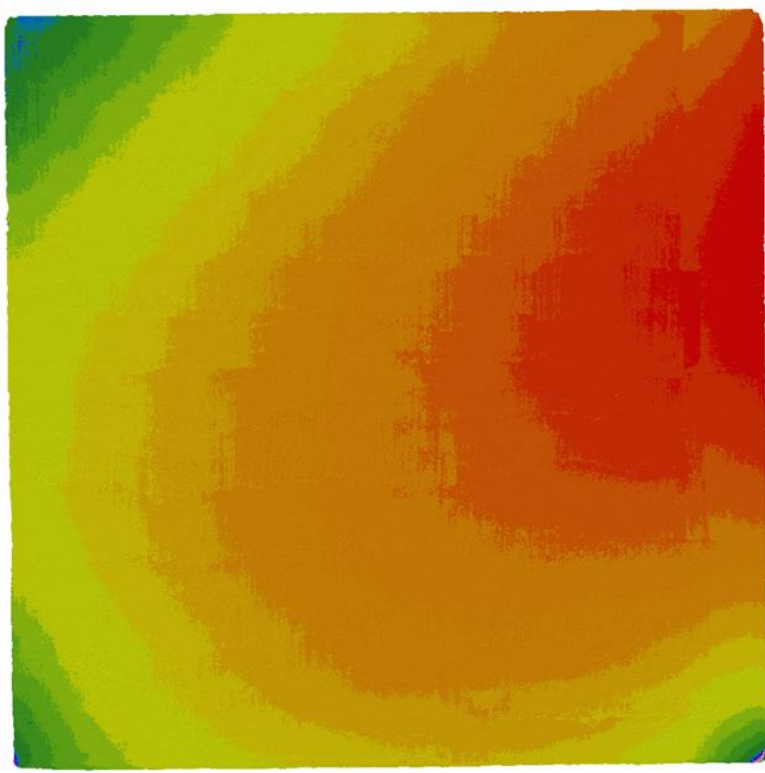

Experimental result

Figure 38. Comparison of tool-side distortion pattern for panel 2 


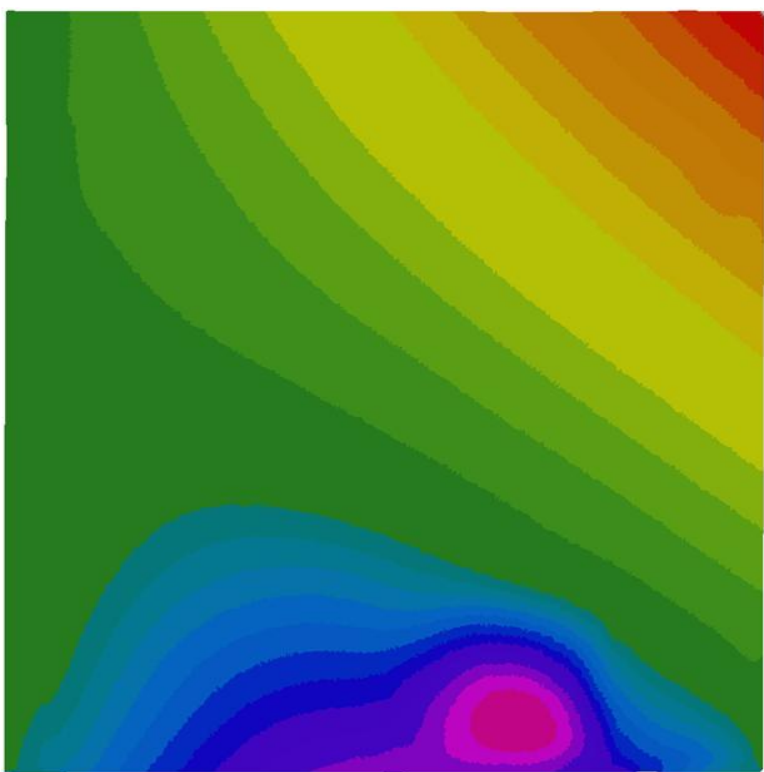

Simulation result

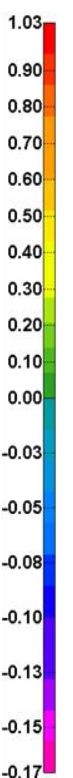

$\mathrm{mm}$

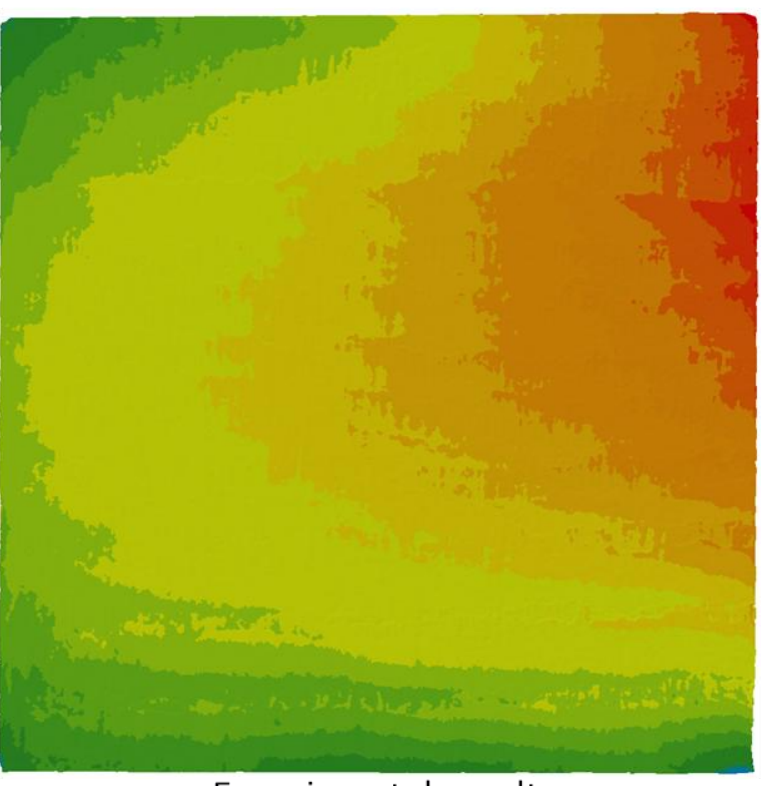

Experimental result

Figure 39. Comparison of tool-side distortion pattern for panel 3

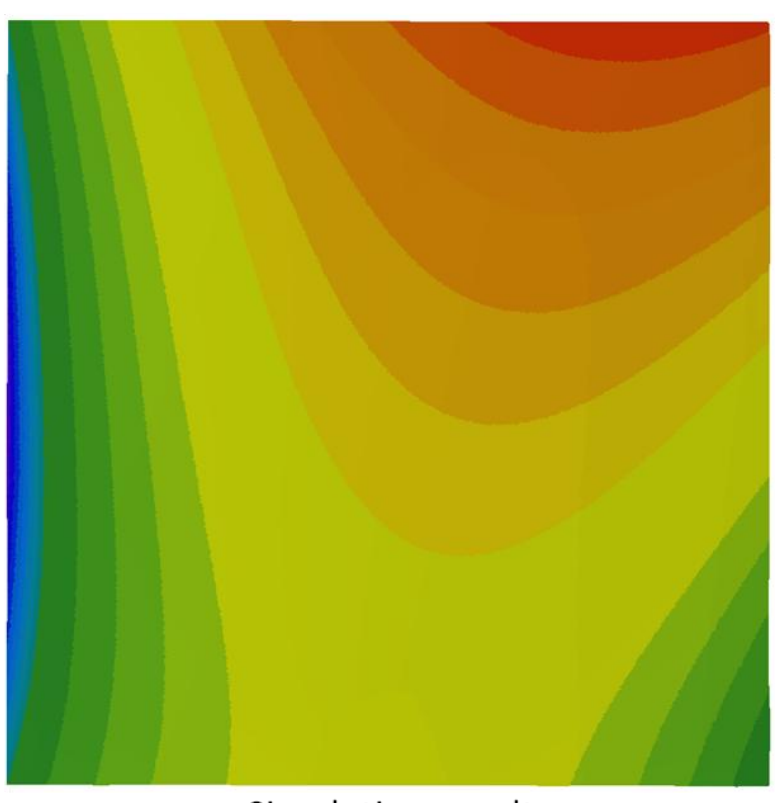

Simulation result

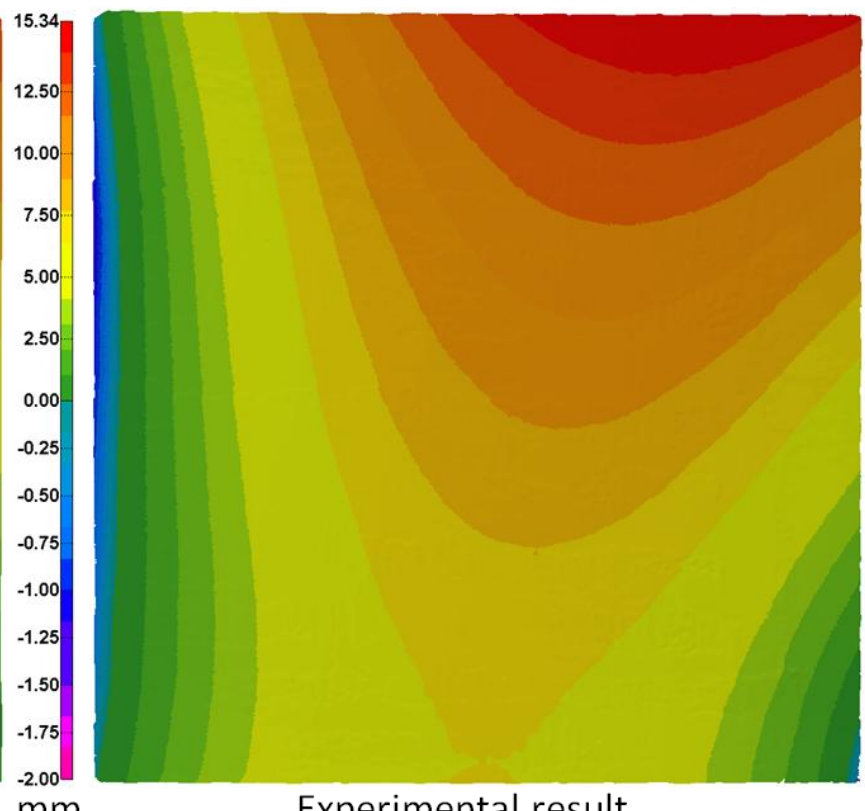

Experimental result

Figure 40. Comparison of tool-side distortion pattern for panel 4 


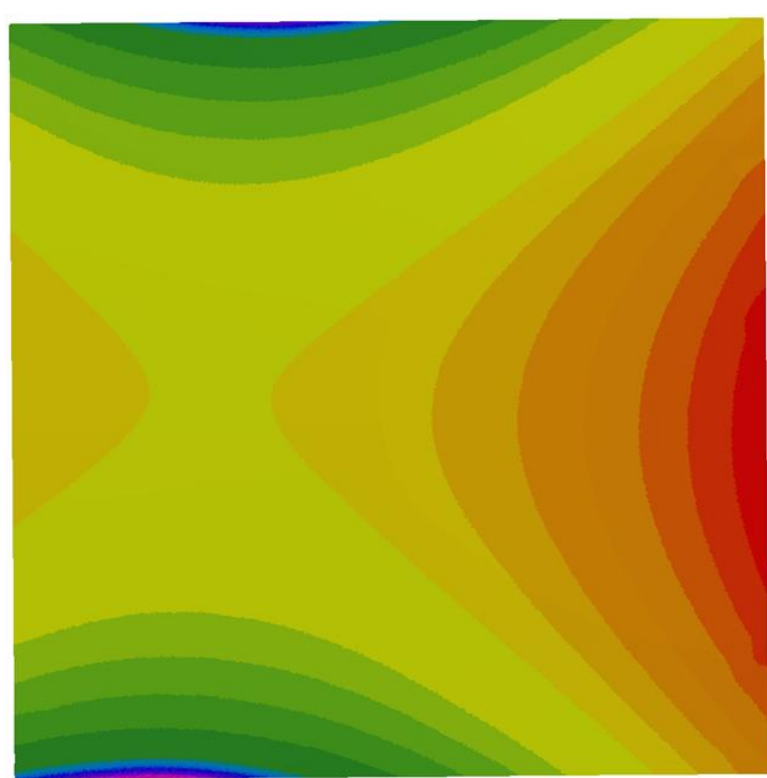

Simulation result

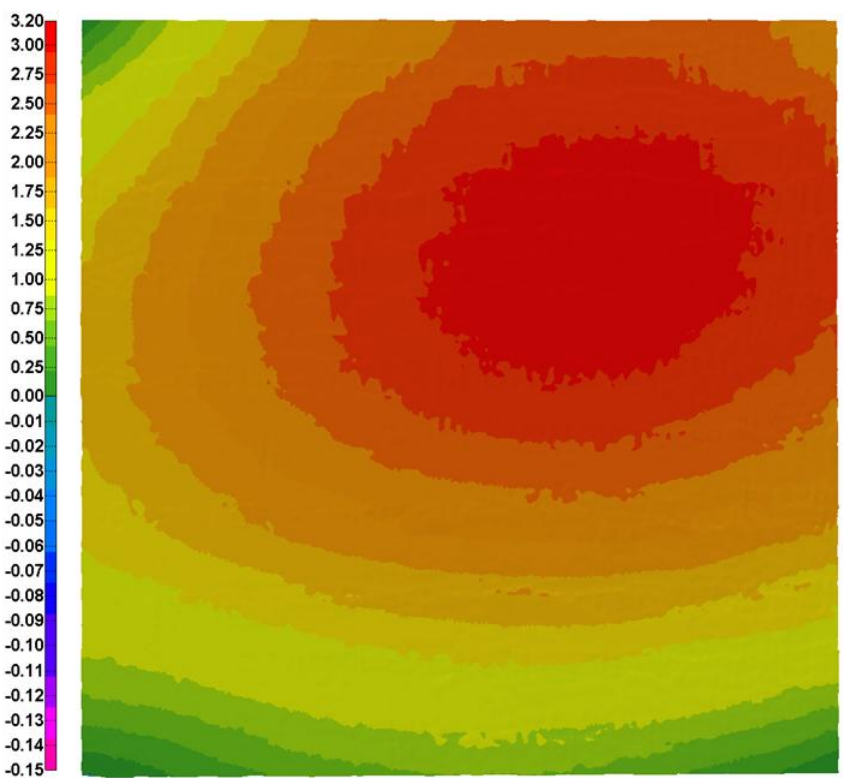

Experimental result

Figure 41. Comparison of tool-side distortion pattern for panel 5

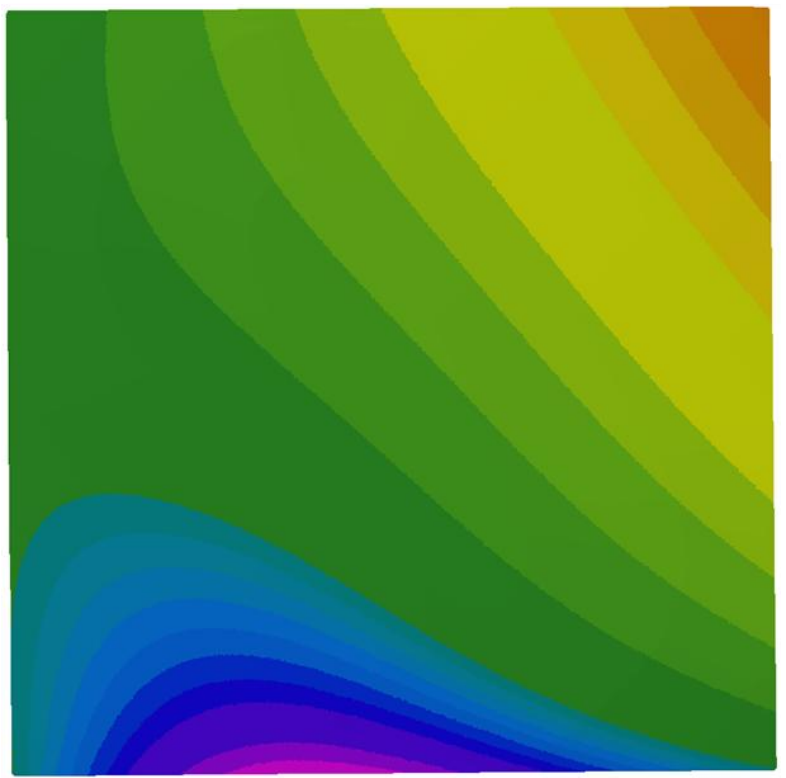

Simulation result

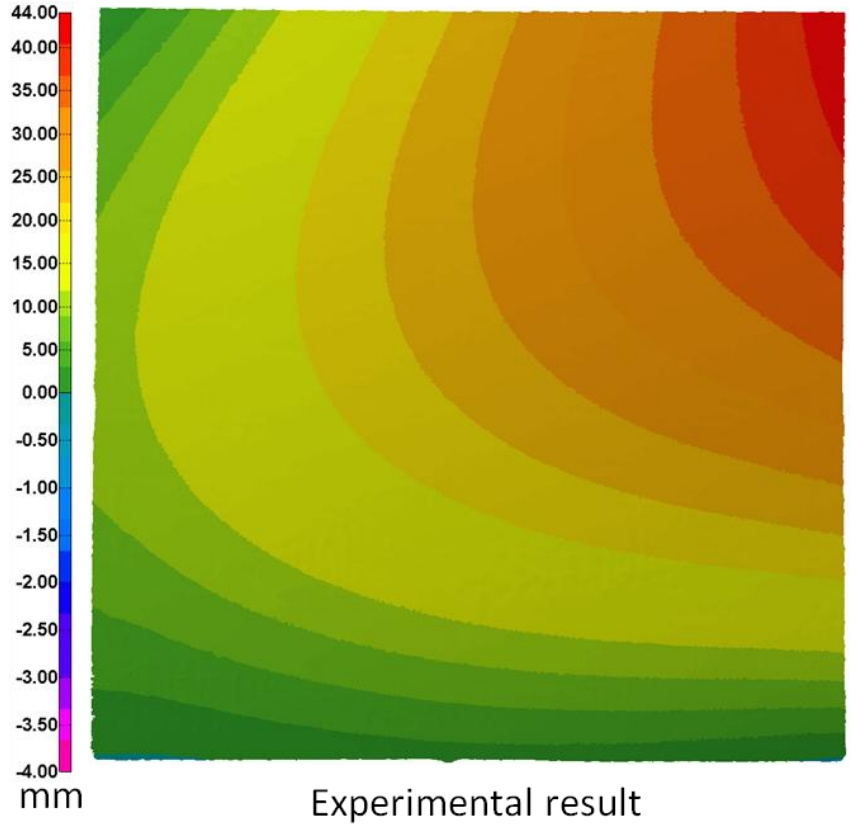

Experimental result

Figure 42. Comparison of tool-side distortion pattern for panel 6 


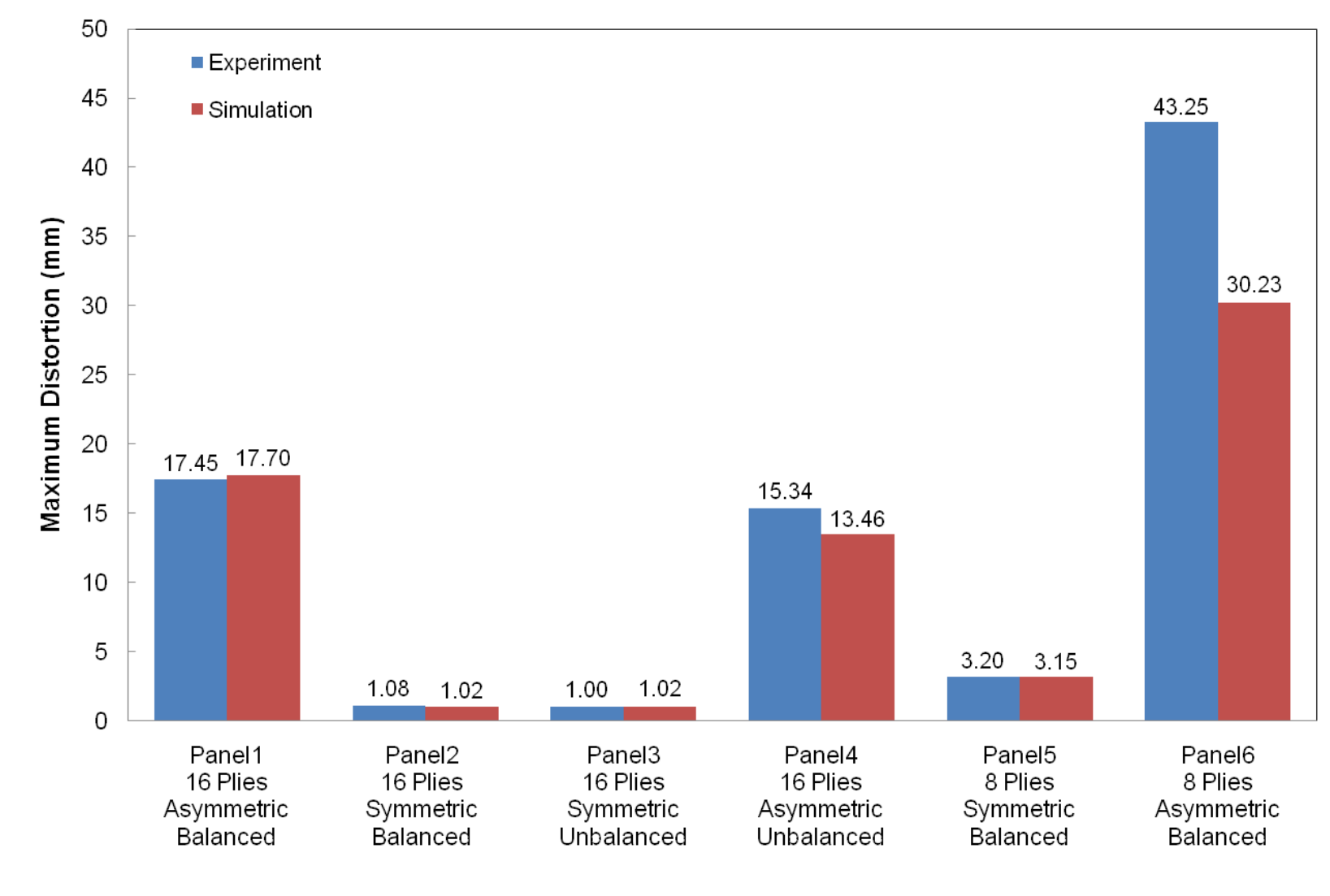

Figure 43. Comparison of simulation results with experimental results for maximum distortion of flat panels with various stacking sequences and different thicknesses

Using the method explained in section 3.1.3.1, maximum amount of distortion was obtained for all the fabricated and simulated flat panels. Figure 43 shows the comparison of simulation results with the experimental results for the panels with different stacking sequences and different thicknesses. The model accurately predicted the maximum amount of distortion in some of the panels and with maximum $30 \%$ error in the others. The error in the simulation could be because of not incorporating stress relaxation module and resin flow module into the model which is recommended as a future work. A comparison of the 3D distortion pattern was done for each panel as shown in Figure 37 to Figure 42. 


\subsection{Experimental Results for U-shaped and L-shaped Panels}

\subsubsection{Effect of Stacking Sequence}

Figure 44 depicts the spring-in angle in L-shaped panels with various stacking sequences. As shown in the figure, the panel having a symmetric and balanced stacking sequence showed the largest spring-in angle, while the panel with asymmetric and unbalanced stacking sequence had the least spring-in angle. In addition, more warpage was obtained in the flanges of the asymmetric panels compared with the symmetric panels. Warpage of the flanges could be one reason to make less spring-in angle in the panels with the asymmetric stacking sequences.

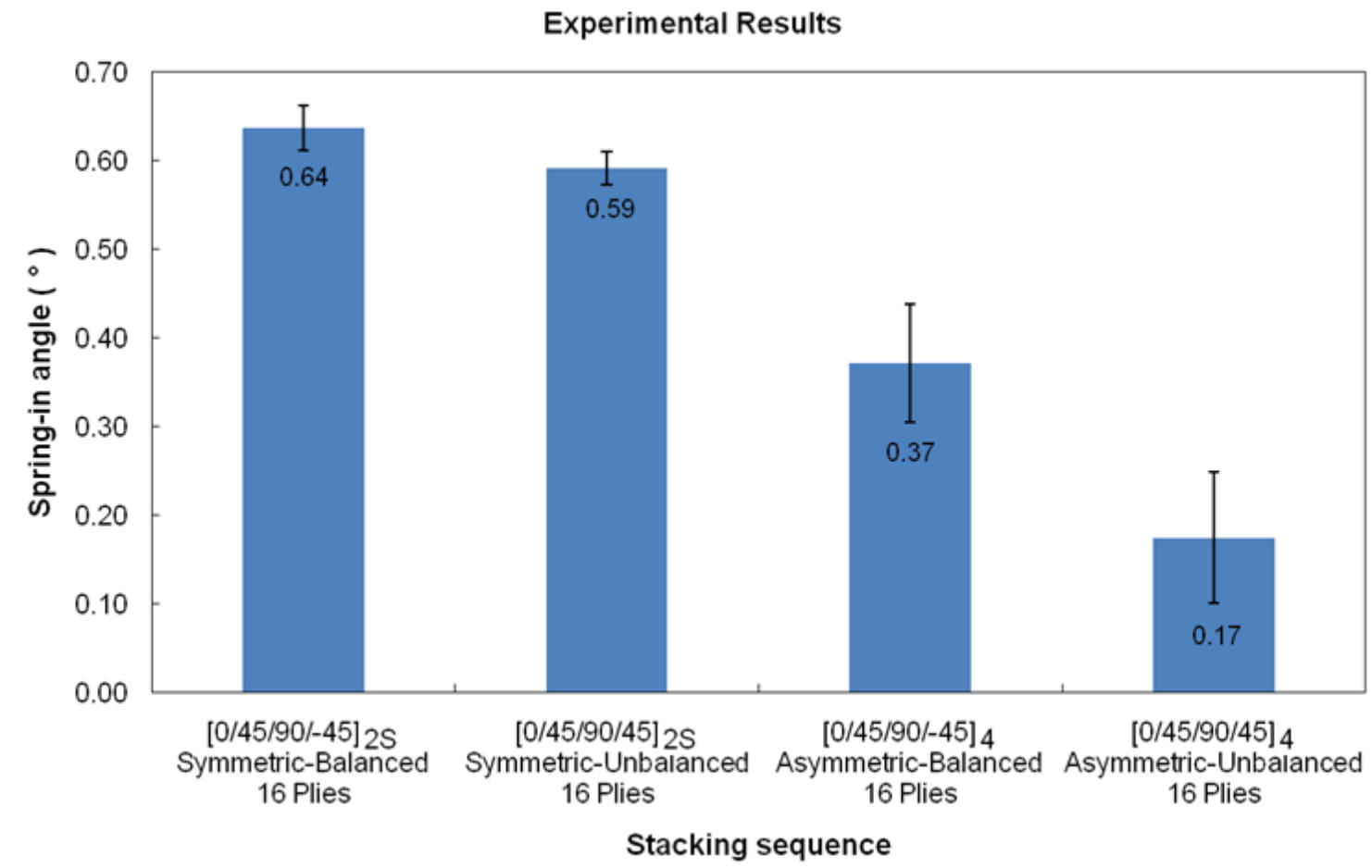

Figure 44. Effect of stacking sequence on spring-in angle of L-shaped panels

The effect of symmetry on the spring-in angle of the U-shaped panels was also investigated. Figure 45 shows the spring-in angles in the U-shaped panels compared to the spring-in angles of the L-shaped panels with the identical stacking sequences. In general, the U- 
shaped panels resulted in larger spring-in angles than the L-shaped panels, as shown in previous studies [1], because of more geometry locking once the part was removed from the tool.

\section{Experimental Results}

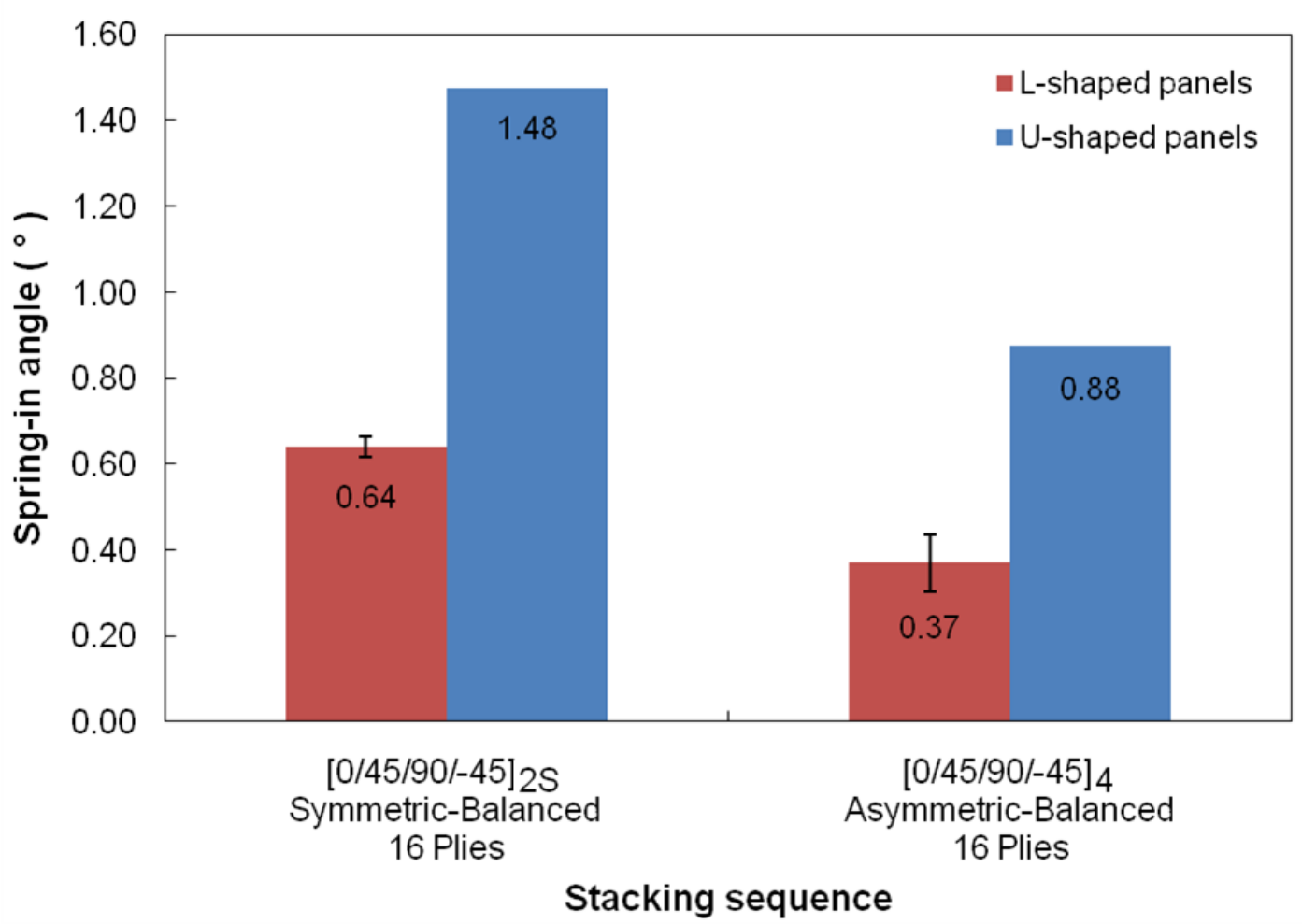

Figure 45. Comparison of the spring-in angle in U-shaped and L-shaped panels

The effect of symmetry on warpage in U-shaped and L-shaped panels was also investigated. For this purpose, same flanges of two panels with asymmetric and symmetric stacking sequences were selected. As illustrated in Figure 46 and Figure 47, the asymmetric panels showed higher warpage compared with the symmetric panels. Similar results were obtained in flat panels with symmetric and asymmetric stacking sequences, section 4.1.1.

A maximum distortion of $0.84 \mathrm{~mm}$ was indicated for the U-shaped panel with the balanced and asymmetric stacking sequence, while the balanced and symmetric panel had 0.33 $\mathrm{mm}$ for maximum distortion. Comparing color bar in Figure 46 with the one in Figure 47 shows that the U-shaped panels resulted in more than twice as much warpage as the L-shaped panels. 


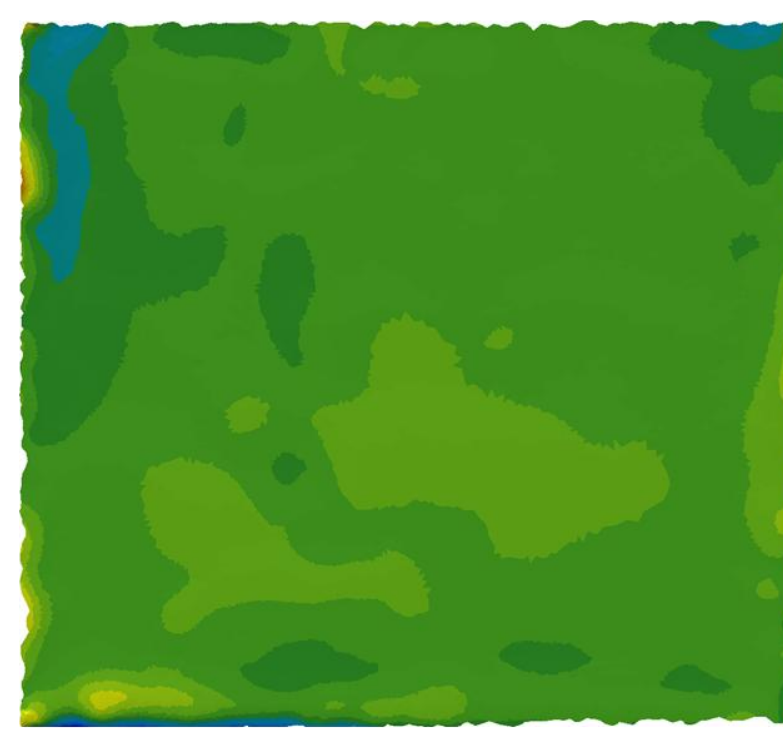

$[0 / 45 / 90 /-45]_{25}$

Symmetric and Balanced

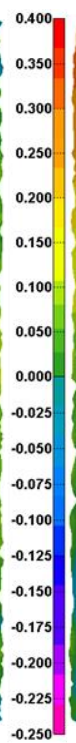

$\mathrm{mm}$
$[0 / 45 / 90 /-45]_{4}$

Asymmetric and Balanced

Figure 46. 3D warpage patterns in flanges of asymmetric and symmetric L-shaped panels

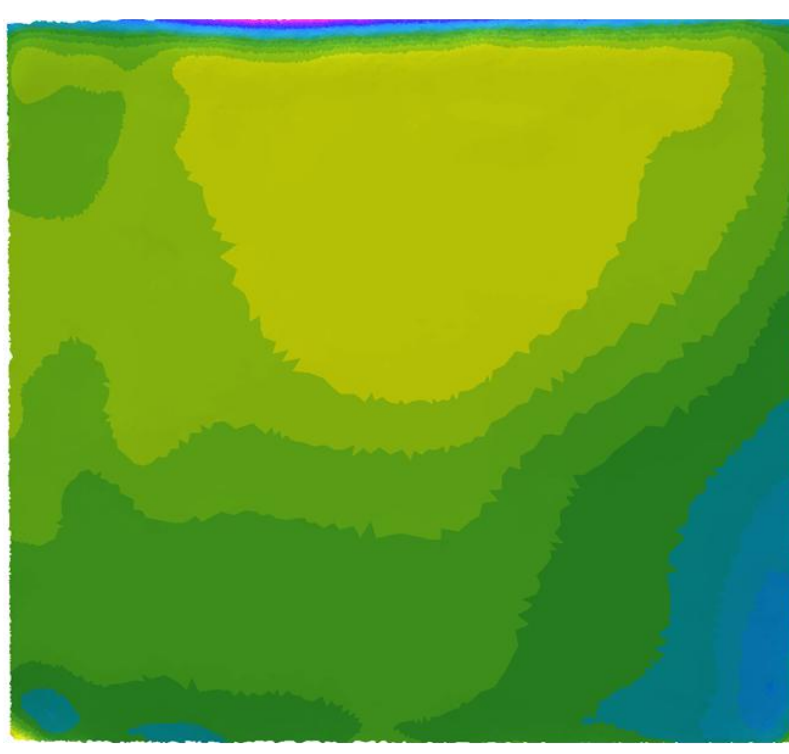

$[0 / 45 / 90 /-45]_{2 s}$

Symmetric and Balanced

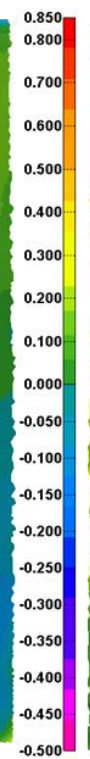

$\mathrm{mm}$

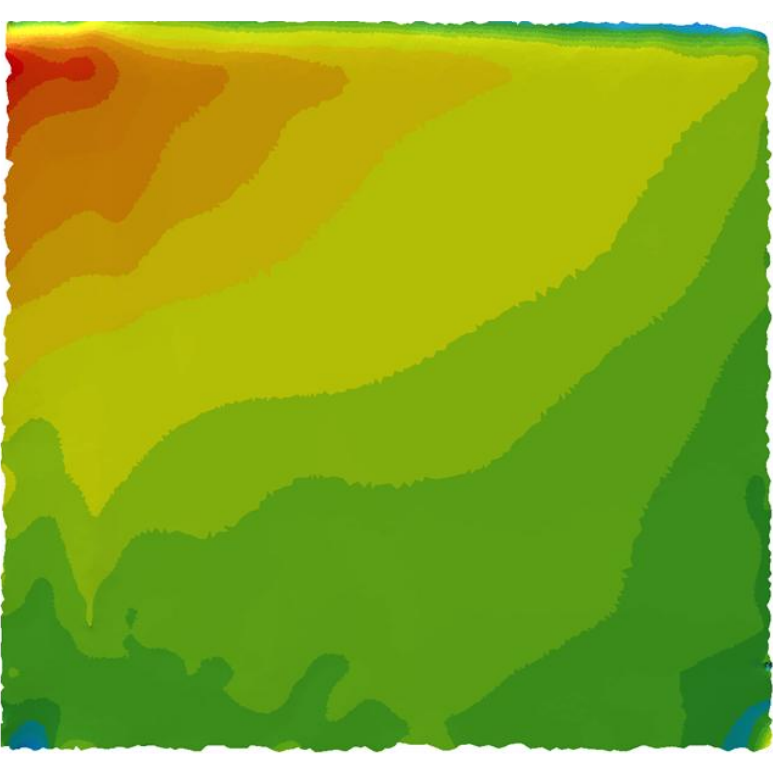

$[0 / 45 / 90 /-45]_{4}$

Asymmetric and Balanced

Figure 47. 3D warpage patterns in flanges of asymmetric and symmetric U-shaped panels 
Patterns of warpage are shown for webs of the U-shaped panels having two different stacking sequences of symmetric and asymmetric (Figure 48). The asymmetric panel showed more than twice distortion compared to the symmetric one.
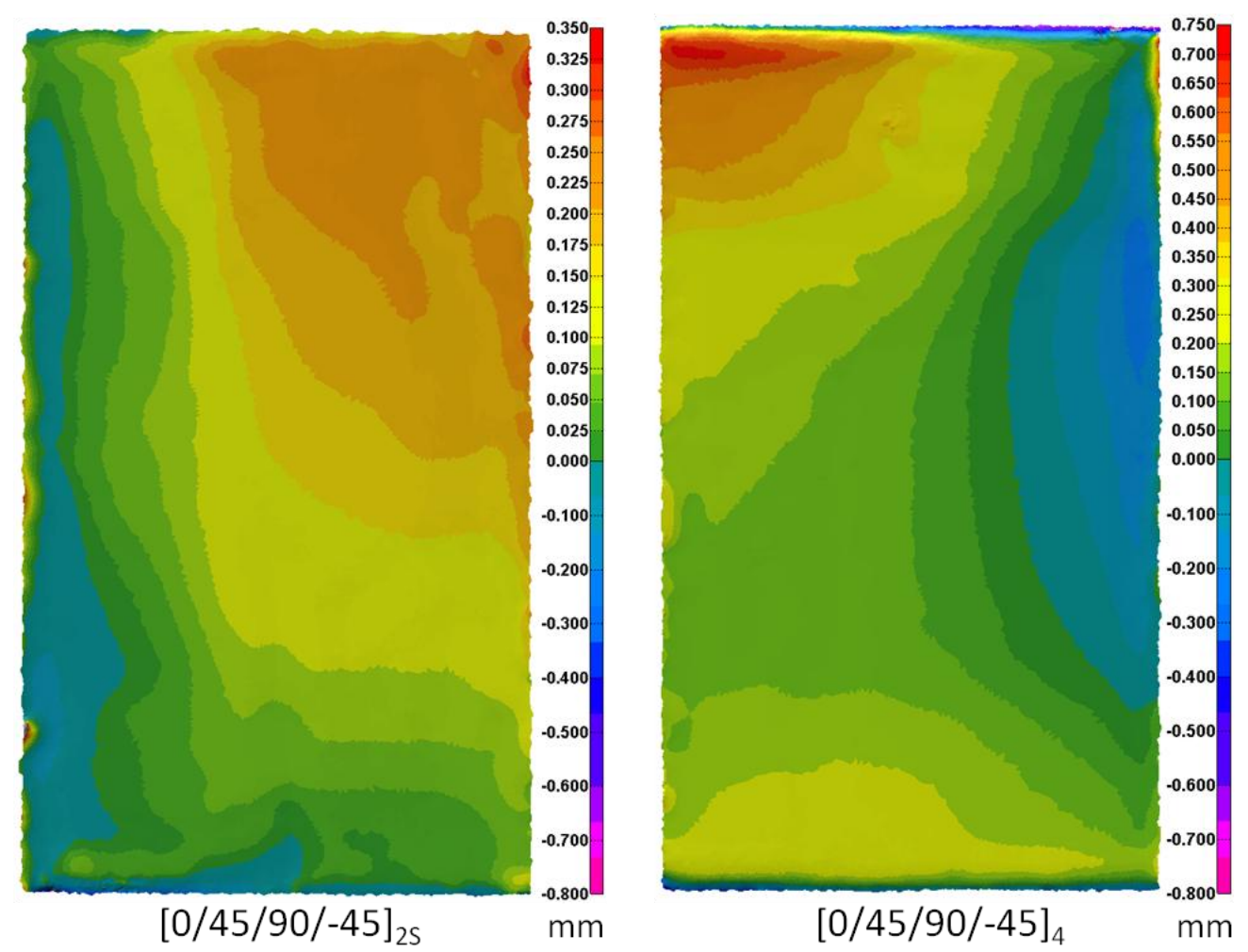

Figure 48. 3D warpage patterns in webs of asymmetric and symmetric U-shaped panels

\subsubsection{Thickness Variation Pattern}

Following the procedure discussed in section 3.1.4.2, thickness variation patterns were obtained for several stacking sequences of the L-shaped panels. As depicted in Figure 49, identical thickness variation patterns were observed for various stacking sequences with the same number of plies. In addition, a pressure gradient in curved sections and on the edges of the panels induced non-uniform resin flow which resulted in thickness variation in agreement with the previous studies [21]. 


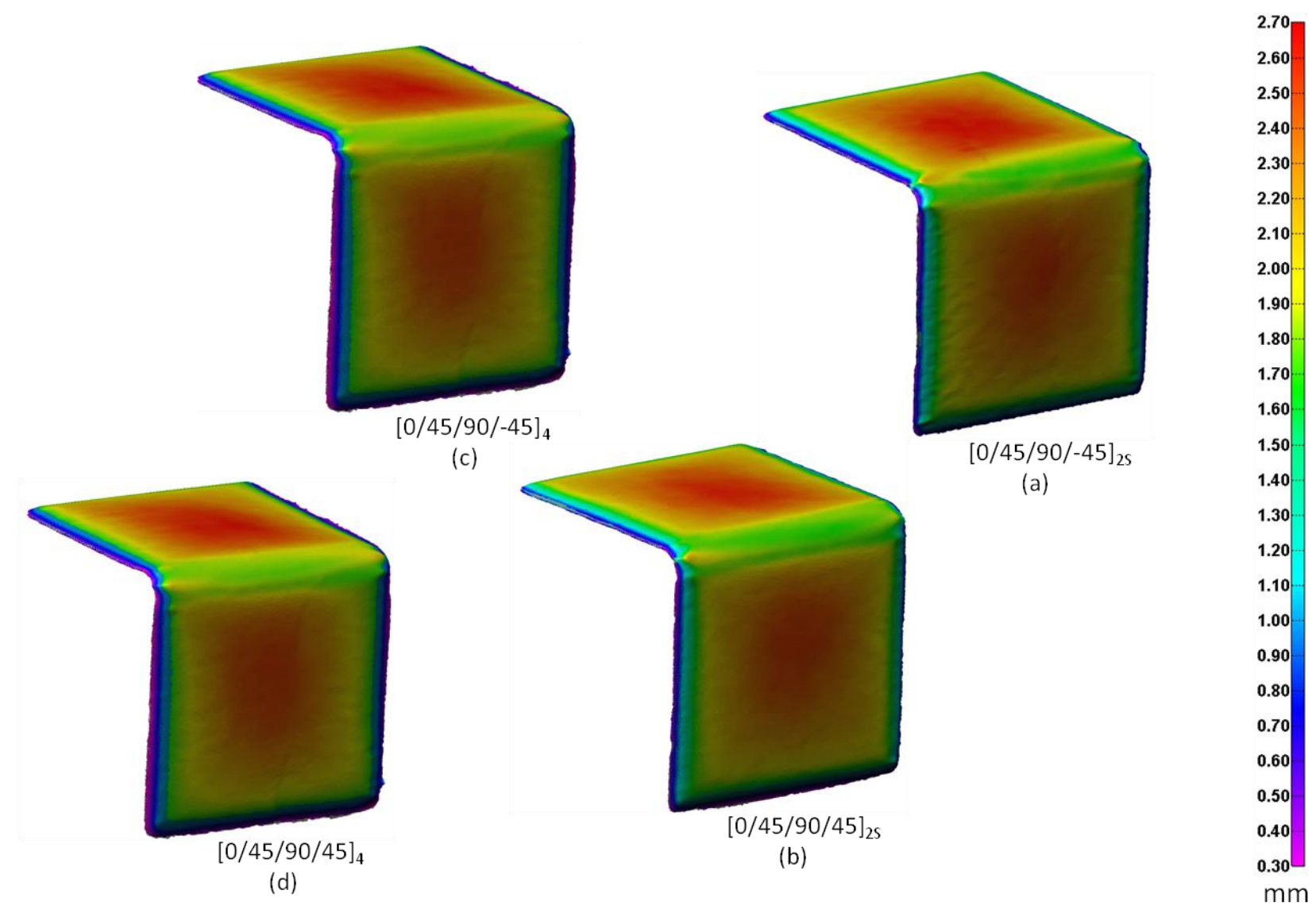

Figure 49. Thickness variation pattern in L-shaped panels with (a) balanced and symmetric stacking sequence, (b) unbalanced and symmetric stacking sequence, (c) balanced and asymmetric stacking sequence, and (d) unbalanced and asymmetric stacking sequence

\subsection{Simulation Results for L-shaped Panels}

\subsubsection{Effect of Stacking Sequence}

The curing process of the L-shaped panel was simulated as explained in section 3.2.2 to predict the dimensional changes during cure. Figure 50 depicts the comparison of simulation results with the experimental results for two different stacking sequences. Satisfactory agreement was obtained between the simulation results and the experimental results. 


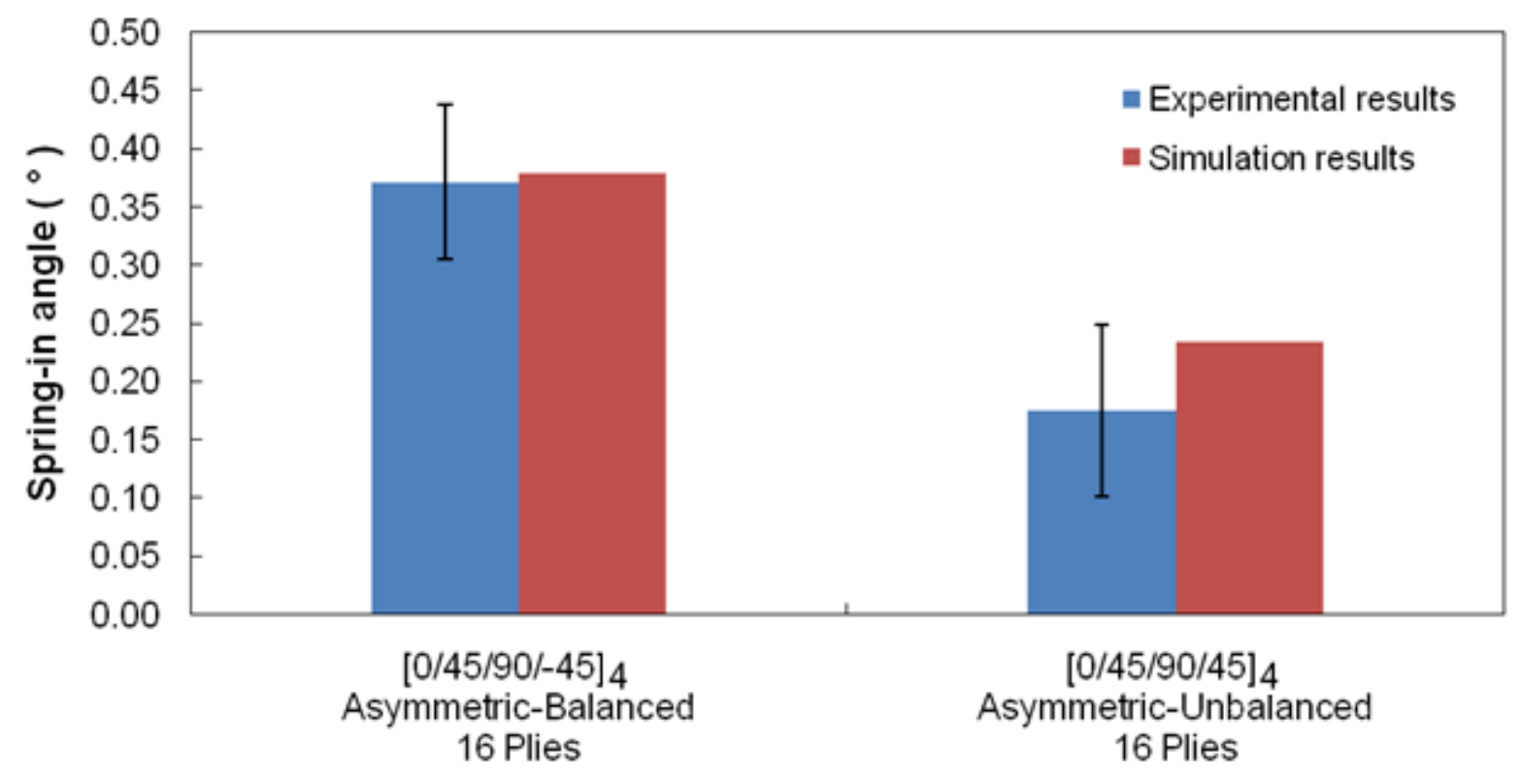

Stacking sequence

Figure 50. Comparison of simulation results with the experimental results for L-shaped panels with asymmetric-balanced and asymmetric-unbalanced stacking sequences

\subsubsection{Effect of Curve Radius}

Simulation was conducted for the stacking sequence of $[0 / 45 / 90 /-45]_{4}$ to study the effect of curve radius on the spring-in angle. Simulation results showed that an L-shaped panel with a larger curve radius resulted in bigger spring-in angle (Figure 51). Significant warpage was obtained in both panels due to asymmetry of the stacking sequences. 


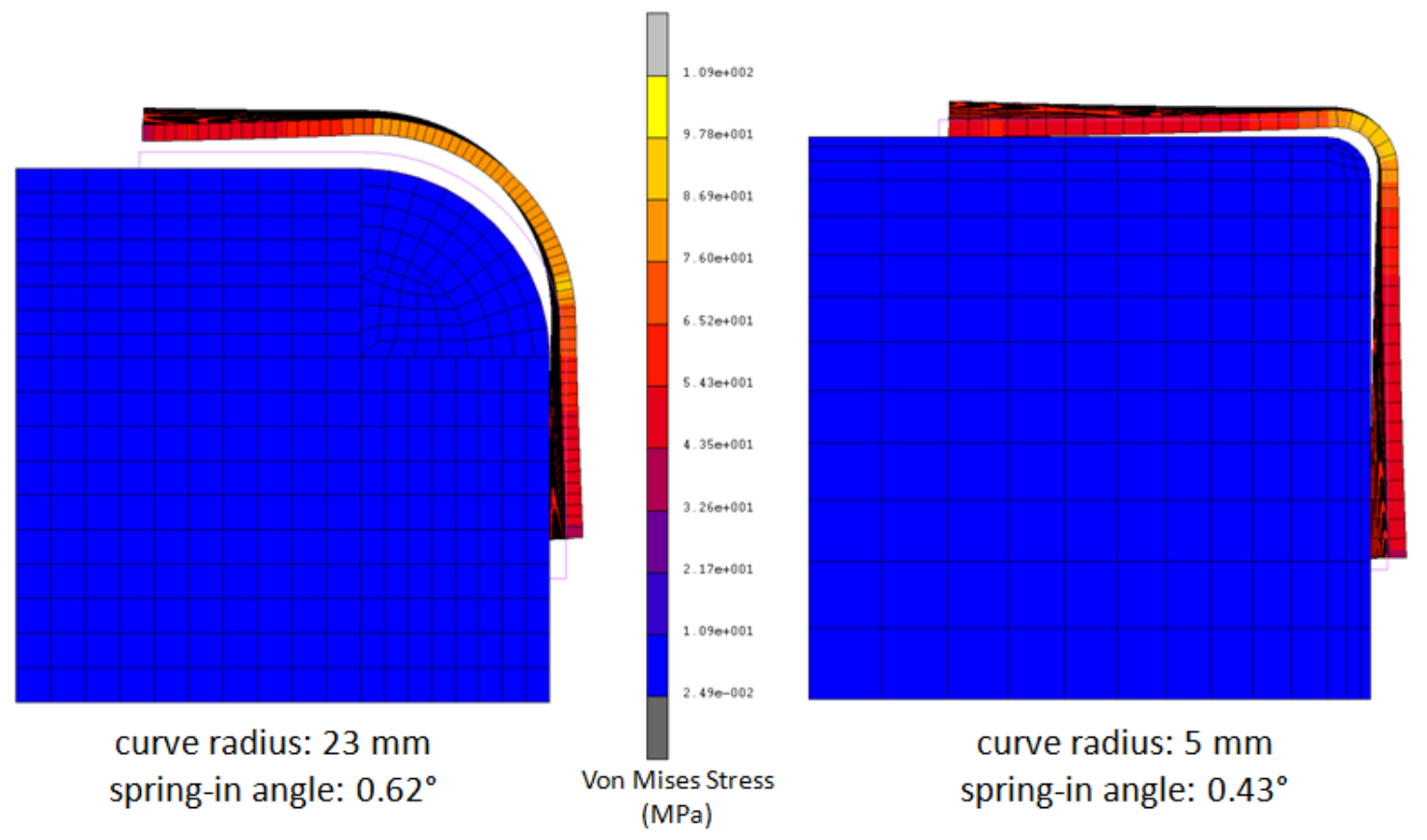

Figure 51. Effect of curve radius on spring-in angle of an L-shaped panel (scale factor of 3 is used for illustration purpose)

\subsubsection{Effect of Tool Geometry}

Finite element analysis was conducted to investigate the effect of tooling geometry on the spring-in angle of an L-shaped panel. For the stacking sequence of [0/45/90/-45] $]_{4}$, the L-shaped panel cured on a concave tool resulted in 30\% less spring-in angle compared with the identical panel cured on a convex tool (Figure 52) in agreement with Radford's study [63]. 


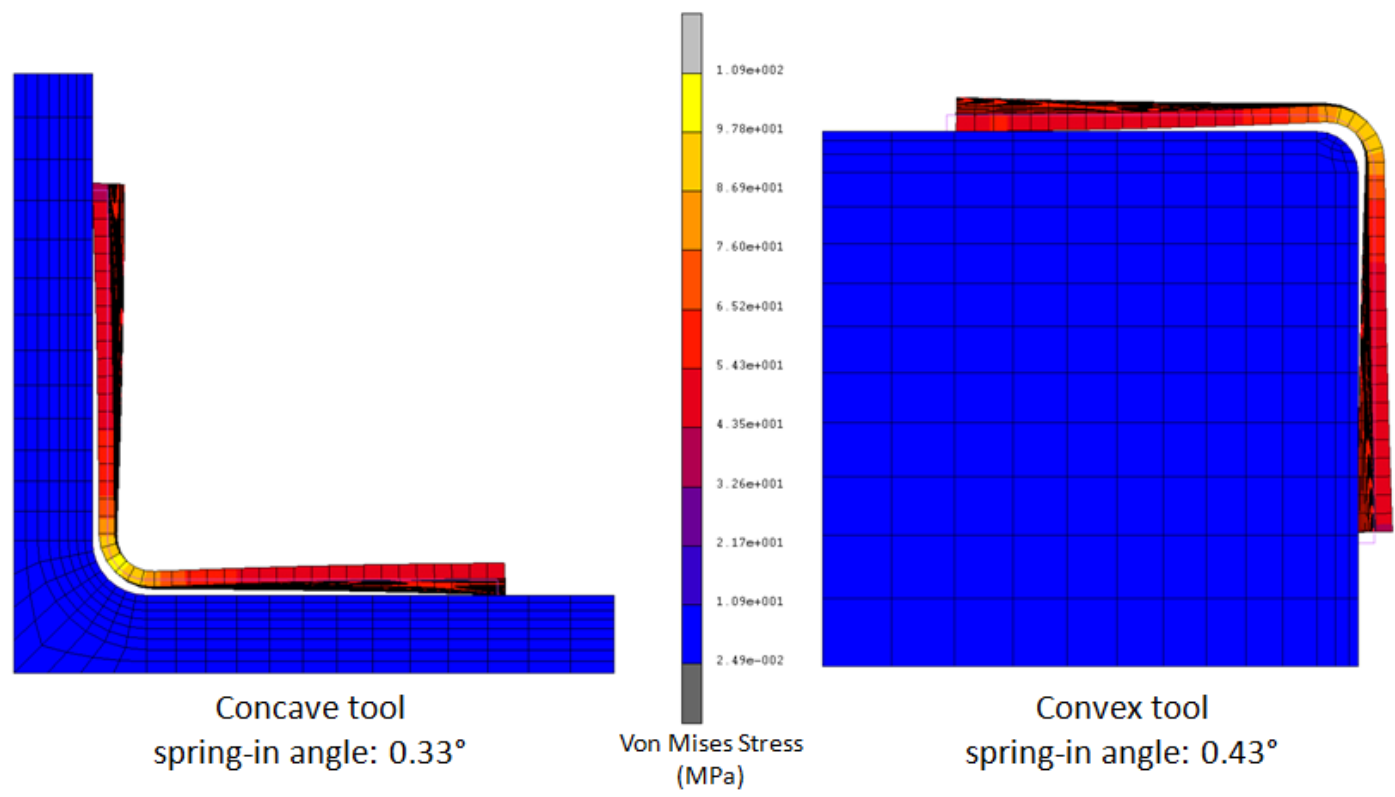

Figure 52. Effect of tool geometry on spring-in angle of an L-shaped panel (scale factor of 3 is used for illustration purpose) 


\section{CHAPTER 5}

\section{CONCLUSIONS}

\subsection{Conclusions}

A method was developed and a Romer arm, equipped with a laser scanning probe, was used to obtain a 3D distortion pattern of the composite panels. Using current method, not only was a 3D continuous distortion pattern obtained, but also the location and amount of maximum distortion was determined for each panel. Moreover, one could use this method to measure the 3D thickness variation pattern.

The panels with different thicknesses and stacking sequences were laid up and cured on different tools to study the effect of such parameters on distortion of composite parts. The results revealed that maximum distortion depends primarily on the symmetric or asymmetric stacking sequence, not the balanced or unbalanced stacking sequence. Similar thickness variation patterns were observed for different stacking sequences, suggesting that the effect of stacking sequence on thickness variation is negligible.

For the panels with similar types of stacking sequences but different thicknesses, it was found that the eight-ply panels were distorted more than twice as much as the sixteen-ply panels. Study of different tooling materials revealed that maximum distortion is aggravated by increasing the CTE mismatch between the part and the tool ; however, the difference between maximum amounts of distortion in such panels was less than $10 \%$ especially due to lack of geometry locking and application of release film.

The U-shaped and the L-shaped parts were also fabricated from IM7/977-2 UD to study the effect of different stacking sequences on warpage and spring-in angle of the panels. A sevenaxis Romer arm equipped with a laser scanner probe was utilized to capture the distortion of the 
cured panels. Among all of the studied stacking sequences for the L-shaped panels, the one with unbalanced and asymmetric stacking sequence showed the least spring-in angle, and the balanced and symmetric panel had the most spring-in angle. Although asymmetric panels had less spring-in angle compared to the symmetric ones, greater warpage was observed in the flanges of the panels with asymmetric stacking sequences. Similar results were also obtained for the U-shaped panels. However, the U-shaped panels generally showed greater spring-in angle than the L-shaped panels.

MSC Marc was utilized to simulate the distortion of the panels by considering all the curing conditions. The simulation results for flat and L-shaped parts with different stacking sequences were validated by the experimental results.

Using simulation, the effect of tool geometry and curve radius on the spring-in angle of an L-shaped panel was studied. It was observed that the L-shaped panel with larger curve radius showed a greater spring-in angle. It was also shown that the spring-in angle in the L-shaped panel laid on a concave tool was $30 \%$ less than that for the identical panel cured on a convex tool. 


\subsection{Recommendations for Future Studies}

$\checkmark$ Simulation of distortion for (non-flat and flat) sandwich panels.

$\checkmark$ Development of a stress-relaxation module for simulation of distortion to account for the effect of during-cure viscoelasticity on process-induced distortion and residual stresses.

$\checkmark$ Development of a 3D resin flow module to estimate the thickness variation in composite parts, and also to enhance the accuracy of simulation results.

$\checkmark$ Investigation of the effect of porosity, pressure variation, resin dam, and caul plate on the thickness variation in composite parts.

$\checkmark$ Development of experiments to obtain thermal models for tool-air, tool-part, and part-bag interfaces to improve the accuracy of the simulation especially when using composite tools.

$\checkmark$ Utilizing the final part geometry predicted by the simulation in tool design to improve dimensional accuracy in the composite part. 


\section{REFERENCES}




\section{LIST OF REFERENCES}

1. Albert, C., and Fernlund, G., Spring-in and warpage of angled composite laminates. Composites Science and Technology, 2002, 62, 1895- 1912.

2. Rennick, T. S., and Radford, D. W., Components of manufacturing distortion in carbon fiber/epoxy angle brackets. Proceedings of the 28th International SAMPE Technical Conference, Seattle, WA, USA, Nov 4-7, 1996.

3. Zeng X., and Raghavan, J., Role of tool-part interaction in process-induced warpage of autoclave-manufactured composite structures. Composites Part A: Applied Science and Manufacturing, 2010, 41, 1174-1183.

4. Arafath, A. R. A., Vaziri, R., and Poursartip, A., Closed-form solution for processinduced stresses and deformation of a composite part cured on a solid tool: Part II Curved geometries. Composites Part A: Applied Science and Manufacturing, 2009, 40, 1545-1557.

5. Wisnom, M. R., Potterand, K. D., Ersoy, N., Shear-lag analysis of the effect of thickness on spring-in of curved composites. Journal of Composite Materials, 2007, 41, 13111324.

6. Fernlund, G., Rahman, N., Courdji, R., Bresslauer, M., Poursartip, A., Willden, K., and Nelson, K., Experimental and numerical study of the effect of cure cycle, tool surface, geometry, and lay-up on the dimensional fidelity of autoclave-processed composite parts. Composites - Part A: Applied Science and Manufacturing, 2002, 33, 341- 351.

7. Dong, C., Modeling the dimensional variations of composites using effective coefficients of thermal expansion. Journal of Composite Materials, 2009, 43, 2639-2652.

8. Kim, B.-S., Bernet, N., Sunderland, P., and Manson, J.-A., Numerical analysis of the dimensional stability of thermoplastic composites using a thermoviscoelastic approach. Journal of Composite Materials, 2002, 36, 2389-2403.

9. Radford, D. W., Balancing mechanisms of distortion to yield distortion-free/shape stable composites. Journal of Reinforced Plastics and Composites, 2010, 29, 1875-1892 .

10. Twigg, G., Poursartip, A., and Fernlund, G., Tool-part interaction in composites processing. Part I: Experimental investigation and analytical model.Composites Part A: Applied Science and Manufacturing, 2004, 35, 121-133.

11. Lee, W. I., Loos, A. C., and Springer, G. S., Heat of reaction, degree of cure, and viscosity of Hercules 3501-6 resin. Journal of Composite Materials, 1982, 16, 510520. 


\section{LIST OF REFERENCES (continued)}

12. Loos, A. C., and Springer, G. S., Curing of epoxy matrix composites. Journal of Composite Materials, 1983, 17, 135-169.

13. Dusi, M. R., Lee, W. I., Ciriscioli, P. R., and Springer, G. S., Cure kinetics and viscosity of fiberite 976 resin. Journal of Composite Materials, 1987, 21, 243-261.

14. Cole, K. C., New approach to modeling the cure kinetics of epoxy amine thermosetting resins. 1. Mathematical development. Macromolecules, 1991, 24, 3093-3097.

15. Cole, K. C., Hechler, J. J., and Noel, D., New approach to modeling the cure kinetics of epoxy amine thermosetting resins. 2. Application to a typical system based on bis[4(diglycidylamino)phenyl]methane and bis(4-aminophenyl) sulfone. Macromolecules, 1991, 24, 3098-3110.

16. White, S. R., and Hahn, H. T., Process modeling of composite materials: Residual stress development during cure. Part II. Experimental validation. Journal of Composite Materials, 1992, 26, 2423-2453.

17. White, S. R., and Hahn, H. T., Process modeling of composite materials: Residual stress development during cure. Part I. Model formulation. Journal of Composite Materials, 1992, 26, 2402-2422.

18. Lee, S.-N., Chiu, M.-T., and Lin, H.-S., Kinetic model for the curing reaction of a tetraglycidyl diamino diphenyl methane/diamino diphenyl sulfone (TGDDM/DDS) epoxy resin system. Polymer Engineering \& Science, 1992, 32, 1037- 1046.

19. Kenny, J. M., Integration of processing models with control and optimization of polymer composites fabrication. 3rd International Conference on Computer Aided Design in Composite Material Technology - CADCOMP 92, Newark, DE, USA, 1992.

20. Scottand, E. P., and Saad, Z., Estimation of kinetic parameters associated with the curing of thermoset resins. Part I: Theoretical investigation. Polymer Engineering and Science, 1993, 33, 1157-1164.

21. Hubert, P., Aspects of Flow and Compaction of Laminated Composite Shapes During Cure, Ph.D. Thesis, The University of British Columbia, Vancouver, BC, Canada, July 1996.

22. MSC Marc 2008 rl, Manual Volume A: Theory and User Information.

23. Shah, D. U., and Schubel, P. J., Evaluation of cure shrinkage measurement techniques for thermosetting resins. Polymer Testing, 2010, 29, 629-639. 


\section{LIST OF REFERENCES (continued)}

24. Schubel, P. J., Warrior, N. A., and Rudd, C. D., Surface quality prediction of thermoset composite structures using geometric simulation tools. Plastics, Rubber and Composites, 2007, 36, 428-437.

25. Bogetti, T. A., and Gillespie, J. W. Jr., Process-induced stress and deformation in thicksection thermoset composite laminates. Journal of Composite Materials, 1992, 26, 626660.

26. Zhu, Q., Geubelle, P. H., Liand, M., and Tucker Iii, C. L., Dimensional accuracy of thermoset composites: Simulation of process-induced residual stresses. Journal of Composite Materials, 2001, 35, 2171-2205.

27. Chapman, T. J., Gillespie, J. W., Pipes, R. B., Manson, J.-A. E., and Seferis, J. C., Prediction of Process-Induced Residual Stresses in Thermoplastic Composites. Journal of Composite Materials, 1990, 24, 616-643.

28. Rabearison, N., Jochum, C., and Grandidier, J. C., A FEM coupling model for properties prediction during the curing of an epoxy matrix. Computational Materials Science, 2009, 45, 715-724.

29. Radford, D. W., and Diefendorf, R. J., Shape instabilities in composites resulting from laminate anisotropy. Journal of Reinforced Plastics and Composites, 1993, 12, 5875.

30. Johnston, A., Vaziri, R., and Poursartip, A., A plane strain model for process-induced deformation of laminated composite structures. Journal of Composite Materials, 2001, $35,1435-1469$.

31. Msallem, Y. A., Jacquemin, F., Boyard, N., Poitou, A., Delaunay, D., and Chatel, S., Material characterization and residual stresses simulation during the manufacturing process of epoxy matrix composites. Composites Part A: Applied Science and Manufacturing, 2010, 41, 108-115.

32. Kimand, Y. K., and White, S. R., Viscoelastic analysis of processing-induced residual stresses in thick composite laminates. Mechanics of Composite Materials and Structures, 1997, 4, 361-387.

33. Arafath, A. R. A., Vaziri, R., and Poursartip, A., Closed-form solution for processinduced stresses and deformation of a composite part cured on a solid tool: Part I - Flat geometries. Composites Part A: Applied Science and Manufacturing, 2008, 39, 11061117. 


\section{LIST OF REFERENCES (continued)}

34. Zarrelli, M., Skordos, A. A., and Partridge, I. K., Toward a constitutive model for curedependent modulus of a high temperature epoxy during the cure. European Polymer Journal, 2010, 46, 1705-1712.

35. Dillman, S. H., and Seferis, J. C., Kinetic viscoelasticity for the dynamic mechanical properties of polymeric systems. Journal of macromolecular science. Chemistry, 1989, A26, 227-247.

36. McGee S. H., Curing characteristics of particulate-filled thermosets. Polymer Engineering and Science, 1982, 22, 484-491.

37. Hartmann, B., Lee, G., and Long, M., Specific heat capacities of some polyepoxides. Journal of Applied Polymer Science, 1982, 27, 289-300.

38. Chern, B.-C., Moon, T.J., Howell, J.R., and Tan, W., New experimental data for enthalpy of reaction and temperature- and degree-of-cure-dependent specific heat and thermal conductivity of the Hercules 3501-6 epoxy resin. Journal of Composite Materials, 2002, 36, 2061-2072.

39. Balvers, J.M., Bersee, A., Beukers, A., and Jansen, K.M.B., Determination of cure dependent properties for curing simulation of thick-walled composites. 49th AIAA/ASME/ASCE/AHS/ASC Structures, Structural Dynamics, and Materials Conference, Schaumburg, IL, USA, April 7-10, 2008.

40. Agari, Y., Ueda, A., and Nagai, S., Measurement of thermal diffusivity and specific heat capacity of polymers by laser flash method. Journal of Polymer Science Part B: Polymer Physics, 1995, 33, 33-42.

41. Mijovic, J., and Wang, H.T., Modeling of processing of composites. Part II: Temperature distribution during cure. SAMPE Journal, 1988, 24, 42-55.

42. Johnston, A., An Integrated Model of the Development of Process-Induced Deformation in Autoclave Processing of Composite Structures. Ph.D. Thesis, The University of British Columbia, Vancouver, BC, Canada, April 1997.

43. Henderson, J. B., Wiebelt, J. A., and Tant, M. R., Model for the thermal response of polymer composite materials with experimental verification. Journal of Composite Materials, 1985, 19, 579-595.

44. Cong, Y., Zhang, Y., Hu, Z., Liu, J., and Cheng, Z., Modeling of the effective thermal conductivity of composite materials with FEM based on resistor networks approach. Microsystem Technologies, 2010, 16, 633-639. 


\section{LIST OF REFERENCES (continued)}

45. Innocenti, P., and Scarpa, F., Thermal conductivity properties and heat transfer analysis of Multi-re-entrant auxetic honeycomb structures. Composite Materials, 2009, 43(21), 2419-2439.

46. Pagliuso, S., Progress in Science and Engineering of Composites, Warpage, a nightmare for composite parts procedures. Proceedings of the 4th International Conference on Composite Materials., Tokyo, Japan, 1982, 1617-1623.

47. Wisnom, M. R., Ersoy, N., Potter, K., and Clegg, M. J., An experimental method to study the frictional processes during composites manufacturing. Composites Part A (Applied Science and Manufacturing), 2005, 36, 1536-1544.

48. Ridgard, C., Accuracy and distortion of composite parts and tools: Causes and solutions . Published by SME, Dearborn, MI, United States, 1993, 1-18.

49. Joven, R., Tavakol, B., Rodriguez, A., and Minaie, B., Experimental investigation of tool/part interface during curing of composites. International SAMPE Symposium and Exhibition (Proceedings), Seattle, WA, United States, May 17-20 2010.

50. Kaushik, V., Zeng, X., Hendrickson, L., and Raghavan, J., Investigation of tool-part interaction during autoclave processing of polymer composites structures. 50th International SAMPE Symposium and Exhibition, Long Beach, CA, United states, May $1-5,2005,621-629$.

51. Dave, R., Kardos, J. L., and Dudukovic, M. P., Model for resin flow during composite processing: part I - general mathematical developement. Polymer Composites, 1987, 8, 29-38.

52. Dave, R., Kardos, J. L., and Dudukovic, M. P., Model for resin flow during composite processing: part II - numerical analysis for unidirectional graphitelepoxy laminates. Polymer Composites, 1987, 8, 123-132.

53. Nelson, R. H., and Cairns, D. S., Prediction of dimensional changes in composite laminates during cure. 34th International SAMPE Symposium and Exhibition Tomorrow's Materials: Today, 1989, Reno, NV, USA, May 8-11, 1989,2397-2410.

54. Huang, C. K., Yang, S.Y., Warping in advanced composite tools with varying angles and radii.Composites Part A: Applied Science and Manufacturing, 1997, 28, 891-893.

55. White, S. R., and Hahn, H. T., Mechanical property and residual stress development during cure of a graphite/BMI composite. Polymer Engineering \& Science, 1990, 30, 1465-1473. 


\section{LIST OF REFERENCES (continued)}

56. Bogetti, T. A., and Gillespie, J. W., Two-dimensional cure simulation of thick thermosetting composites. Journal of Composite Materials, 1991, 25, 239-273.

57. Harper, B. D., and Weitsman, Y., On the effects of environmental conditioning on residual stresses in composite laminates. International Journal of Solids and Structures, 1985, 21, 907-926.

58. Stango, R. J., and Wang, S. S., Process-induced residual thermal stresses in advanced fiber-reinforced composite laminates. Journal of engineering for industry, 1984, 106, 4854.

59. White, S. R., and Kim, Y. K., Process-induced residual stress analysis of AS4/3501-6 composite material. Mechanics of Composite Materials and Structures, 1998, 5, 153 186.

60. Zhao, L. G., Warrior, N. A., and Long, A. C., A thermo-viscoelastic analysis of processinduced residual stress in fibre-reinforced polymer-matrix composites. Materials Science and Engineering A, 2007, 452-453, 483-498.

61. Tavakol, B., Roozbehjavan, P., Ahmed, A., Das, R., Joven, R., Koushyar, H., Rodriguez, A., and Minaie, B., Prediction of Residual Stresses and Distortion in Carbon FiberEpoxy Composite Parts Due to Curing Process using Finite Element Analysis. Journal of Applied Polymer Science, 2012, DOI: 10.1002/app.38075.

62. Cytec Eng. Materials, Cycom 977-2 Datasheet. http://cytec.com/engineeredmaterials/products/Datasheets/CYCOM\%20977-2.pdf (accessed March 12 2012).

63. Radford, D. W., Volume fraction gradient induced warpage in curved composite plates. Composites Engineering, 1995, 5, 923-934. 